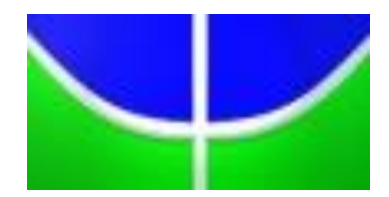

Waleska de Fátima Monteiro

\title{
O casamento inter-racial pode reduzir a desigualdade educacional? Uma comparação entre 2002 e 2012.
}




\title{
O casamento inter-racial pode reduzir a desigualdade educacional? Uma comparação entre 2002 e 2012.
}

Tese de doutorado submetida ao Departamento de Economia da Universidade de Brasília como requisito para a obtenção do grau de Doutor em Economia.

UNIVERSIDADE DE BRASÍLIA

FACE - DEPARTAMENTO DE ECONOMIA

PÓS GRADUAÇÃO EM ECONOMIA

Orientador: Prof ${ }^{\mathrm{a}}$.Dr ${ }^{\mathrm{a}}$. Maria Eduarda Tannuri Pianto

\author{
Brasília - DF
}

Agosto de 2015 
Tese de Doutorado sob o título "O casamento inter-racial pode reduzir a desigualdade educacional? Uma comparação entre 2002 e 2012.”, defendida por Waleska de Fátima Monteiro em 21 de agosto de 2015, em Brasília, Distrito Federal, e avaliada pela banca examinadora constituída pelos doutores ${ }^{1}$.

Prof $^{\mathrm{a}}$ Dr $^{\mathrm{a}}$ Maria Eduarda Tannuri Pianto
Departamento de Economia - UNB
Orientadora

Orientadora

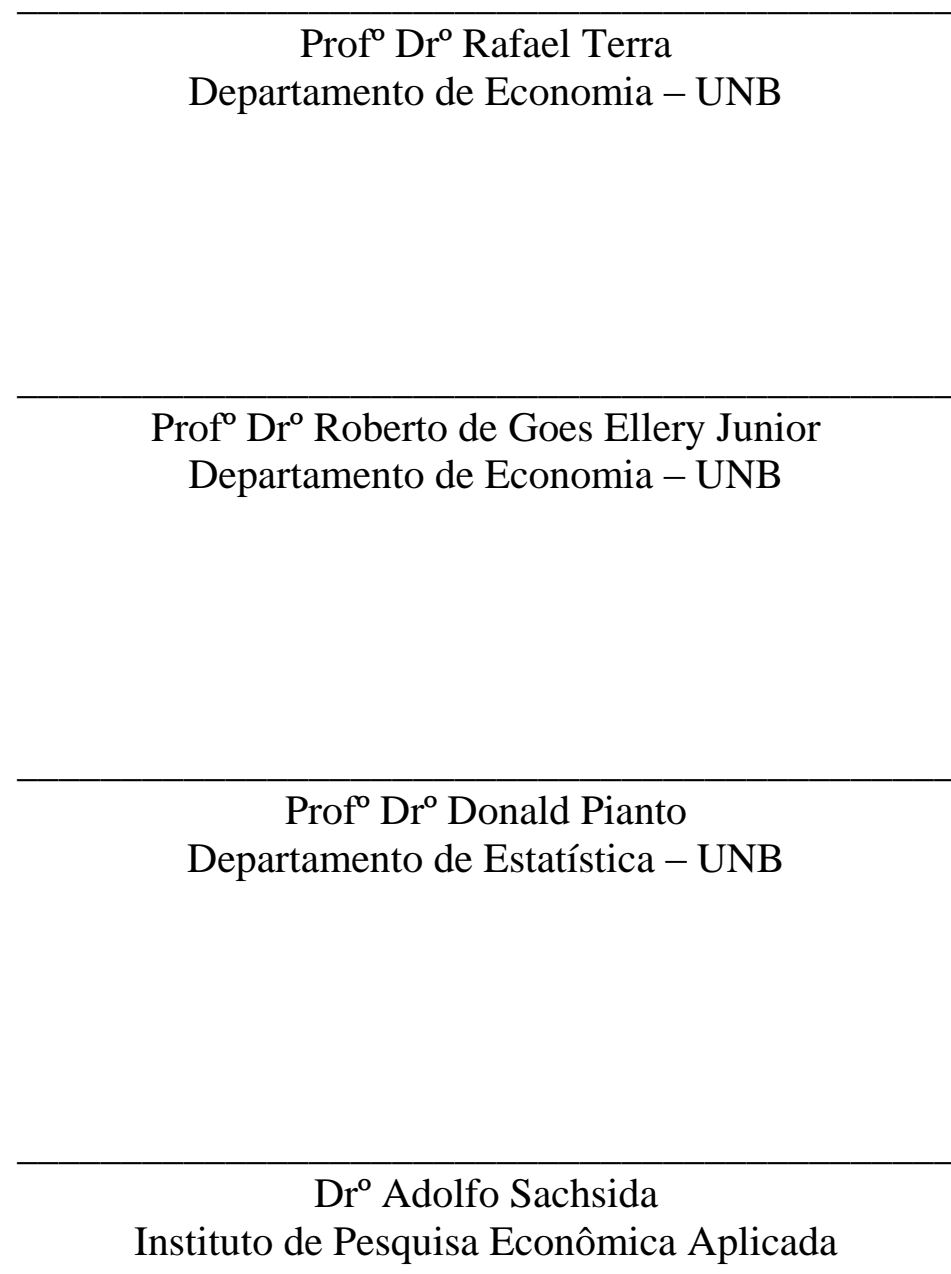

\footnotetext{
${ }^{1}$ Assinaturas constam na ata oficial disponível no Departamento de Economia da UnB.
} 
Aos meus pais 


\section{Agradecimentos}

Inicialmente manifesto meu agradecimento a Deus, pela saúde, sabedoria e disposição para finalizar esse trabalho.

A minha mãe, Fátima, que sempre foi minha fortaleza. Sempre me apoiou nas minhas escolhas e fez de tudo para me ajudar, estando ao meu lado em todos os momentos.

Agradeço meu marido Rodrigo, pelo companheirismo de sempre, pela paciência nos momentos de stress, pelo amor, pelas orações e principalmente por ter acreditado em mim.

Ao meu irmão Wesley e a minha cunhada Grace, que me incentivaram e apoiaram, de longe ou de perto, e sempre torceram por essa conquista.

À minha sogra Tânia e a Dona Carmem pelas incansáveis orações. Ao meu sogro Fábio pela torcida e pelas conversas de apoio.

Agradeço a minha orientadora, Maria Eduarda, pela sugestão do tema, pelo aprendizado, por fomentar a curiosidade e mostrar que os obstáculos surgem todos os dias e devem ser superados. Aos demais membros da banca, Rafael Terra, Donald Pianto, Roberto Ellery, Adolfo Saschida e Ana Carolina Zoghbi, agradeço a disponibilidade e as valiosas contribuições.

Agradeço também ao Andrew Francis, por ter me acolhido na Emory University e por todo aprendizado, tanto acadêmico como pessoal.

Aos professores José Guilherme de Lara Resende, Gil Riella, Ricardo da Silva Azevedo, Joaquim Andrade, Daniel Cajueiro, Michael Christian Lehmann e Milene Takasago pelo apoio durante o curso.

Aos amigos mais que especiais, Luciana Carvalho, Luís Fernando Brands, Paulo Leitão, Roberto Batista, Anderson Mutter Teixeira, Vinicius Brandi, Gilvan Candido, Marcio Francisco, Camila Schoti, Fernanda Senra de Moura, Fernanda Ledo e Marcos Marcolino que compartilharam comigo todos os momentos, bons e ruins, e que de alguma forma contribuíram nesta caminhada.

Um agradecimento especial à Tatiana Moddy e ao Jaison Moddy por terem me recebido em sua casa durante o doutorado sanduiche nos Estados Unidos.

Aos demais amigos de hoje e sempre, mesmo que não tenham me acompanhado neste momento, estiveram dentro do meu coração. 
“...E ainda que tivesse o dom da profecia, e conhecesse todos os mistérios e toda a ciência e ainda que tivesse toda a fé, de maneira tal que transportasse os montes, e não tivesse Amor, nada seria..." Epístola aos Coríntios

"Dizem que a vida é para quem sabe viver, mas ninguém nasce pronto.

A vida é para quem é corajoso

o suficiente para se arriscar e humilde o bastante para aprender."

Clarice Lispector 


\section{Sumário}

Lista de Tabelas ....................................................................................................... viii

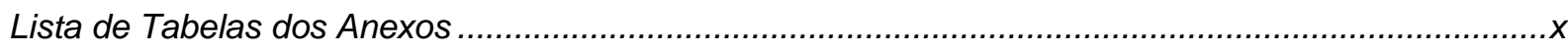

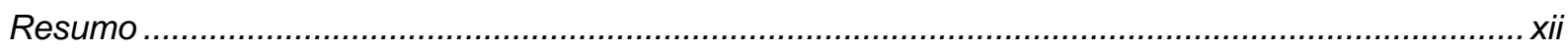

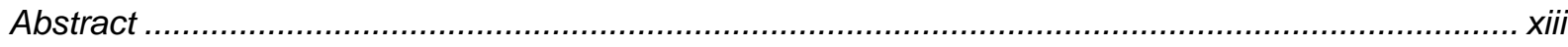

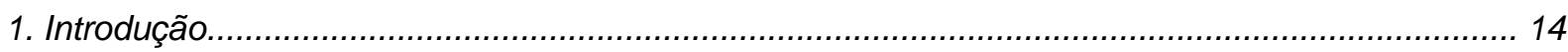

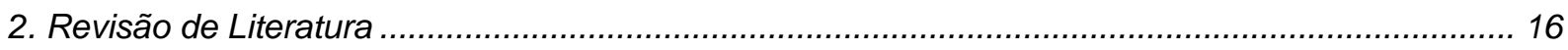

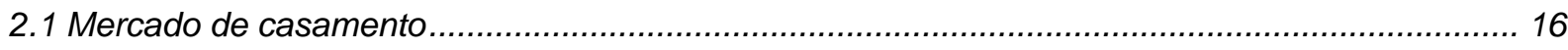

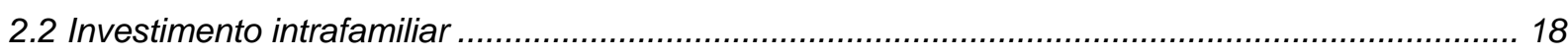

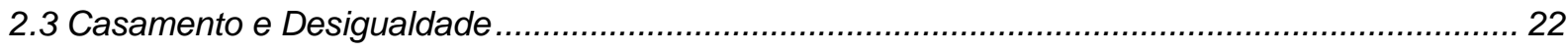

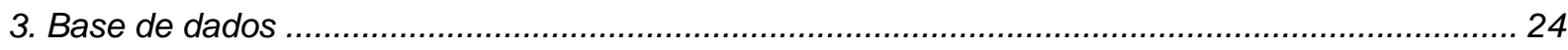

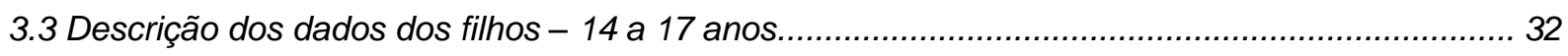

3.4 Descrição dos dados dos filhos - 18 a 25 anos.......................................................... 40

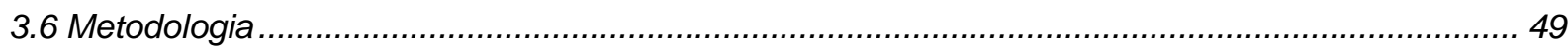

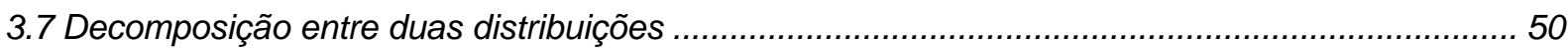

3.8 Decomposição entre período de tempo e grupos específicos.............................................5 55

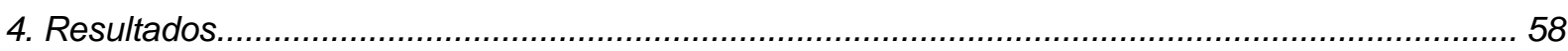

4.1 Decomposição da desigualdade educacional para jovens de 14 a 17 anos .............................. 58

4.2 Decomposição da desigualdade educacional para jovens de 18 a 25 anos .............................. 70

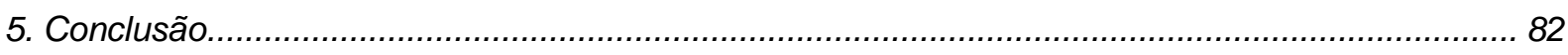

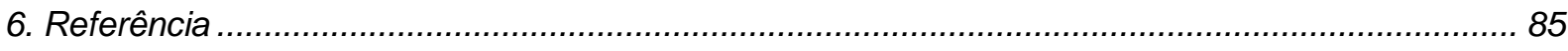

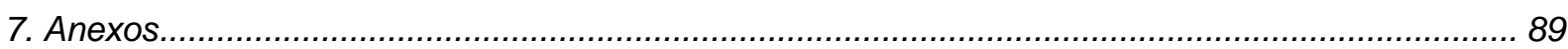




\section{Lista de Tabelas}

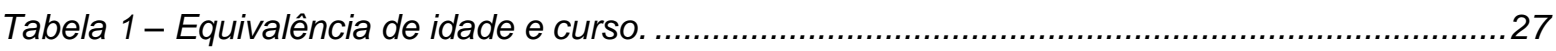

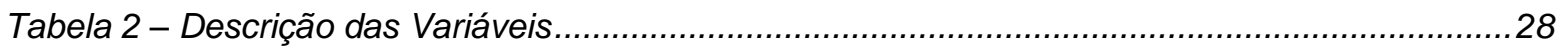

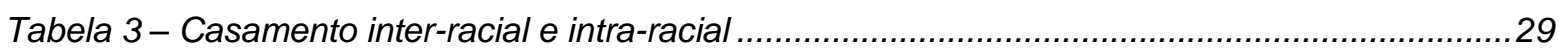

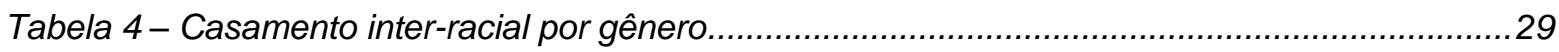

Tabela 5 - Nível educacional do pai por classificação racial......................................................... 30

Tabela 6 - Nível educacional da mãe por classificação racial ...................................................... 31

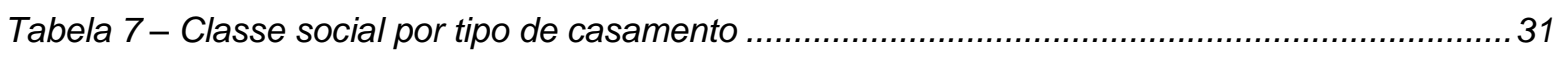

Tabela 8 - Classificação racial dos filhos - 14 a 17 anos ............................................................ 32

Tabela 9 - Atraso escolar dos filhos de casamento intra-racial Branco de 14 a 17 anos..................33

Tabela 10 - Atraso escolar dos filhos de casamento intra-racial Pardo de 14 a 17 anos...................34

Tabela 11 - Atraso escolar dos filhos de casamento intra-racial Preto de 14 a 17 anos....................34

Tabela 12 - Atraso escolar dos filhos de casamento inter-racial Branco-Pardo de 14 a 17 anos.......35

Tabela 13 - Atraso escolar dos filhos de casamento inter-racial Branco-Preto de 14 a 17 anos........36

Tabela 14 - Atraso escolar dos filhos de casamento inter-racial Pardo-Preto de 14 a 17 aos...........36

Tabela 15 - Nível educacional dos pais de casamento intra-racial branco-branco de filhos de 14 a

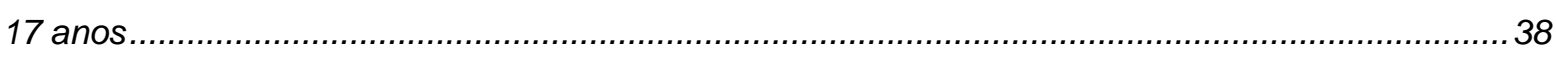

Tabela 16 - Nível educacional dos pais de casamento intra-racial pardo-pardo de filhos de 14 a 17

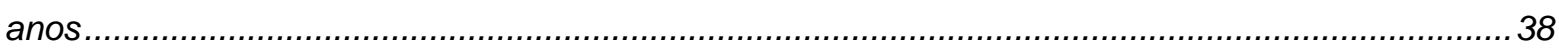

Tabela 17 - Nível educacional dos pais de casamento intra-racial preto-preto de filhos de 14 a 17

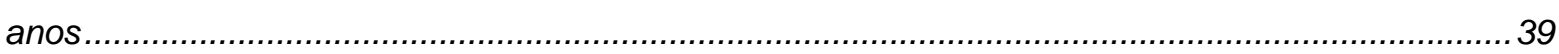

Tabela 18 - Classificação racial dos filhos - 18 a 25 anos ...................................................... 40

Tabela 19 - Atraso escolar dos filhos de casamento intra-racial Branco-Branco de 18 a 25 anos .... 41

Tabela 20 - Atraso escolar dos filhos de casamento intra-racial Pardo-Pardo de 18 a 25 anos........ 42

Tabela 21 - Atraso escolar dos filhos de casamento intra-racial Preto-Preto de 18 a 25 anos.......... 43

Tabela 22 - Atraso escolar dos filhos de casamento inter-racial Branco-Pardo de 18 a 25 anos...... 44

Tabela 23 - Atraso escolar dos filhos de casamento inter-racial Branco-Preto de 18 a 25 anos....... 44

Tabela 24 - Atraso escolar dos filhos de casamento inter-racial Preto-Pardo de 18 a 25 anos......... 45

Tabela 25 - Nível educacional de pais de casamento intra-racial Branco-Branco de filhos de 18 a 25

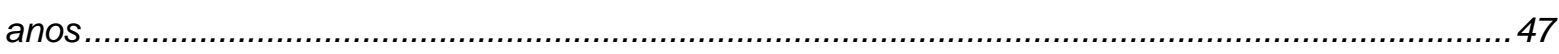


Tabela 26 - Nível educacional de pais de casamento intra-racial Pardo-Pardo de filhos de 18 a 25 anos.

Tabela 27 - Nível educacional de pais de casamento intra-racial Preto-Preto de filhos de 18 a 25 anos.

Tabela 28 - Descrição da Amostra 49

Tabela 29 - Decomposição das desigualdades educacionais para jovens de 14 a 17 anos 59

Tabela 30 - Decomposição da mudança do hiato de anos de estudo de jovens entre 14 e 17 anos65 Tabela 31 - Decomposição das desigualdades educacionais com casamento inter-racial para jovens de 14 a 17 anos. 69

Tabela 32 - Decomposição das desigualdades educacionais para jovens de 18 a 25 anos 72

Tabela 33 - Decomposição da mudança do hiato de anos de estudo de jovens entre 18 e 25 anos76 Tabela 34 - Decomposição das desigualdades educacionais com casamento inter-racial para jovens de 18 a 25 anos. 79 


\section{Lista de Tabelas dos Anexos}

Tabela A1- Nível educacional dos pais de casamento inter-racial Branco-Pardo dos jovens de 14 a 17 anos. 89

Tabela A2 - Nível educacional dos pais de casamento inter-racial Branco-Preto. 89

Tabela A3 - Nível educacional dos pais de casamento inter-racial Pardo-Preto. 90

Tabela A4- Classe social por tipo de casamento e classificação racial dos jovens de 14 a 17 anos 91

Tabela A5 - Tabulação total da variável atraso escolar dos jovens de 14 a 17 anos. .92

Tabela A6 - Resultados das regressões dos jovens de 14 a 17 anos - tipo de casamento como referência.

Tabela A7 - Resultados das regressões dos jovens de 14 a 17 anos - ano 2012 como referência.. 94

Tabela A8 - Resultados das regressões dos jovens de 14 a 17 anos - ano 2012 como referência e interação raça e educação dos pais

Tabela A9 - Decomposição das desigualdades educacionais com interação raça \& educação para jovens de 14 a 17 anos

Tabela A10 - Tabulação total da variável atraso escolar dos jovens de 18 a 25 anos. 98

Tabela A11 - Nível educacional de pais de casamento inter-racial Branco-Pardo dos jovens de 18 a 25 anos. 98

Tabela A12 - Nível educacional de pais de casamento inter-racial Branco-Preto dos jovens de 18 a 25 anos.

Tabela A13 - Nível educacional de pais de casamento inter-racial Preto-Pardo dos jovens de 18 a 25 anos.

Tabela A14 - Anos de estudos dos filhos de casamento intra-racial Branco-Branco dos jovens de 18 a 25 . 100

Tabela A15 - Anos de estudos dos filhos de casamento intra-racial Pardo-Pardo dos jovens de 18 a 25.

Tabela A16 - Anos de estudos dos filhos de casamento intra-racial Preto-Preto dos jovens de 18 a 25. 102

Tabela A17 - Anos de estudos dos filhos de casamento inter-racial Branco-Pardo dos jovens de 18 a 25. 103

Tabela A18 - Anos de estudos dos filhos de casamento inter-racial Branco-Preto dos jovens de 18 a 25. 104

Tabela A19 - Anos de estudos dos filhos de casamento inter-racial Pardo-Preto dos jovens de 18 a 25. 105 
Tabela A20 - Classe social por tipo de casamento e classificação racial dos jovens de 18 a 25 anos 106

Tabela A21 - Resultados das regressões dos jovens de 18 a 25 anos. 107

Tabela A22 - Resultados das regressões dos jovens de 18 a 25 anos - ano 2012 como referência 108

Tabela A23 - Resultados das regressões dos jovens de 18 a 25 anos - ano 2012 como referência e interação raça e educação dos pais 109

Tabela A24 - Decomposição das desigualdades educacionais com interação raça \& educação para jovens de 18 a 25 anos 


\section{Resumo}

Em um contexto de desigualdade econômica, estudos que abordam casamento inter-racial e desigualdade tem ganhado importância no meio acadêmico. A contribuição deste trabalho está em alinhar os debates sobre estes dois temas no cenário brasileiro e responder a seguinte pergunta: o casamento entre diferentes raças pode reduzir a desigualdade para as próximas gerações? Usando a metodologia proposta por Juhn, Murphy e Pierce (1993 e 1991), com dados da PNAD para os anos de 2002 e 2012, encontramos que tanto para jovens entre 14 e 17 anos como para jovens entre 18 e 25 anos, o casamento inter-racial não contribui para a redução da desigualdade entre grupo de branco e não branco. Porem, outras características individuais como: mãe com nível superior de escolaridade, por exemplo, contribuem para a redução da desigualdade. Além disso, a desigualdade educacional vem reduzindo ao longo do tempo.

Palavra Chave: Casamento, Desigualdade, Educação. 


\begin{abstract}
In a context of economic inequality, studies on interracial marriage and inequality have gained importance. The contribution of this work is to align the discussions on these two subjects in the Brazilian scenario and answer the following question: Marriage between different races can reduce inequality for the next generations? Using the methodology proposed by Juhn, Murphy and Pierce (1993 and 1991), with PNAD data for the years 2002 and 2012, this paper founds that for both young people between 14 and 17 and between 18 and 25 years, interracial marriage does not contribute to reducing inequality between white and non-white group. However, other individual characteristics such as mother with higher education level, for example, contribute to reducing inequality. Furthermore, educational inequality has reduced over time.
\end{abstract}

Keywords: Marriage, Inequality and Education. 


\section{Introdução}

Em um contexto de desigualdade econômica, a contribuição dos estudos relacionados a casamento inter-racial e desigualdade, e principalmente de sua reprodução intergeracional, se tornou um tema de preocupação para os economistas.

Algumas pesquisas sugerem que a distância separando brancos, pardos e pretos, no mercado matrimonial, não seria equivalente às distâncias socioeconômicas entre os grupos raciais, uma vez que desigualdades no sistema educacional, por exemplo, indicam claramente que pardos estão bem mais próximos de pretos e que ambos estão em desvantagem em relação aos brancos.

Ribeiro e Silva (2009) destacam que os relacionamentos inter-raciais no Brasil têm aumentado e que existe uma aceitação maior nas relações entre diferentes raças. Essa aceitação vem ocorrendo principalmente pela mudança que o Brasil vem sofrendo desde a década de 1960. O país expandiu o acesso à educação em todos os níveis, e nos últimos anos, uma expansão ainda maior em nível universitário, aumentando, portanto, a possibilidade de ingressar na universidade. Mesmo com o aumento do acesso às universidades, Marteleto (2012) discute em sua pesquisa que os jovens de raça branca permanecem em vantagem educacional em relação aos pardos e pretos, entretanto a partir de 2007, segundo a autora, os pardos e pretos ficaram mais próximos dos brancos em níveis educacionais. Um dos fatores que contribuiu para esse progresso foi a implementação da política de cotas raciais nas universidades. Francis e Tannuri-Pianto (2013) também encontram esse mesmo resultado. Os autores relatam que política de cotas raciais adotadas em universidades do Brasil promove a equidade entre as raças. Contudo, os autores relatam que ainda há muito a ser feito no sentido de fomentar a igualdade na educação.

Acompanhando essa expansão ao acesso à educação, paralelamente ao aumento dos casamentos inter-raciais, ocorreram duas outras mudanças que podem estar relacionadas. Inicialmente, houve uma diminuição das barreiras educacionais aos casamentos, Silva, (2003). Ou seja, o percentual de casamentos, entre maridos e esposas com níveis educacionais distintos (inter-educacionais), aumentou ao longo do tempo. Somando-se esse aumento de casamentos e o crescimento do acesso ao sistema educacional, verifica-se uma progressão relativa de pretos e pardos, levando a uma diminuição proporcional das desigualdades educacionais entre os grupos de cor (Ribeiro e Silva, 2009).

Desigualdade educacional entre raças tem recebido atenção especial porque a educação é um fator importante na formação do nível socioeconômico do indivíduo, bem 
como relevante à sua mobilidade social, e essa importância independe da raça (Fu e Heaton 2008; Kalmijn 1998).

Ducan et al. (2011) aponta que o aumento dos casamentos inter-raciais, resulta em redução da desigualdade educacional. Os autores alegam que filhos de casamento intraracial desfrutam de certa vantagem relacionada ao capital humano, quando comparado aos filhos de casamento inter-racial, porém não há um consenso nas pesquisas. Henriques (2001) e Telles (2004) alegam que o casamento inter-racial não é indicador confiável de inclusão e redução da desigualdade educacional. Com isso, vem aumentando o número de trabalhos que visam estudar os casamentos inter-raciais e desigualdade educacional racial, (Schwartz, 2003; Telles, 2004; Torch, 2010). Entretanto, a redução da desigualdade não pode ser vista apenas pelo prisma da desigualdade educacional, pois conforme afirmação de Osorio (2009), a desigualdade de renda também é um fator que contribui para a desigualdade racial, pois ela gera impactos na realização educacional do indivíduo. Além disso, características individuais dos casais, e futuros pais, podem influenciar de alguma forma a educação dos filhos.

Ambos, homem e mulher, buscam maximizar suas preferências por meio de características dos cônjuges, e conforme Becker (1991), a raça é definitivamente um aspecto relevante no mercado de casamento, além da renda e da educação, por exemplo. Segundo o autor, a interação dessas características, pode afetar a educação dos filhos, uma vez que todo e qualquer benefício gerado neste grupo só pode ser repassado a membros que pertençam a ela, isto é, não há transferência de benefício (conhecimento, por exemplo) entre pessoas que não sejam da família.

Diante dos aspectos relacionados, este trabalho visa identificar se pode haver uma redução da desigualdade racial em educação com o aumento do casamento inter-racial. Para este fim, utilizando a decomposição proposta por Juhn, Murphy e Pierce (1991 e 1993), o estudo avaliará mudanças estruturais na desigualdade do nível educacional de filhos de casamento inter-racial, que tenham entre 14 e 25 anos. Para isso, serão utilizados dados da PNAD - Pesquisa Nacional por Amostra de Domicílios, disponibilizados pelo IBGE Instituto Brasileiro de Geografia e Estatística, nos anos de 2002 e 2012. Para alcançar o objetivo proposto, o presente estudo contém, além dessa introdução, a revisão da literatura, a metodologia, a discursão dos resultados bem como a conclusão. 


\section{Revisão de Literatura}

A revisão de literatura abordará temas que ajudam a compreender a relação de casamento e a desigualdade educacional das próximas gerações, ou seja, dos filhos desses casais. Para realizar tal propósito, inicialmente será exposto o debate da literatura sobre o mercado de casamento, em seguida será apresentado a literatura de investimento intrafamiliar e por fim, alguns trabalhos que abordam casamento e desigualdade educacional.

\subsection{Mercado de casamento}

Os estudos sobre o mercado de casamento têm como objetivo principal entender a escolha que as pessoas fazem ao se casar. Avaliar essa escolha é importante, pois à medida que as pessoas se casam e escolhem parceiros com características semelhantes, essa escolha é considerada um importante indicador comportamental da sociedade (Kalmijn, 1998). A escolha do parceiro influencia no bem estar de cada um dos parceiros, além de influenciar no bem estar da família que será formada (cônjuges e filhos).

Começando com o trabalho pioneiro de Becker (1973, 1974, 1991), o modelo apresentado pelo autor assume dois pressupostos básicos: primeiro - cada pessoa tenta encontrar um companheiro que maximiza seu bem-estar; e segundo, o mercado matrimonial está em equilíbrio, ou seja, nenhuma pessoa pode trocar de companheiro e estar em situação melhor. Nesse sentido, pode-se avaliar que o mercado de casamento é eficiente no sentido de Pareto, pois uma pessoa não consegue melhorar seu casamento sem piorar a situação de outros. E em caso de possiblidade de trocas, a coalização ideal é no núcleo, uma vez que nenhuma coalização (casamento) fora do núcleo poderia fazer qualquer um dos seus membros melhor sem tornar o outro pior.

O autor ao avaliar os ganhos do casamento, assume que as pessoas decidem se casar se somente se, eles aumentarem sua utilidade. Assumindo essa hipótese, a utilidade depende diretamente dos "bens" produzidos por cada família e não dos bens e serviços ofertados pelo mercado. Tais "bens" não são negociáveis ou transferíveis entre diferentes famílias, entretanto podem ser transferidas entre membros da mesma família. Os "bens" produzidos entre os membros da família são numerosos, e inclui: qualidade das refeições, qualidade e quantidade de filhos, prestígio, recreação, companheirismo, amor, estado de saúde, etc. O ganho de casamento também depende de características, como a beleza, inteligência e educação, que afetam a produtividade no mercado, bem como, oportunidades de mercado. 
O modelo de mercado de casamento implica que homens com diferente capital físico, educação ou inteligência, altura, raça, ou muitas outras características tendem a se casar com mulheres com características próximas a essas. Logo, haverá uma correlação positiva das características entre homens e mulheres. Furtado (2012) argumenta que no instante que Becker assume a eficiência no mercado de casamento, o autor verifica correlação positiva entre os cônjuges em qualquer característica quantitativa, uma vez que a produtividade marginal da característica do marido na produção familiar depende positivamente da característica da esposa. Furtado (2012) cita a inteligência, a educação, a saúde, a fecundidade, religião e raça como exemplos de características para o qual este é susceptível de apresentar correlação positiva. Lam (1988) estende a análise de Becker, demonstrando que a correlação entre casamento e renda também é positiva (que a renda dos cônjuges também está positivamente correlacionada).

Características como educação, renda, raça, entre outros, são atributos importantes para que as pessoas escolham se casar, desde que esses atributos venham maximizar sua utilidade. Browning et al. (2011) enfatizam que casamento com base nos atributos de ambos os parceiros, que apresentam interações entre os atributos individuais de cada cônjuge, gera ganhos mútuos. Por exemplo, um homem com nível educacional elevado, pode se beneficiar mais ao casar-se com uma mulher com nível educacional mais elevado, do que se casar com uma mulher de nível educacional menor. Lewis e Oppenheimer (2000) afirmam que muitas vezes os casais se formam com base em escolaridade. Este processo é motivado não só pelo ganho mútuo do casamento, mas também pela disponibilidade de parceiros com diferentes níveis de escolaridade e a chance de encontrá-los na escola ou local de trabalho.

A literatura sobre mercado de casamento tem focado em indicadores socioeconômicos: como a educação ou renda (Qian, 1998). No trabalho de Chiappori et al. (2011), os autores verificam casamentos inter-raciais tanto pelo nível educacional como pelo nível de renda. Segundo os autores há certa assimetria nos casamentos inter-raciais: mulheres pretas de casamentos inter-raciais são mais educadas do que mulheres brancas. Mulheres brancas de casamento inter-racial casam-se em média com homens mais pobres. Já os homens pretos casam-se com mulheres brancas se elas forem mais educadas.

Outros trabalhos também analisam a relação entre as características socioeconômicas educação e raça. Wong (2003) considera em suas análises casamento entre homens pretos e 
mulheres brancas. A autora estima um modelo que avalia o mercado de casamento em relação à educação e raça dos cônjuges. Sua explicação para a baixa prevalência de casamentos entre homens pretos e mulheres brancas, está associada à falta de interesse de pessoas brancas em casar-se com pessoas de outra raça. Logo, para a autora, não é o atributo educação que determinam a maximização da utilidade no mercado de casamento, quando analisado o casamento inter-racial, e sim a preferência por determinada raça.

As características de raça e educação também são avaliadas por Fisman et al. (2006). Os autores verificam que enquanto a preferência nas escolhas dos homens está associada à aspectos físicos das mulheres, as mulheres maximizam sua utilidade escolhendo homens mais educados - maior nível educacional - além de dar maior importância à raça do parceiro do que os homens.

Diante do debate apresentado, verificou-se quais são os aspectos relevantes para o casamento. Ambos, homem e mulher, buscam maximizar suas preferências por meio de características dos cônjuges, e conforme Becker (1991), a raça é definitivamente um aspecto relevante no mercado de casamento, além da renda e da educação, por exemplo. O ganho de casamento depende dessas características e afetam a produção familiar, bem como afetam a quantidade e qualidade dos filhos, fruto dessa relação. Ainda segundo o autor, a interação dessas características, pode afetar a educação dos filhos, uma vez que os "bens" produzidos por cada família são transferidos apenas entre membros da mesma família.

A partir das ideias debatidas nessa seção, será apresentado na seção seguinte, como o comportamento dos pais pode afetar a educação dos filhos e como isso pode contribuir para a desigualdade educacional entre filhos de casamento inter-racial.

\subsection{Investimento intrafamiliar}

Ao modelar a economia da educação, é preciso considerar o fato de que os investimentos em educação em geral, inicialmente não são feitos pelos principais beneficiários, mas sim por seus pais. Desse modo, a escolha dos pais em qual dos filhos a renda será aplicada para ampliar o nível de educação é um dos fatores que podem contribuir para a diferença educacional que existe entre brancos e negros. Os critérios adotados pelos pais para escolherem entre um ou outro também é relevante para essa abordagem, pois a escolha pode ser influenciada pelo retorno que o filho pode gerar a família. Tais retornos podem estar associados à habilidade que cada um dos filhos possui. Assim, há questões não 
só da eficiência do investimento, mas também da dotação ${ }^{2}$ inicial de cada filho e dos benefícios esperados por suas famílias.

Por outro lado, a decisão de investimento dos pais pode estar associada também a possibilidade de financiamento das famílias, ou seja, mesmo que todos os filhos tenham a mesma habilidade, os pais não tem rendimento suficiente para investir em todos, logo terá que escolher apenas um deles. Rangel (2007) destaca, por exemplo, que os determinantes das diferenças salariais entre brancos e negros surgem durante a infância de uma criança, com destaque para as decisões de investimento que os pais tomam em relação à educação de seus filhos. Em situações adversas, o filho que proporcionar maior retorno receberá maior investimento em educação.

Becker (1974) afirma que o conhecimento adquirido entre os membros das famílias são intransferíveis entre outros grupos, entretanto podem ser transferidas entre membros da mesma família. Diante deste fato, a decisão de investimento dos pais na educação dos filhos, pode ser analisada não só quanto ao retorno esperado, mas também quanto às experiências dos pais, principalmente aquelas adquiridas no mercado de trabalho. Emerson e Souza (2002) enfatizam que pais que tiveram experiências no mercado de trabalho ainda jovens, ou seja, iniciaram o trabalho ainda criança, tem impacto direto no investimento da educação dos filhos. Outro caso relacionado a experiências dos pais foi comentado por Rangel (2007). O autor alega que pais que sofreram algum tipo de racismo no mercado de trabalho acabam tendo maior incentivo a investir em filhos com peles mais claras, pois eles acreditam que haverá uma probabilidade menor dos filhos de pele mais clara passar por algum tipo de preconceito. Hoff et al. (2006) corroboram este fato, e sugerem que os mecanismos de discriminação operaram, em parte, pelos indivíduos que foram discriminados. Os autores explicam que os efeitos da discriminação ocorrida no passado, persistem ao longo do tempo.

Outros fatores associados às diferenças de cor da pele no contexto do mercado de trabalho, também podem influenciar no investimento intrafamiliar. Indivíduos de pele escura que recebem salários mais baixos são mais propensos a ser desempregados, ou ter acesso limitado a determinados postos de trabalho devido à discriminação. Essas diferenças observadas podem resultar em menor investimento dos indivíduos de pele mais escura na acumulação de competências, o que se traduz em uma escassez de oportunidades econômicas. Se as habilidades não são justamente recompensadas, os membros destes

\footnotetext{
${ }^{2}$ Nos modelos de investimento intrafamiliar as dotações das crianças são as habilidades ou a capacidade inerente em cada uma delas. Cada criança tem habilidades diferentes umas das outras, mesmo que sejam gêmeas (Becker et al. 1976).
} 
grupos têm menos incentivos para investir em si próprio (Carneiro et al. (2005), Heckman (1998) e Neal e Johnson (1996)). Esses resultados também destacam o fato de que as diferenças no desempenho do mercado de trabalho tendem a persistir ao longo de gerações, pois quanto menor for a oportunidade econômica, menor será a renda da família para investir nos filhos.

A partir disso, Alderman et al. (1998) argumentam que há questões não só da eficiência do investimento das famílias, mas também dos benefícios esperados pelos pais. Os autores alegam que há duas razões distintas na decisão de investimento. Em primeiro lugar, a aprendizagem pode contribuir diretamente para o bem-estar da criança e dos pais, contribuição essa que pode ser superior ao investimento. Isto é, a aprendizagem, neste caso, é vista como um bem de consumo. Em segundo lugar, a preferência entre as crianças influencia a forma como os investimentos em educação são alocados para crianças com diferentes taxas de retorno esperada. Uma característica importante na tomada de decisão de investimento, conforme Alderman et al. (1998), está relacionada tanto aos incentivos de mercado quanto a preferências dos pais.

Behrman et al. (1982) avaliou a preferências dos pais quanto à alocação de recursos entre seus filhos. Os autores argumentam que os pais ao decidirem investir na educação dos filhos, avaliam os potenciais ganhos de cada um deles, antes de realizar o investimento educacional. Ou seja, uma vez que o investimento implica em retornos marginais iguais à educação para todas as crianças em uma família, isso implica que os pais alocam recursos entre os seus filhos de modo a maximizar os ganhos da família. Os autores estimam a função de utilidade das famílias sujeita a duas restrições: salário e escolaridade, e nesse contexto encontram que pais com aversão à desigualdade, irão investir mais recursos nos filhos com menor habilidade. O modelo de preferências, utilizado pelos autores, assume que os pais têm igual interesse para todos os seus filhos; ou seja, que a função de bem-estar dos pais trata todas as crianças simetricamente, no entanto esta hipótese foi rejeitada, uma vez que famílias com aversão à desigualdade não tratarão seus filhos de forma simétrica, pois eles investirão mais recursos nos filhos com menor habilidade.

Modelos que estudam investimento intrafamiliar em um contexto mais geral, isto é, avaliam o grau de aversão à desigualdade, apontam resultados semelhantes ao relatado acima. Becker et al. (1976) argumenta que efeito preço $^{3}$ domina o efeito riqueza ${ }^{4}$, isto é,

\footnotetext{
${ }^{3}$ Efeito-Preço é a contribuição que o pai dará aos filhos para aumentar sua qualidade, ou seja, melhorar suas habilidades.
} 
famílias investirão mais capital na educação de crianças mais bem dotadas. Portanto, os pais contribuem para a desigualdade, investindo mais capital em crianças que receberão um salário mais elevado de qualquer maneira devido à sua maior dotação. No entanto, os pais investem mais capital não humano em crianças menos dotadas, e com isso eles reduzem a desigualdade na renda total em relação aos ganhos. Este fato ocorre, pois segundo o autor, os pais incentivariam a transferência de recursos voluntários dos irmãos "melhor dotados" aos irmãos "menos dotados".

Corroborando com o resultado de Becker et al. (1976), Rangel (2007) afirma que pais, a fim de maximizar o bem estar da família, contribuem para a persistência da diferença salarial entre brancos e pretos ao longo do tempo, quando escolhem investir na educação de filhos com a pele mais clara. Neste estudo, a dotação avaliada é a cor da pele do filho. Famílias com composição de casamento inter-racial (os pais tem classificação racial diferente) ao perceberem a existência de diferenças no retorno para investimentos em capital humano (de acordo com a cor da pele) tendem a investir mais em filhos com peles mais claras. Neste caso, mesmo que os pais não atribuam nenhuma preferência à cor da pele dos filhos, os resultados encontrados pelo autor sugerem que filhos com peles mais claras estão em melhor situação e que os pais nada fazem para compensar totalmente essa diferença. Neste caso o efeito preço domina o efeito renda, aumentando a diferença educacional entre brancos e pretos.

Esse debate relacionado à preferência de investimento dos pais permanece mesmo quando há restrição no orçamento familiar. Kaushal et al. (2011) relata que os investimentos da família não são distribuídos aleatoriamente entre as crianças; a escolha de investimento reflete além das preferências e as restrições orçamentárias, o custo de oportunidade. A família que tem dificuldade de financiar os estudos de todos os filhos escolherá aquele que maximizar os ganhos da família.

A preferência de investimento também pode estar associada ao tamanho da família. Dado o número de filhos, os pais podem direcionar o investimento a determinada criança. Neste caso especificamente, Black et al. (2005) argumentam que o nível de escolaridade dos filhos está relacionado à ordem de nascimento, ou seja, os filhos mais velhos podem receber maior investimento em educação. Mas este fato ocorre pela dificuldade dos pais em avaliar o filho com melhor dotação, dado que o número de filhos é elevado. No entanto, o autor alerta pelo fato de o número de filhos por família estar reduzindo com o passar do tempo, e isso

\footnotetext{
${ }^{4}$ Efeito-Riqueza ou efeito-renda significa que a família irá contribuir para a igualdade entre os filhos por meio de transferência de recursos do filho com maior dotação, para o filho com menor dotação.
} 
deixará, ao longo do tempo, de ser um mecanismo de desigualdade educacional intrafamiliar.

\subsection{Casamento e Desigualdade}

Estudos têm contribuído para o debate entre casamento inter-racial e desigualdade. Alguns trabalhos tem sugerido que o casamento inter-racial tem contribuído para desigualdade de renda em países desenvolvidos (Schwartz, 2003; Breen et al. 2009; Breen, 2012).

Fu (2008) testa se o casamento inter-racial causou alguma mudança no status sócio econômicos das famílias utilizando três medidas: educação, prestígio no trabalho e renda. $\mathrm{O}$ autor destaca que alguns estudos mostram que o casamento inter-racial tem sido um mecanismo de igualdade racial, entretanto seus resultados apontam que casamentos endogâmicos têm status socioeconômicos semelhantes e que não há nenhuma evidência de alteração de status socioeconômico para casamentos exogâmicos. $\mathrm{O}$ autor ainda afirma que casamentos inter-raciais resultam em uma maior aceitação entre os grupos, no entanto, também podem preservar as classes sociais por raça e dificultar a ascensão social da próxima geração para os mais desfavorecidos.

Ducan et al. (2011) exploram a relação entre casamento inter-racial e desigualdade. Os autores usam dados dos Estados Unidos, de jovens entre 16 e 17 anos, para identificar se o casamento entre diferentes raças trouxe algum progresso inter-geracional à população mexicana que vive nos Estados Unidos. Os resultados apresentados mostram que jovens de casamento mistos (mexicanos com americanos) desfrutam de vantagens relacionadas ao capital humano, quando comparados a jovens de casamento endogâmicos (entre mexicanos que vivem nos Estados Unidos).

Apenas três trabalhos para o Brasil, fazem a relação entre casamento inter-racial e desigualdade. Telles, (2004) adota uma abordagem diferente dos estudos sociais abordando casamento inter-racial, os quais mostram que "as altas taxas de casamentos mistos e os baixos níveis de segregação" indicam "uma maior aceitação de grupos externos". Segundo Telles (2004) tal proximidade social não se traduz em plena inclusão na vida econômica. Casamento inter-racial não é um indicador confiável de inclusão e redução da desigualdade educacional, e um dos argumentos utilizados pelo autor é o fato de o Brasil ser um país com grau elevado de desigualdade, e o aumento de casamento entre diferentes raças não garante igualdade de renda ou igualdade educacional. Já no trabalho de Torch, (2010), o autor alega 
que há uma associação entre o gap salarial e a categoria educacional no Brasil, México e Chile, o que contribui para a desigualdade econômica. Esta constatação reforça a hipótese de que a desigualdade econômica reduz os incentivos econômicos e amplia as distâncias culturais e espaciais que impedem a interação e romance entre indivíduos com diferentes níveis de ensino.

Francis (2014) também elabora um trabalho para o Brasil. O autor utiliza dados do Censo 2010 para analisar a relação entre casamento inter-racial e desigualdade racial. O autor separa sua amostra em duas bases: jovens entre 14 e 17 anos e jovens entre 19 e 25 anos. As evidencias encontradas sugerem que o casamento inter-racial pode diminuir a desigualdade racial educacional para as próximas gerações, no entanto, os efeitos do casamento sobre a desigualdade são relativamente pequenos. Outra conclusão que o trabalho apresenta é que filhos classificados como brancos por pais de casamento intra-racial (entre brancos) mantém uma vantagem socioeconômica sobre os filhos de outros tipos de famílias. Em uma análise geral, o autor infere que embora o casamento inter-racial possa reduzir a desigualdade racial, em certa medida, essa desigualdade entre os grupos raciais deve persistir no futuro se os padrões socioeconômicos e educacionais atuais continuarem.

Nesta breve passagem pelos principais trabalhos que abordam casamento inter-racial e desigualdade é possível notar que parte desses estudos são categóricos em afirmar que o casamento inter-racial não reduz a desigualdade. Já Francis (2014) e Ducan et al. (2011) afirmam que há um ganho quanto ao capital humano para os filhos desses casamentos.

Com o mesmo objetivo, o presente trabalho tenta analisar se o casamento inter-racial pode reduzir a desigualdade racial educacional para as próximas gerações. Analisamos quais as características individuais contribuem para a redução dessa desigualdade e em qual grupo a desigualdade é maior, entre jovens de 14 e 17 anos ou entre 18 e 25 anos. Explicaremos a base de dados que utilizaremos para responder essas questões. 


\section{Base de dados}

Analisar como o casamento inter-racial afeta a desigualdade educacional para futuras gerações é um estudo bem complexo, principalmente pelo fato da educação ocorrer não só no ambiente educacional, mas também em ambientes externos. Medeiros et al. (2013) afirma que a lista de determinantes que afeta a desigualdade educacional pode ser bem extensa e uma forma de organizar isso é dividi-los em grupos. Os autores destacam três grupos: o primeiro denominado Escola, que inclui a característica dos professores, da administração, infraestrutura das instalações, currículos e técnicas de ensino, porém esta lista não é exaustiva; o segundo grupo é o Ambiente social, que tenta abarcar fatores não escolares da sociedade que afetam de modo relevante à educação como, por exemplo, transporte, segurança e valores culturais relacionados à educação e ao trabalho; finalmente, o terceiro grupo pode ser denominado Características individuais e familiares, o qual remete à educação dos pais, sua renda, a composição da família e atributos individuais como raça, sexo e deficiência, por exemplo. Trata-se de uma divisão puramente analítica, pois há alguma interseção e muita interação entre essas categorias.

Alguns estudos argumentam que tanto as escolas como outros fatores escolares não são os principais determinantes da desigualdade, quando analisado pelo lado da educação. Há evidência indicando que a origem social, identificada por meio de características pessoais e familiares, possui um peso maior no desempenho educacional de crianças e jovens (Alves, et al. 2007; Cesar, et al. 2001; Gonçalves, et al. 2008), e isso é um dos principais determinantes das desigualdades educacionais no Brasil, Silva et al., (2000). E essa desigualdade aumenta com o envelhecimento das pessoas (Barros, et al. 2001).

Diante desses argumentos, para alcançar o objetivo proposto, nos concentraremos nas características individuais e familiares de jovens entre 14 e 25 anos, filhos de casamentos intra e inter-raciais. Os dados foram divididos em dois grupos: jovens entre $14 \mathrm{e}$ 17 anos e entre 18 e 25 anos. O objetivo dessa divisão é permitir que as características familiares tenham impacto diferenciado na desigualdade educacional dos jovens das duas faixas etárias. As características consideradas são: se os pais são de casamento inter-racial ou intra-racial, logaritmo da renda familiar, nível educacional dos pais, região, situação censitária (área urbana ou rural), idade dos pais, se a mãe trabalha mais de 15 horas por semana, além das características dos filhos, tais como classificação racial, e para jovens de 18 a 25 anos, verificamos qual a proporção de famílias chefiadas por jovens na região censitária que habitam. Para tanto, serão utilizadas PNAD’s dos anos de 2002 e 2012. 
A PNAD não possui a informação sobre o estado civil do responsável pela família, por isso foi necessário criar uma variável que indique tal situação. Para isso, foi utilizado o número de controle, número de série, número da ordem e a condição na família, pois com essas variáveis é possível saber quais são os integrantes de cada família ${ }^{5}$, e supor que as famílias que possuem uma pessoa de referência e um cônjuge são casadas ou vivem com um(a) companheiro(a).

Após a criação da variável que indica a união ou casamento entre os integrantes da família, foi necessário utilizar a classificação racial de cada um deles, para criar a variável que indica se o casamento é inter-racial ou intra-racial. No questionário da PNAD há seis possibilidades de classificação racial: branca, preta, amarela, parda, indígena e sem declaração. Como o número de pessoas que se declararam com a raça amarela, indígena ou ignorada é pequeno e estatisticamente não significativo, decidimos desconsiderá-las, sem prejuízo aos resultados, conforme trabalho de Schwartzman (2007). Portanto foram mantidas apenas as raças, branca, preta e parda.

A partir do relato acima, é possível criar nove combinações ${ }^{6}$ de casamento entre raças, como segue: casamento entre Branco e Branco, Branco e Preto, Branco e Pardo; Preto e Preto, Preto e Branco, Preto e Pardo; Pardo e Pardo, Pardo e Preto, Pardo e Branco. Sendo casamentos entre a mesma raça o casamento intra-racial e entre raças diferentes inter-racial. Dada essas combinações, criamos as variáveis indicadoras intermarBB, intermarBPaPr e intermarPrPr. A dummy intermarBB ${ }^{7}$ assume o valor 1 para o casal da raça branca e 0 caso contrário; já a segunda, intermar $\mathrm{BPaPr}^{8}$, assume 1 para o casal de casamento inter-racial, ou seja, os cônjuges não tem a mesma classificação racial, e 0 caso contrário; e por fim, intermarPrPr ${ }^{9}$ assume 1 para o casal da raça preta e 0 caso contrário. Um fato importante a ser comentado é que serão considerados apenas casais que tenham filhos, portanto casais sem filhos ${ }^{10}$ não farão parte da amostra.

\footnotetext{
${ }^{5}$ Conforme dicionário das variáveis da PNAD, os integrantes da família podem ser classificados como: pessoa de referência, cônjuge, filho, outro parente, agregado, pensionista, empregado doméstico e parente do empregado doméstico.

${ }^{6}$ Para criar essas combinações foi usado o seguinte padrão: a pessoa de referência como o primeiro indivíduo e o cônjuge como o segundo indivíduo. Por exemplo, na combinação Branca e Parda, a pessoa de referência tem a classificação racial Branca e o cônjuge Pardo, já na combinação Parda e Branca, a pessoa de referência tem classificação racial Parda e o cônjuge Branco.

${ }^{7}$ Neste caso intermarBB será composto por: Branco e Branco; Branco e Preto; Branco e Pardo; Preto e Branco; Pardo e Branco.

${ }^{8}$ Neste caso intermarBPaPr será composto por: Branco e Preto; Branco e Pardo; Preto e Branco; Pardo e Branco.

${ }^{9}$ IntermarPrPr será composto por: Preto e Preto.

${ }^{10}$ Filhos que possuem ou só a mãe ou só o pai como pessoa de referência também foram desconsiderados da amostra.
} 
A variável nível educacional dos pais foi criada a partir dos anos de estudos de cada um deles. A variável foi construída a partir do agrupamento dos anos de estudo, seguindo o seguinte critério:

$\checkmark$ De zero a três anos de estudo - ensino primário incompleto

$\checkmark$ De quatro a nove anos de estudo - ensino fundamental incompleto

$\checkmark$ De dez a doze anos de estudo - ensino médio incompleto

$\checkmark$ De treze ou mais anos de estudo - ensino superior ${ }^{11}$ incompleto

Urbana é uma variável binária que assume valor 1 quando o respondente mora em uma área urbana e 0 ele mora em uma área rural. As variáveis que correspondem a características dos filhos são raça, a proporção de domicílios chefiada por jovens entre 18 e 25 anos na região censitária que habitam, além da variável dependente - atraso escolar. A classificação racial dos filhos foi feita de forma semelhante a dos pais, isto é, considerando apenas os jovens com classificação racial, branco, pardo e preto.

A variável dependente deste estudo será os anos de atraso escolar, entretanto, essa variável não está disponível na PNAD. A partir de informações divulgadas pelo MEC Ministério da Educação ${ }^{12}$ foi possível à criação da mesma. O primeiro passo foi criar uma variável com os anos de estudo para todos os filhos, a partir da variável da PNAD V4703 que representa os anos de estudo de todos os indivíduos. Em seguida, criar outra variável, a partir da idade dos filhos, a série ideal (sem reprovação) que o jovem deveria estar cursando. Para tanto, é necessário utilizar a informação disponibilizada pelo MEC, seguindo o padrão descrito na tabela a seguir:

\footnotetext{
${ }^{11}$ Neste caso, estamos considerando tanto os pais que estão cursando o nível superior quanto aqueles que já cursaram.

${ }^{12}$ Ensino fundamental de nove anos - passo a passo do processo de implantação. Publicado em Setembro de 2009.
} 
Tabela 1 - Equivalência de idade e curso.

\begin{tabular}{|c|c|c|c|c|}
\hline $\begin{array}{c}\text { Idade } \\
\text { correspondente } \\
\text { (sem distorção / } \\
\text { reprovação) }\end{array}$ & $\begin{array}{l}8 \text { anos de duração } \\
\text { (Antes de 2009) }\end{array}$ & $\begin{array}{c}\text { Anos de } \\
\text { Estudo }\end{array}$ & $\begin{array}{l}9 \text { anos de duração } \\
\text { (Depois de 2009) }\end{array}$ & $\begin{array}{l}\text { Anos de } \\
\text { Estudo }\end{array}$ \\
\hline 5 anos & - & - & - & 0 \\
\hline 6 anos & - & 0 & $\begin{array}{c}1^{\circ} \text { ano }- \text { Ensino } \\
\text { Fundamental }\end{array}$ & 1 \\
\hline 7 anos & $1^{a}$ Série & 1 & $\begin{array}{c}2^{\circ} \text { ano - Ensino } \\
\text { Fundamental }\end{array}$ & 2 \\
\hline 8 anos & $2^{a}$ Série & 2 & $\begin{array}{c}3^{\circ} \text { ano }- \text { Ensino } \\
\text { Fundamental }\end{array}$ & 3 \\
\hline 9 anos & $3^{\text {a }}$ Série & 3 & $\begin{array}{l}4^{\circ} \text { ano }- \text { Ensino } \\
\text { Fundamental }\end{array}$ & 4 \\
\hline 10 anos & $4^{a}$ Série & 4 & $\begin{array}{l}5^{\circ} \text { ano }- \text { Ensino } \\
\text { Fundamental }\end{array}$ & 5 \\
\hline 11 anos & $5^{\text {a }}$ Série & 5 & $\begin{array}{c}6^{\circ} \text { ano }- \text { Ensino } \\
\text { Fundamental }\end{array}$ & 6 \\
\hline 12 anos & $6^{\mathrm{a}}$ Série & 6 & $\begin{array}{l}7^{\circ} \text { ano }- \text { Ensino } \\
\text { Fundamental }\end{array}$ & 7 \\
\hline 13 anos & $7^{\text {a }}$ Série & 7 & $\begin{array}{l}8^{\circ} \text { ano }- \text { Ensino } \\
\text { Fundamental }\end{array}$ & 8 \\
\hline 14 anos & $8^{a}$ Série & 8 & $\begin{array}{c}9^{\circ} \text { ano }- \text { Ensino } \\
\text { Fundamental }\end{array}$ & 9 \\
\hline 15 anos & $1^{\circ}$ ano $-2^{\circ}$ grau & 9 & $\begin{array}{c}1^{\circ} \text { ano - Ensino } \\
\text { Médio }\end{array}$ & 10 \\
\hline 16 anos & $2^{\circ}$ ano $-2^{\circ}$ grau & 10 & $\begin{array}{l}2^{\circ} \text { ano }- \text { Ensino } \\
\text { Médio }\end{array}$ & 11 \\
\hline 17 anos & $3^{\circ}$ ano $-2^{\circ}$ grau & 11 & $\begin{array}{c}3^{\circ} \text { ano }- \text { Ensino } \\
\text { Médio }\end{array}$ & 12 \\
\hline 18 anos ou + & Ensino Superior & $12 \mathrm{ou}+$ & Ensino Superior & $13 \mathrm{ou}+$ \\
\hline
\end{tabular}

Fonte: Criado pela autora a partir das informações do MEC

Para obter a variável atraso escolar, basta diminuir os anos de estudo da série ideal que o jovem deveria estar cursando pelos anos de estudo que ele realmente possui. Por exemplo: um jovem de 15 anos da PNAD de 2002 tem 6 anos de estudo. De acordo com a terceira coluna da Tabela 1 ele deveria ter 9 anos de estudo, no entanto ele só tem 6 , portanto ele está com atraso escolar de 3 anos. Se este mesmo exemplo for utilizado na PNAD de 2012, o jovem de 15 anos permanecerá com 3 anos de atraso escolar, porque ele ingressou nos estudos antes da alteração dos anos de estudo do ensino fundamental em 2009.

A Tabela 2 apresenta todas variáveis utilizadas no presente estudo, assim como a descrição de cada uma delas. 
Tabela 2 - Descrição das Variáveis

\begin{tabular}{ll}
\hline Variável & Descrição \\
\hline intermarBB & Casamento entre cônjuges de raça branca \\
intermarBPaPr & Casamento entre diferentes raças \\
intermarPrPr & Casamento entre cônjuges de raça preta \\
Inrend & Logaritmo da renda ${ }^{13}$ \\
\hline pai_educ_primário & Dummy para ensino primário - Pai \\
pai_educ_fundamental & Dummy para ensino fundamental - Pai \\
pai_educ_médio & Dummy para ensino médio - Pai \\
pai_educ_superior & Dummy para ensino superior - Pai \\
mãe_educ_primário & Dummy para ensino primário - Mãe \\
mãe_educ_fundamental & Dummy para ensino fundamental - Mãe \\
mãe_educ_médio & Dummy para ensino médio - Mãe \\
mãe_educ_superior & Dummy para ensino superior - Mãe \\
RNorte & Dummy para Região Norte \\
RNordeste & Dummy para Região Nordeste \\
RSudeste & Dummy para Região Sudeste \\
RSul & Dummy para Região Sul \\
RCentro-Oeste & Dummy para Região Centro Oeste \\
Urbana & Dummy para Situação censitária urbana \\
\hline H_Trab_Mae & Dummy para Mãe trabalha mais de 15 horas \\
IdadeM & Idade da Mãe \\
\hline IdadeP & Idade do Pai \\
\hline Atraso_escF & Anos de atraso escolar do filho \\
RaçaF_B & Dummy para filho de raça branca \\
RaçaF_Pa & Dummy para filho de raça parda \\
RaçaF_Pr & Dummy para filho de raça preto \\
Pchefejovem & Proporção de domicílios chefiada por jovens entre 18 e \\
\hline
\end{tabular}

Fonte: Criado pela autora.

\subsection{Descrição dos dados sobre os pais}

A Tabela 3 apresenta os padrões raciais dos casamentos no Brasil em 2002 e 2012.

Tal padrão não se alterou muito ao longo do período analisado. Houve uma pequena queda no percentual de casamento entre brancos de 2002 para 2012. Essa queda pode ser explicada pela mudança de classificação racial que vem ocorrendo nos últimos anos. Os trabalhos de Marteleto (2012) e Bailey (2009) evidenciam esses fatos e argumentam que, pricipalmente a partir do ano 2000, os indivíduos tem mudado sua autoclassificação racial, logo, pessoas que se classificaram como brancos no passado estão alterando sua classificação racial ou para pardo ou para preto ${ }^{14}$.

\footnotetext{
${ }^{13}$ A variável renda foi criada com base na renda mensal da família com agregado, ou seja, considera a renda de todas as pessoas da família que estejam recebendo algum tipo de rendimento.

${ }^{14}$ Marteleto (2012) argumenta que melhorias socioeconômicas e políticas governamentais são também motivos para a mudança da classificação racial que vem ocorrendo a partir do ano 2000.
} 
Tabela 3 - Casamento inter-racial e intra-racial

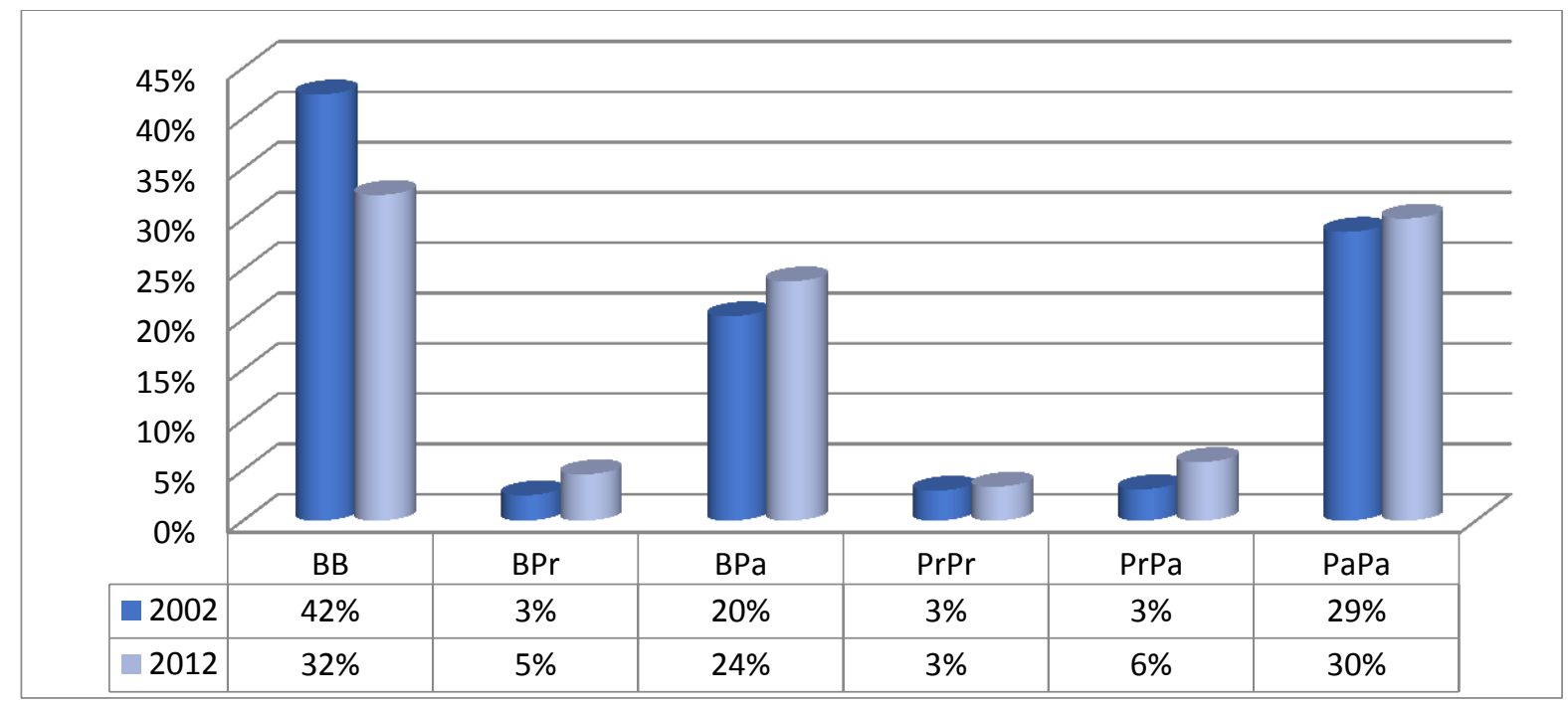

Fonte: Criado pela autora a partir das informações da PNAD.

Legenda: B - raça branca; $\mathrm{Pr}$ - raça preta; $\mathrm{Pa}$ - raça parda

A Tabela 4 mostra o casamento por raça e por gênero. Verifica-se que há maior predominância de casamento inter-racial com esposas de raça branca e marido de raça parda, do que de raça preta. Este resultado corrobora os estudos feitos por Wong (2003), no qual a autora afirma que a baixa prevalência de casamentos entre homens pretos e mulheres brancas está associada à falta de interesse de pessoas brancas em casar-se com pessoas de outra raça.

Tabela 4 - Casamento inter-racial por gênero

\begin{tabular}{|c|c|c|c|c|c|}
\hline \multicolumn{1}{|c|}{} & & \\
\hline
\end{tabular}

Fonte: Criado pela autora a partir das informações da PNAD.

O nível de escolaridade do pai pode ser visto na Tabela 5. Percebe-se que cerca de $40 \%$ a $50 \%$ do nível de escolaridade, para todas as raças, está concentrado no nível fundamental incompleto. Outro ponto a ser observado é que existe uma maior representação de pais brancos com nível médio ou superior, comparado com as demais raças. Verifica-se 
também que houve uma queda no percentual de pais com ensino primário incompleto entre os anos de 2002 e 2012, e em contrapartida, houve um aumento nos demais níveis de escolaridade.

Já a Tabela 6 apresenta os resultados para o nível de escolaridade da mãe. É possível verificar que cerca de $85 \%$ das mães tem nível fundamental e/ou médio. Outro ponto importante a ser analisado é a queda no percentual, em média de 10p.p., do nível primário entre os anos de 2002 e 2012. Há também uma leve redução do percentual entre os anos de 2002 e 2012 no nível fundamental e, em contrapartida, o aumento de mães com o ensino médio.

Em geral, ao comparar as duas tabelas, verifica-se que existe um maior percentual de mães com nível fundamental e médio incompleto do que pais. Quando se faz a mesma análise para o ensino superior incompleto, percebe-se que um percentual maior para os pais no nível superior em relação às mães.

Tabela 5 - Nível educacional do pai por classificação racial

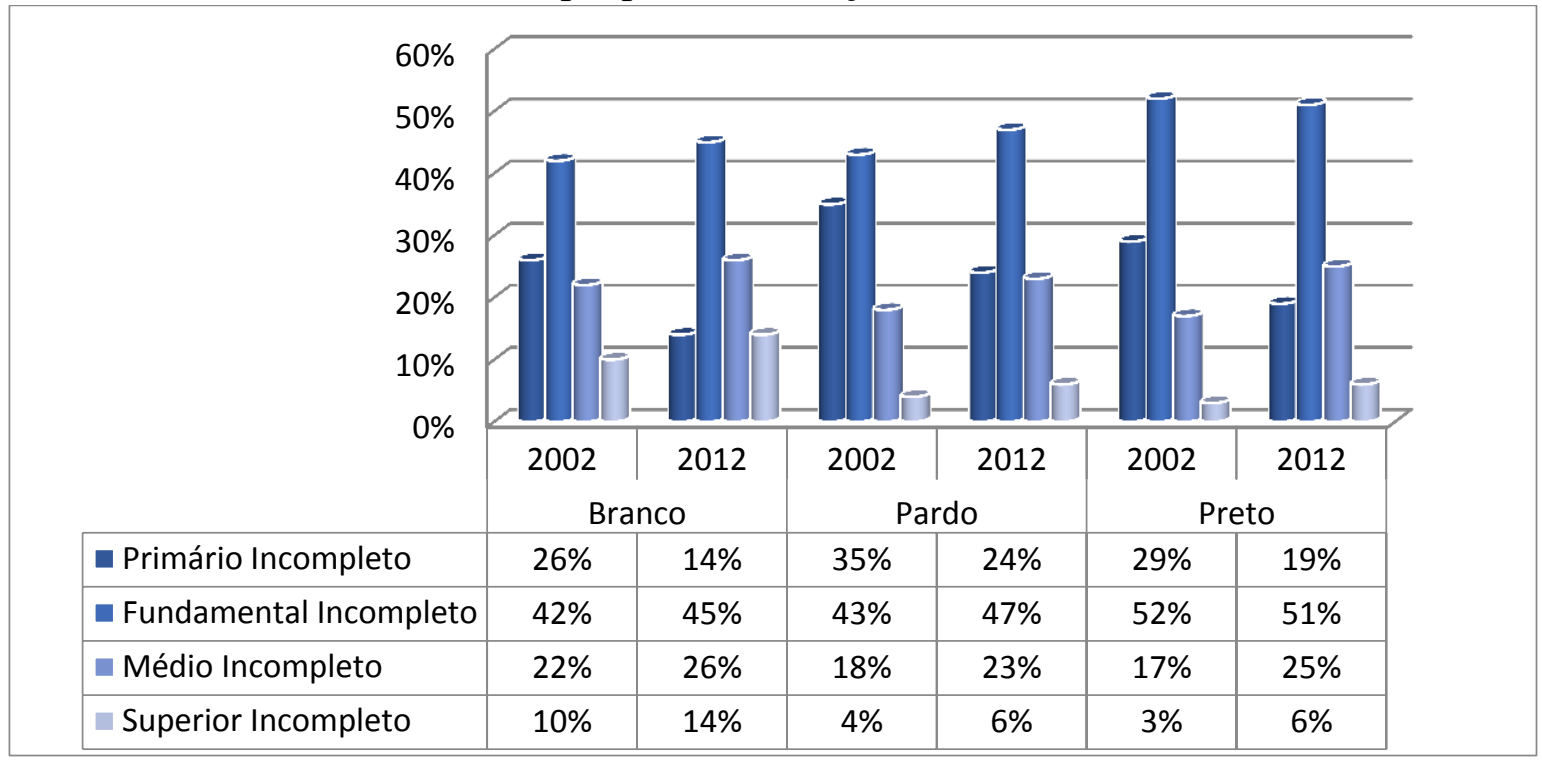

Fonte: Criado pela autora a partir das informações da PNAD. 
Tabela 6 - Nível educacional da mãe por classificação racial

\begin{tabular}{|c|c|c|c|c|c|c|}
\hline \multirow[t]{4}{*}{$\begin{array}{r}80 \% \\
70 \% \\
60 \% \\
50 \% \\
40 \% \\
30 \% \\
20 \% \\
10 \% \\
0 \%\end{array}$} & \multirow{2}{*}{2002} & & 2 & & $=$ & -1 \\
\hline & & 2012 & 2002 & 2012 & 2002 & 2012 \\
\hline & \multicolumn{2}{|c|}{ Branco } & \multicolumn{2}{|c|}{ Pardo } & \multicolumn{2}{|c|}{ Preto } \\
\hline & $14 \%$ & $4 \%$ & $27 \%$ & $9 \%$ & $17 \%$ & $6 \%$ \\
\hline Fundamental Incompleto & $67 \%$ & $55 \%$ & $65 \%$ & $63 \%$ & $72 \%$ & $63 \%$ \\
\hline Médio Incompleto & $14 \%$ & $30 \%$ & $7 \%$ & $23 \%$ & $9 \%$ & $27 \%$ \\
\hline Superior Incompleto & $5 \%$ & $11 \%$ & $1 \%$ & $5 \%$ & $1 \%$ & $4 \%$ \\
\hline
\end{tabular}

Fonte: Criado pela autora a partir das informações da PNAD.

A Tabela 7 exibe os resultados para a classe social por tipo de casamento. Para calcular a classe social da família consideramos classe baixa aquela que recebeu entre 0 e 4 salários mínimos, classe média entre 5 e 20 salários mínimos e classe alta a família que recebeu mais de 20 salários mínimos. Em 2002, o salário mínimo correspondia à R \$ 200,00 enquanto que em 2012 o salário mínimo correspondia à $\mathrm{R} \$ 622,00$.

Por meio dos resultados verifica-se que famílias com casamento intra-racial entre brancos estão em situação melhor do que famílias de casamento intra-racial pardo e intraracial preto. Se fizer a mesma análise para os casamentos inter-raciais, nota-se que famílias em que pelo menos um dos cônjuges são classificados como branco tem cerca de $20 \%$ de sua renda entre 5 e 20 salários mínimos no ano de 2012, ou seja, é classificado nesta pesquisa como classe média, enquanto que apenas $12 \%$ dos casais pardos e pretos são classificados como classe média em 2012.

Tabela 7 - Classe social por tipo de casamento

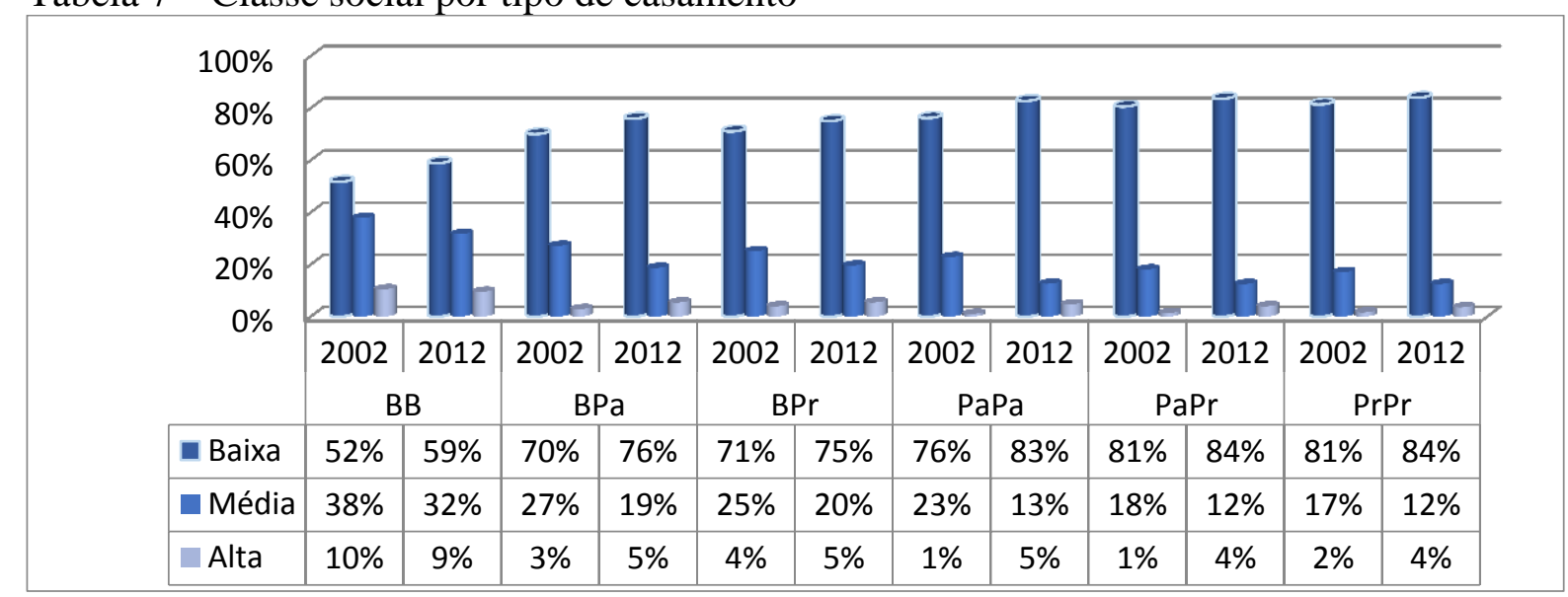

Fonte: Criado pela autora a partir das informações da PNAD.

Legenda: $\mathrm{B}$ - raça branca; $\mathrm{Pr}$ - raça preta; $\mathrm{Pa}$ - raça parda 
Ao analisar os dados sobre os pais constata-se que casais de raça branca tem maior nível de escolaridade além de possuírem maior nível de renda. Estes resultados são similares aos resultados apresentados por Furtado (2012), que argumenta a existência de correlação positiva entre casamento e educação, assim como casamento e renda.

\subsection{Descrição dos dados dos filhos - 14 a 17 anos}

Os dados a seguir apresentam os resultados para os filhos de 14 a 17 anos. A Tabela 8 ilustra a classificação racial dos filhos por tipo de casamento. Vale destacar dois pontos importantes: primeiro cerca de $70 \%$ a $80 \%$ dos filhos de casamento inter-racial são classificados ou como brancos ou como pardos. No casamento entre branco e preto, por exemplo, 31\% dos filhos de 2012 foram classificados como branco. O segundo ponto é que 4\% dos filhos de casais de raça preta foram classificados como branco em 2012.

Tabela 8 - Classificação racial dos filhos - 14 a 17 anos

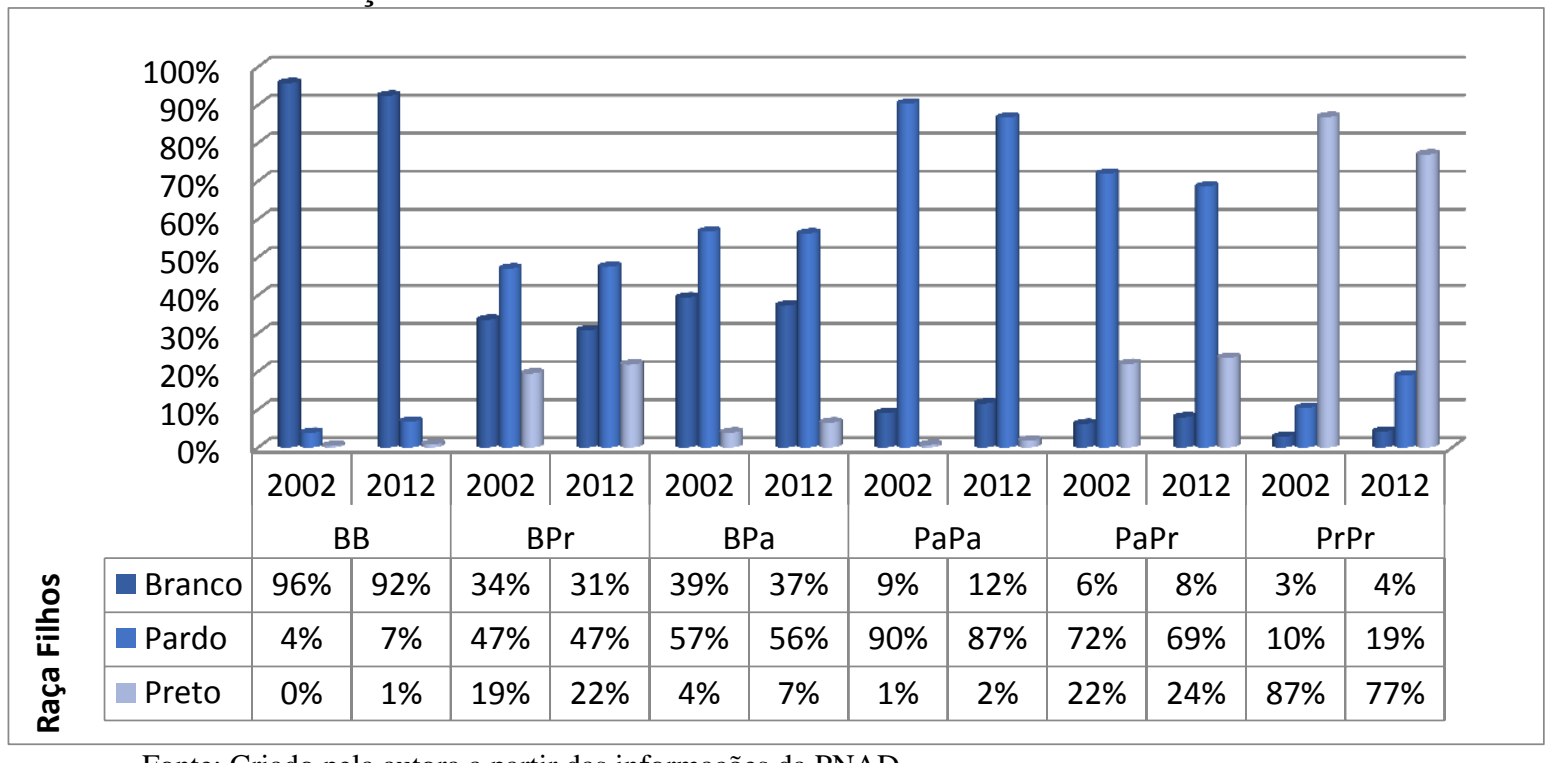

Fonte: Criado pela autora a partir das informações da PNAD.

Legenda: $\mathrm{B}$ - raça branca; $\mathrm{Pr}$ - raça preta; $\mathrm{Pa}$ - raça parda

As próximas seis tabelas mostram dados sobre atraso escolar ${ }^{15}$. Ao analisar os valores absolutos, é possível verificar que houve uma queda $20 \%$ nos anos de atraso escolar entre os anos de 2002 e 2012, apresentando, portanto uma melhoria no nível educacional dos jovens entre 14 e 17 anos. Os gráficos a seguir mostram os resultados separados por tipo de casamento e classificação racial dos filhos. A Tabela 9 mostra os anos de atraso escolar,

\footnotetext{
${ }^{15}$ Nos anexos apresentamos os valores totais por classificação racial e tipo de casamento.
} 
separados pela classificação racial dos filhos, para os casamentos entre brancos. Verifica-se que cerca de $60 \%$ dos valores concentram-se entre 2 anos de atraso e nenhum ano de atraso.

Dos filhos de casamento intra-racial classificados como branco, cerca de $40 \%$ apresentou 1 ano de atraso escolar em 2002 e 47\% em 2012. O ano de 2002 para filhos classificados como preto está em branco, pois neste período não houve filhos classificados como preto nos casais de casamento intra-racial branco.

Tabela 9 - Atraso escolar dos filhos de casamento intra-racial Branco de 14 a 17 anos

\begin{tabular}{|c|c|c|c|c|c|c|}
\hline $50 \%$ & & & & & & \\
\hline $40 \%$ & & & & & & \\
\hline $30 \%$ & & & & & & \\
\hline $20 \%$ & & & & & & \\
\hline $10 \%$ & & & & & & \\
\hline & 2002 & 2012 & 2002 & 2012 & 2002 & 2012 \\
\hline & & & & & & \\
\hline s/atraso & $8 \%$ & $15 \%$ & $5 \%$ & $10 \%$ & - & $8 \%$ \\
\hline$\square 1$ & $40 \%$ & $47 \%$ & $24 \%$ & $34 \%$ & - & $13 \%$ \\
\hline 2 & $22 \%$ & $18 \%$ & $21 \%$ & $23 \%$ & - & $35 \%$ \\
\hline$\square$ & $12 \%$ & $10 \%$ & $18 \%$ & $13 \%$ & - & $15 \%$ \\
\hline 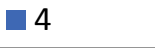 & $7 \%$ & $5 \%$ & $10 \%$ & $9 \%$ & - & $13 \%$ \\
\hline 5 & $4 \%$ & $3 \%$ & $7 \%$ & $5 \%$ & - & $10 \%$ \\
\hline 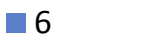 & $3 \%$ & $1 \%$ & $6 \%$ & $2 \%$ & - & $3 \%$ \\
\hline$\square 7$ & $1 \%$ & $1 \%$ & $3 \%$ & $2 \%$ & - & $3 \%$ \\
\hline 8 & $1 \%$ & $0 \%$ & $1 \%$ & $1 \%$ & - & $3 \%$ \\
\hline 9 & $1 \%$ & $0 \%$ & $2 \%$ & $0 \%$ & - & $0 \%$ \\
\hline 10 & $1 \%$ & $0 \%$ & $2 \%$ & $0 \%$ & - & $0 \%$ \\
\hline 11 & $0 \%$ & $0 \%$ & $1 \%$ & $0 \%$ & - & $0 \%$ \\
\hline
\end{tabular}

Fonte: Criado pela autora a partir das informações da PNAD.

Nota: Tamanho da Amostra $-2002=\mathrm{Ba}-1494, \mathrm{~Pa}-1128, \mathrm{Pr}-136 ; 2012=\mathrm{Ba}-1793, \mathrm{~Pa}-1249, \mathrm{Pr}-140$

A Tabela 10 apresenta os resultados para os filhos de casamento intra-racial pardo. É possível perceber que cerca de $30 \%$ do atraso escolar está concentrado em 1 ano de atraso, quando analisado os filhos classificados como brancos, assim como os filhos classificados como pardo. Apenas em 2002, o valor é inferior, representando cerca 14\% dos filhos com 1 ano de atraso escolar. Vale ressaltar que em 2012, $10 \%$ dos filhos classificados como branco alcançaram 6 anos de atraso escolar, bem como 5\% deles chegaram a 11 anos de atraso escolar. Avaliando este resultado de forma mais específica, os dados mostram que essas crianças com 11 anos de atraso escolar concentram-se nas regiões Norte e Nordeste, ou seja, $20 \%$ delas estão na região Norte e $40 \%$ na região Nordeste. 
Tabela 10 - Atraso escolar dos filhos de casamento intra-racial Pardo de 14 a 17 anos

\begin{tabular}{|c|c|c|c|c|c|c|c|}
\hline \multirow{3}{*}{\multicolumn{2}{|c|}{$\begin{array}{r}40 \% \\
30 \% \\
20 \% \\
10 \% \\
0 \%\end{array}$}} & H & & & & & he \\
\hline & & 2002 & 2012 & 2002 & 2012 & 2002 & 2012 \\
\hline & & \multicolumn{2}{|c|}{ Branco } & \multicolumn{2}{|c|}{ Pardo } & \multicolumn{2}{|c|}{ Preto } \\
\hline \multirow{12}{*}{ 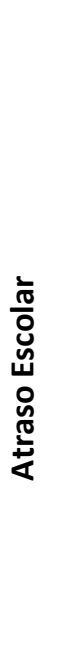 } & n/ atraso & $4 \%$ & $11 \%$ & $2 \%$ & $8 \%$ & $4 \%$ & $9 \%$ \\
\hline & $\square 1$ & $36 \%$ & $34 \%$ & $14 \%$ & $30 \%$ & $23 \%$ & $29 \%$ \\
\hline & $\square 2$ & $19 \%$ & $10 \%$ & $25 \%$ & $15 \%$ & $22 \%$ & $24 \%$ \\
\hline & - 3 & $14 \%$ & $13 \%$ & $16 \%$ & $13 \%$ & $13 \%$ & $11 \%$ \\
\hline & $\square 4$ & $19 \%$ & $5 \%$ & $10 \%$ & $18 \%$ & $9 \%$ & $11 \%$ \\
\hline & $\square$ & $6 \%$ & $8 \%$ & $10 \%$ & $5 \%$ & $10 \%$ & $10 \%$ \\
\hline & 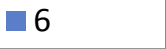 & $5 \%$ & $10 \%$ & $3 \%$ & $5 \%$ & $7 \%$ & $5 \%$ \\
\hline & 7 & $0 \%$ & $0 \%$ & $6 \%$ & $1 \%$ & $4 \%$ & $2 \%$ \\
\hline & 8 & $0 \%$ & $0 \%$ & $5 \%$ & $2 \%$ & $3 \%$ & $1 \%$ \\
\hline & 9 & $0 \%$ & $0 \%$ & $2 \%$ & $0 \%$ & $2 \%$ & $1 \%$ \\
\hline & 10 & $0 \%$ & $0 \%$ & $1 \%$ & $0 \%$ & $2 \%$ & $0 \%$ \\
\hline & 11 & $0 \%$ & $5 \%$ & $1 \%$ & $0 \%$ & $1 \%$ & $0 \%$ \\
\hline
\end{tabular}

Fonte: Criado pela autora a partir das informações da PNAD.

Nota: Tamanho da Amostra - $2002=\mathrm{Ba}-1508, \mathrm{~Pa}-1513, \mathrm{Pr}-1106 ; 2012=\mathrm{Ba}-1603, \mathrm{~Pa}-1645, \mathrm{Pr}-1242$

Tabela 11 - Atraso escolar dos filhos de casamento intra-racial Preto de 14 a 17 anos

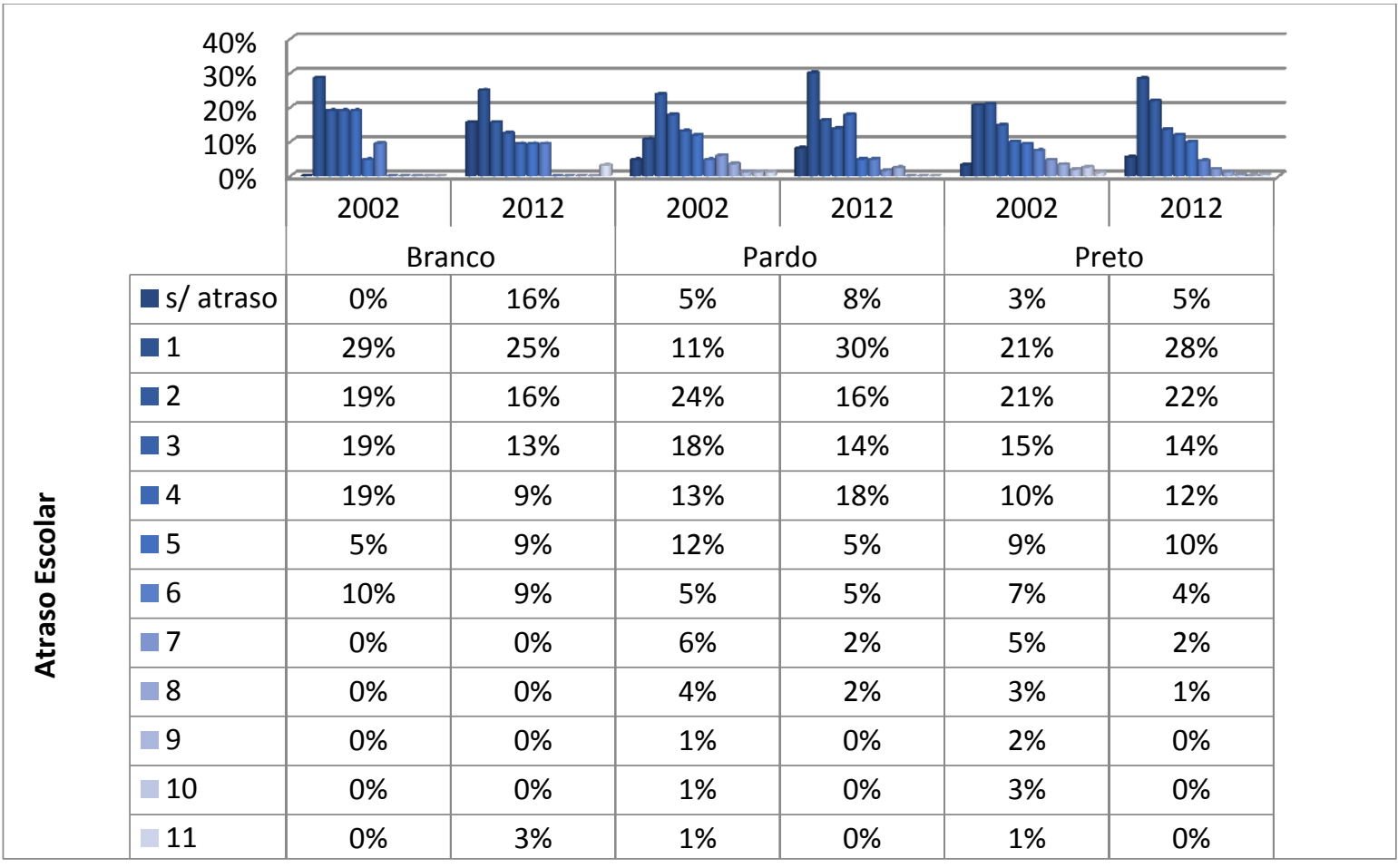

Fonte: Criado pela autora a partir das informações da PNAD.

Nota: Tamanho da Amostra $-2002=\mathrm{Ba}-1139, \mathrm{~Pa}-1122, \mathrm{Pr}-1401 ; 2012=\mathrm{Ba}-1188, \mathrm{~Pa}-1181, \mathrm{Pr}-1651$ 
A Tabela 11 mostra os resultados para os filhos de casamento intra-racial preto. $\mathrm{O}$ gráfico da tabela indica que os filhos de raça preta de casamento intra-racial preto são os que apresentam o menor percentual de crianças sem atraso escolar e o maior percentual de crianças com maior tempo de atraso escolar.

Os resultados para o casamento inter-racial são apresentados nas tabelas a seguir. Os filhos classificados como pardos nos casamentos inter-raciais são os que apresentam pior resultado, de acordo com a Tabela 12 . Cerca de $86 \%$ dos filhos de raça parda estão com atraso escolar entre 2 e 5 anos no ano de 2012. Enquanto que $60 \%$ dos filhos de raça preta e $43 \%$ dos filhos de raça branca estão com atraso escolar entre 2 e 5 anos no mesmo período.

Tabela 12 - Atraso escolar dos filhos de casamento inter-racial Branco-Pardo de 14 a 17 anos

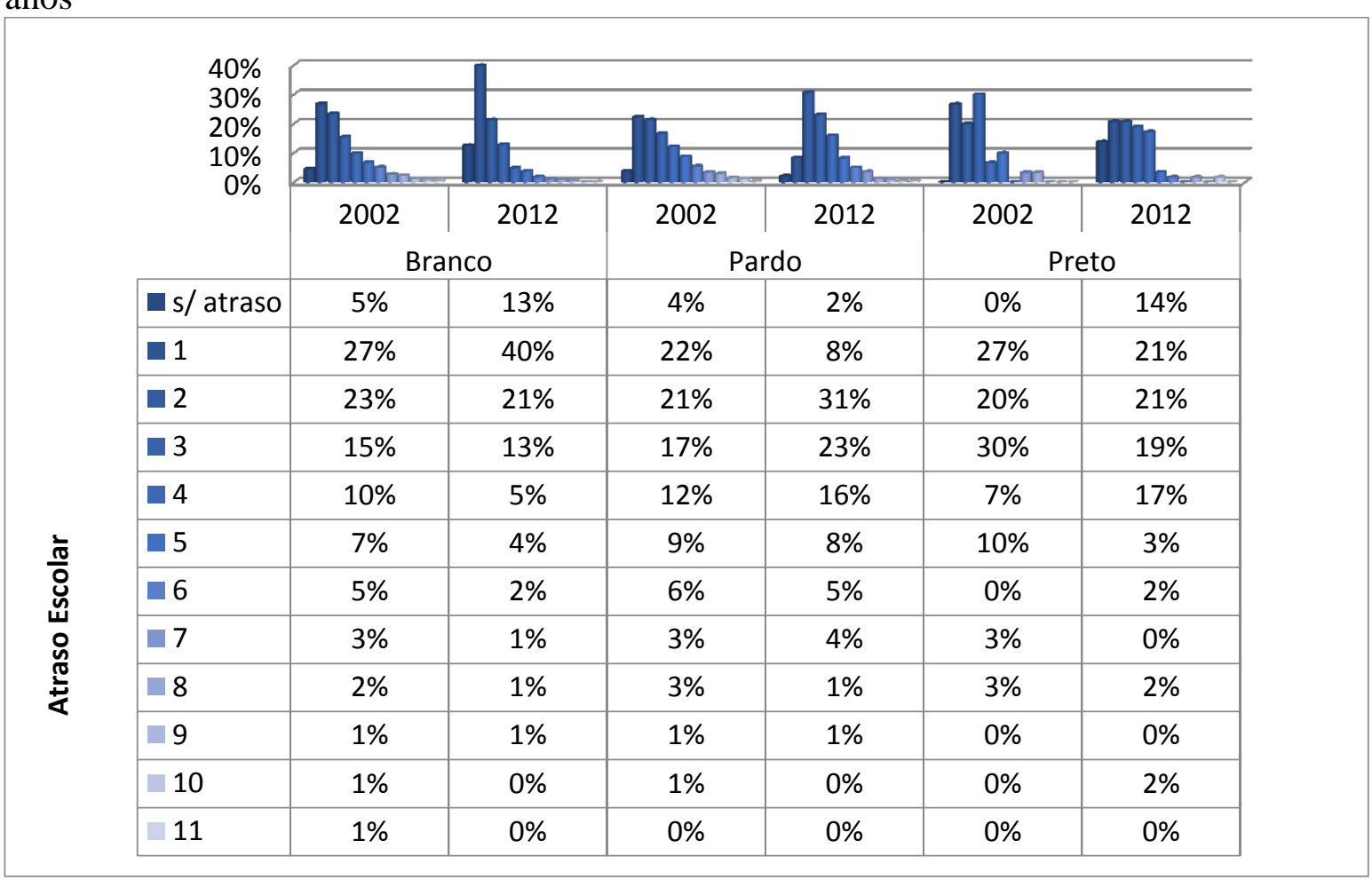

Fonte: Criado pela autora a partir das informações da PNAD.

Os resultados apresentados na Tabela 12, mostram que os filhos classificados como brancos apresentam menos anos de atraso escolar do que os demais, ao analisar o atraso escolar entre 2 e 5 anos. Este resultado reforça os encontrados no trabalho de Rangel (2007), que afirma que ao perceberem a existência de diferenças no retorno para investimentos em capital humano (de acordo com a cor da pele) as famílias tendem a investir mais em filhos com peles mais claras. 
A Tabela 13 e a Tabela 14 mostram os resultados para casamento inter-racial Branco-Preto e Pardo-Preto, respectivamente. Verifica-se que os filhos classificados como brancos, apresentam resultados semelhantes aos filhos classificados como pardos ou pretos. Os filhos de raça branca apresentam cerca de $76 \%$ de atraso escolar entre 1 e 4 anos em 2012, os filhos de raça preto $79 \%$ e parda $77 \%$ conforme Tabela 13. Já para filhos de casamento Preto-Pardo, daqueles que foram classificados como brancos, $80 \%$ tem atraso escolar entre 1 e 4 anos, $78 \%$ para pardos e $75 \%$ para os pretos.

Tabela 13 - Atraso escolar dos filhos de casamento inter-racial Branco-Preto de 14 a 17 anos

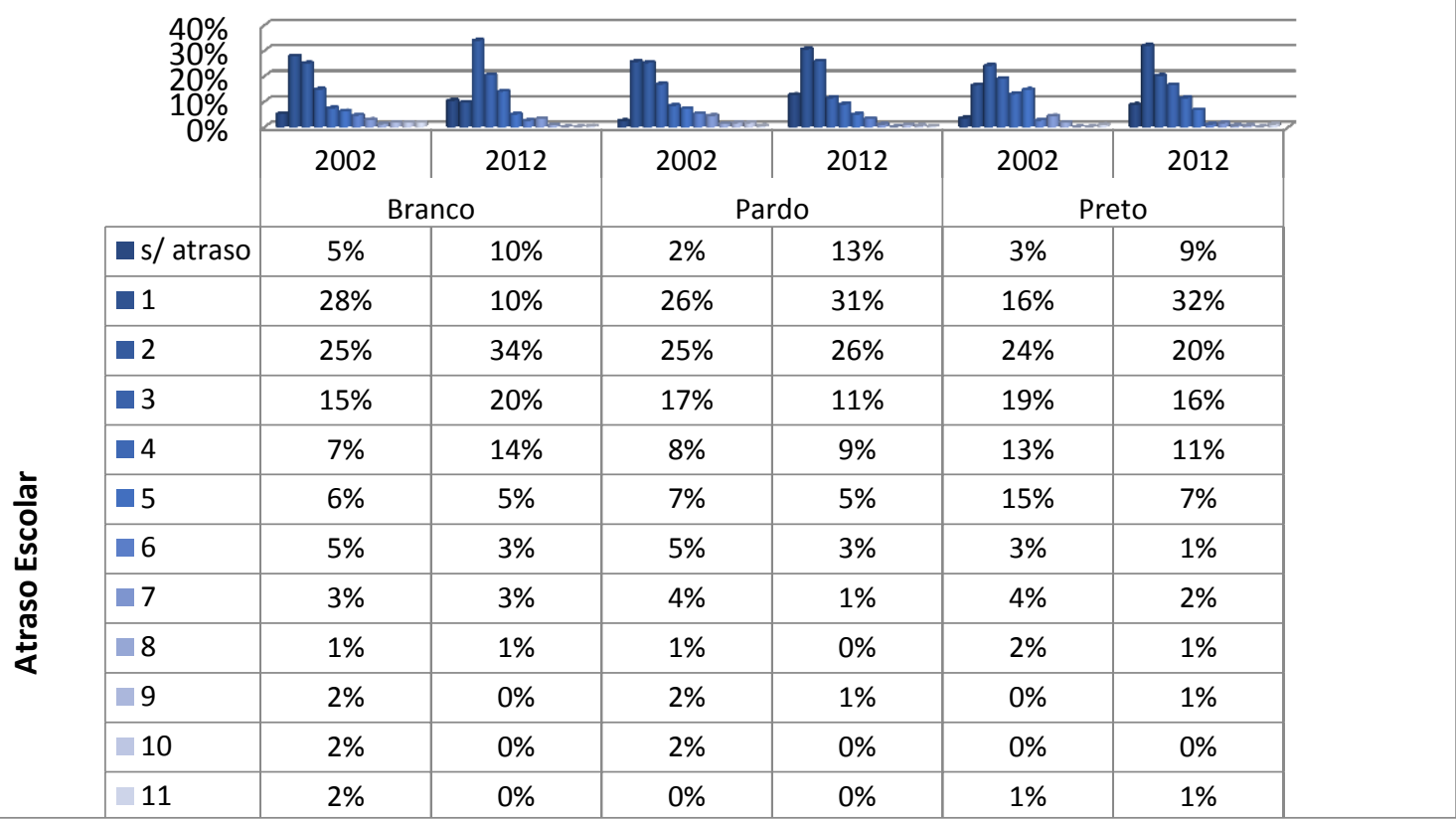

Fonte: Criado pela autora a partir das informações da PNAD.

Tabela 14 - Atraso escolar dos filhos de casamento inter-racial Pardo-Preto de 14 a 17 aos

\begin{tabular}{|c|c|c|c|c|c|c|c|}
\hline & \multirow{2}{*}{$\begin{array}{r}40 \% \\
30 \% \\
10 \% \\
0 \%\end{array}$} & \multirow{2}{*}{\multicolumn{2}{|c|}{$\begin{array}{c}2002 \underset{3}{\text { Branco }} \\
\text { Branc }\end{array}$}} & 2002 & 2012 & 2002 & 2012 \\
\hline \multirow{13}{*}{ 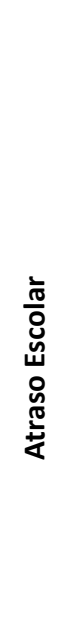 } & & & & \multicolumn{2}{|c|}{ Pardo } & \multicolumn{2}{|c|}{ Preto } \\
\hline & $\mathrm{s} /$ atraso & $9 \%$ & $7 \%$ & $1 \%$ & $9 \%$ & $3 \%$ & $8 \%$ \\
\hline & $\square 1$ & $15 \%$ & $27 \%$ & $14 \%$ & $27 \%$ & $17 \%$ & $28 \%$ \\
\hline & $\square 2$ & $13 \%$ & $32 \%$ & $21 \%$ & $23 \%$ & $18 \%$ & $23 \%$ \\
\hline & $\square 3$ & $19 \%$ & $11 \%$ & $18 \%$ & $17 \%$ & $17 \%$ & $12 \%$ \\
\hline & $\square 4$ & $13 \%$ & $10 \%$ & $14 \%$ & $11 \%$ & $17 \%$ & $12 \%$ \\
\hline & $\square$ & $15 \%$ & $6 \%$ & $12 \%$ & $5 \%$ & $8 \%$ & $7 \%$ \\
\hline & $\square 6$ & $13 \%$ & $2 \%$ & $8 \%$ & $4 \%$ & $9 \%$ & $4 \%$ \\
\hline & $\square$ & $2 \%$ & $1 \%$ & $5 \%$ & $2 \%$ & $5 \%$ & $2 \%$ \\
\hline & $\square$ & $0 \%$ & $1 \%$ & $3 \%$ & $1 \%$ & $2 \%$ & $1 \%$ \\
\hline & $\square 9$ & $2 \%$ & $1 \%$ & $2 \%$ & $1 \%$ & $2 \%$ & $1 \%$ \\
\hline & $\square 10$ & $0 \%$ & $2 \%$ & $1 \%$ & $0 \%$ & $2 \%$ & $1 \%$ \\
\hline & 11 & $0 \%$ & $0 \%$ & $1 \%$ & $0 \%$ & $0 \%$ & $1 \%$ \\
\hline
\end{tabular}

Fonte: Criado pela autora a partir das informações da PNAD. 
De acordo com Barros et al. (2001) existe uma associação importante entre o desempenho educacional dos filhos e o nível de escolaridade dos pais. Segundo os autores, quanto mais elevada à escolaridade dos pais, menores tendem a ser as dificuldades e os custos de aprendizagem dos filhos. Portanto, o nível de escolaridade dos pais é crucial para desempenho dos filhos, e por isso é importante avaliá-la. As tabelas a seguir irão apresentar o nível educacional dos pais, em conjunto, para cada tipo de casamento e classificação racial dos filhos.

Na seção anterior, apresentamos o nível educacional dos pais da seguinte forma: de zero a três anos de estudo - ensino primário incompleto; de quatro a nove anos de estudo ensino fundamental incompleto; de dez a doze anos de estudo - ensino médio incompleto; e por fim, de treze ou mais anos de estudo - ensino superior incompleto. A diferença nos resultados a seguir é que faremos união entre o ensino primário e o ensino fundamental, tornando-os uma única categoria de nível de escolaridade. Portanto, haverá três categorias e não quatro ${ }^{16}$ : de zero a nove anos de estudo - ensino fundamental incompleto; de dez a doze anos de estudo - ensino médio incompleto; e por fim, de treze ou mais anos de estudo ensino superior incompleto.

Nas Tabela 15 a 17, apresentaremos como o nível de escolaridade dos pais está relacionado com a forma como eles classificam a raça de seus filhos. Vimos na Tabela 8 que mais de $90 \%$ dos casais de casamento branco-branco classificam seus filhos como branco no ano de $2012,7 \%$ dos filhos são classificados como pardos e apenas $1 \%$ como pretos. Na Tabela 15, se analisarmos o nível educacional desses pais, verifica-se que cerca de $81 \%$ dos cônjuges de casamento branco-branco, em que pelo menos um deles tem o ensino fundamental, classifica seu filho como pardo no ano de 2012, enquanto que $76 \%$ classificam o filho de raça preta e $65 \%$ deles classificam seus filhos de raça branca. Se verificarmos os níveis médio e superior (incompleto), 35\% dos pais de casamento branco-branco, com nível médio ou superior, classificam os filhos como brancos, $24 \%$ como pretos, sendo que desses $24 \%$, apenas $6 \%$ corresponde a nível superior, e por fim $19 \%$ classificam os filhos de raça parda.

Já para o casamento intra-racial pardo, a Tabela 8 mostrou que quase $10 \%$ dos filhos foram classificados como branco, quase $90 \%$ dos filhos foram classificados como pardos e apenas $1 \%$ como preto. Se analisarmos o ano de 2012 na Tabela 16, 80\% dos pais de

\footnotetext{
${ }^{16}$ Para os resultados das regressões que será apresentado na próxima seção, permaneceremos com quatro níveis educacionais.
} 
casamento pardo-pardo que classificou seus filhos como branco, $82 \%$ classificou seu filho como pardo e $72 \%$ classificou seus filhos de raça preta, possuem nível fundamental.

Tabela 15 - Nível educacional dos pais de casamento intra-racial branco-branco de filhos de 14 a 17 anos

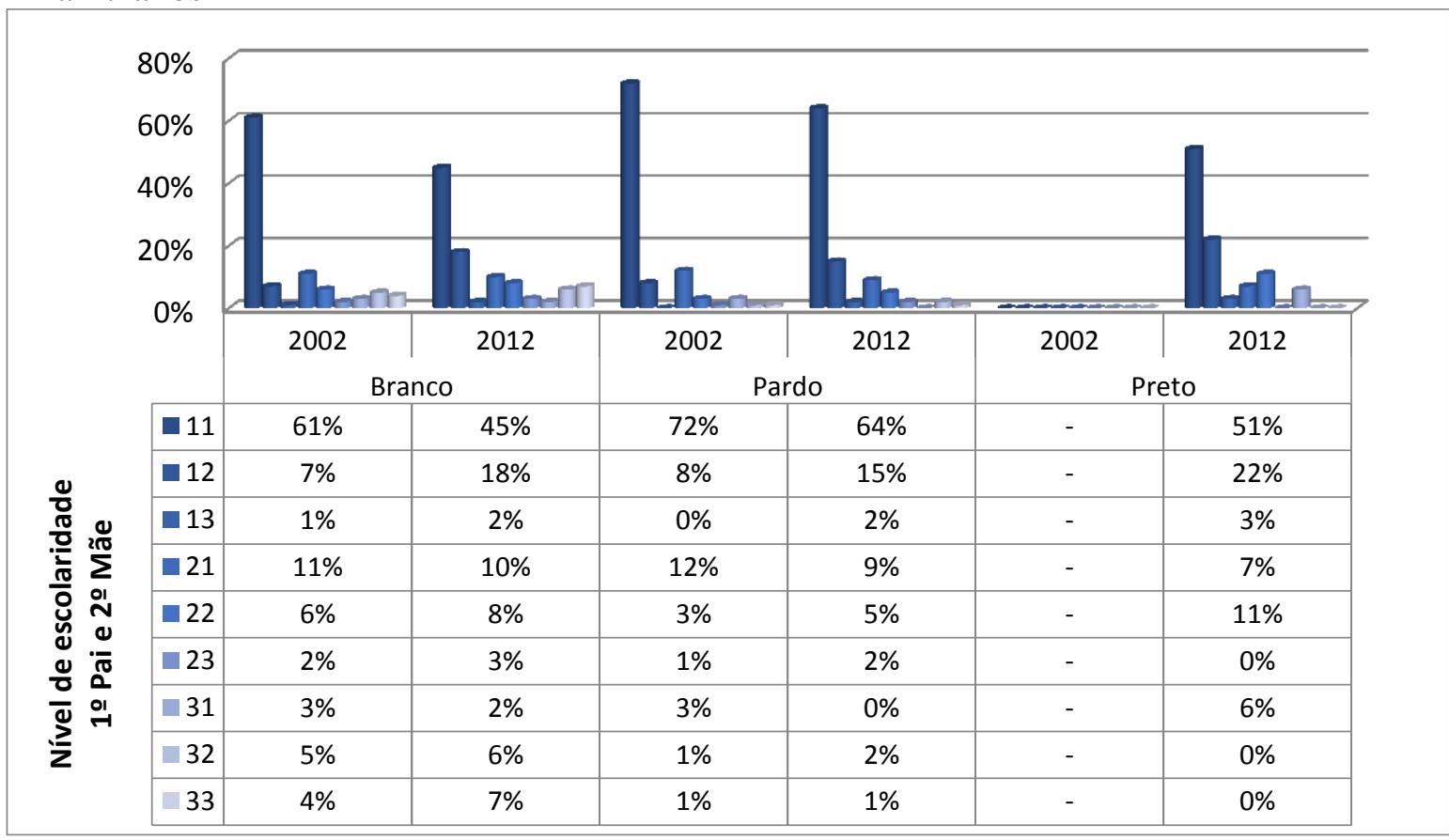

Fonte: Criado pela autora a partir das informações da PNAD.

Legenda - 1 Nível fundamental; 2 - Nível médio; 3 - Nível Superior

Tabela 16 - Nível educacional dos pais de casamento intra-racial pardo-pardo de filhos de 14 a 17 anos

\begin{tabular}{|c|c|c|c|c|c|c|c|}
\hline & $0 \%$ & & & & & & \\
\hline & $0 \%$ & & & & & & \\
\hline & $0 \%$ & & & & & & \\
\hline & $0 \%$ & & & & & & \\
\hline \multirow{11}{*}{ 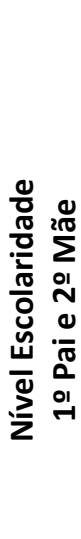 } & \multirow{2}{*}{$0 \%$} & \multirow[t]{2}{*}{2002} & \multirow[t]{2}{*}{2012} & 2002 & \multirow[t]{2}{*}{2012} & 2002 & \multirow[t]{2}{*}{2012} \\
\hline & & & & Pardo & & Preto & \\
\hline & - 11 & $75 \%$ & $63 \%$ & $78 \%$ & $69 \%$ & $77 \%$ & $57 \%$ \\
\hline & -12 & $6 \%$ & $16 \%$ & $5 \%$ & $13 \%$ & $2 \%$ & $14 \%$ \\
\hline & 13 & $1 \%$ & $1 \%$ & $0 \%$ & $0 \%$ & $0 \%$ & $1 \%$ \\
\hline & $=21$ & $10 \%$ & $8 \%$ & $11 \%$ & $8 \%$ & $11 \%$ & $17 \%$ \\
\hline & -22 & $7 \%$ & $5 \%$ & $2 \%$ & $4 \%$ & $2 \%$ & $5 \%$ \\
\hline & 23 & $0 \%$ & $1 \%$ & $0 \%$ & $1 \%$ & $0 \%$ & $0 \%$ \\
\hline & -31 & $1 \%$ & $1 \%$ & $2 \%$ & $2 \%$ & $4 \%$ & $3 \%$ \\
\hline & -32 & $0 \%$ & $3 \%$ & $2 \%$ & $2 \%$ & $4 \%$ & $1 \%$ \\
\hline & 33 & $1 \%$ & $2 \%$ & $0 \%$ & $1 \%$ & $0 \%$ & $2 \%$ \\
\hline
\end{tabular}

Fonte: Criado pela autora a partir das informações da PNAD.

Legenda - 1 Nível fundamental; 2 - Nível médio; 3 - Nível Superior 
Este mesmo cenário também pode ser visto na Tabela 17. Dos $4 \%$ de casais de casamento preto-preto que classificaram seus filhos de raça branca em 2012, em 77\% deles, pelo menos um tem ensino fundamental e $23 \%$ deles, pelo menos um, ou tem o ensino médio ou o superior. Já dos 19\% que classificaram seus filhos de raça parda, $87 \%$ tem pelo menos o ensino fundamental, $10 \%$ pelo menos o médio e apenas $3 \%$, pelo menos um dos cônjuges tem o ensino superior. Por fim, daqueles $77 \%$ que classificaram o filho de raça preta, conforme Tabela $8,84 \%$ deles, pelo menos um tem nível fundamental, $12 \%$ o nível médio e apenas $4 \%$ o nível superior. Logo, verifica-se que pais com maior nível educacional classificam seus filhos de forma mais semelhante ás suas raças do que os pais com menor nível educacional. Segundo Marteleto (2012), este caso é conhecido como "escurecimento", ou seja, pais com nível maior de escolaridade tendem a classificar a raça de seus filhos mais próximos de suas raças ${ }^{17}$.

Tabela 17 - Nível educacional dos pais de casamento intra-racial preto-preto de filhos de 14 a 17 anos

\begin{tabular}{|c|c|c|c|c|c|c|c|}
\hline \multicolumn{2}{|c|}{$100 \%$} & & & & & & \\
\hline \multicolumn{2}{|c|}{$80 \%$} & & & & & & \\
\hline \multicolumn{2}{|c|}{$60 \%$} & & & & & & \\
\hline \multicolumn{2}{|c|}{$40 \%$} & & & & & & \\
\hline \multicolumn{2}{|c|}{$20 \%$} & & & & & & \\
\hline \multirow{2}{*}{\multicolumn{2}{|c|}{$0 \%$}} & 2002 & 2012 & 2002 & 2012 & 2002 & 2012 \\
\hline & & & & & & & \\
\hline \multirow{9}{*}{ 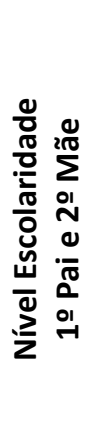 } & $\square 11$ & $81 \%$ & $58 \%$ & $81 \%$ & $75 \%$ & $76 \%$ & $69 \%$ \\
\hline & $\square 12$ & $0 \%$ & $16 \%$ & $10 \%$ & $9 \%$ & $4 \%$ & $15 \%$ \\
\hline & $\square 13$ & $0 \%$ & $3 \%$ & $0 \%$ & $3 \%$ & $2 \%$ & $0 \%$ \\
\hline & $\square 21$ & $5 \%$ & $13 \%$ & $10 \%$ & $7 \%$ & $10 \%$ & $6 \%$ \\
\hline & $\square 22$ & $0 \%$ & $7 \%$ & $0 \%$ & $3 \%$ & $5 \%$ & $6 \%$ \\
\hline & 23 & $0 \%$ & $0 \%$ & $0 \%$ & $1 \%$ & $1 \%$ & $0 \%$ \\
\hline & $\square 31$ & $0 \%$ & $3 \%$ & $0 \%$ & $1 \%$ & $0 \%$ & $1 \%$ \\
\hline & $\quad 32$ & $14 \%$ & $0 \%$ & $0 \%$ & $2 \%$ & $1 \%$ & $2 \%$ \\
\hline & 33 & $0 \%$ & $0 \%$ & $0 \%$ & $0 \%$ & $1 \%$ & $1 \%$ \\
\hline
\end{tabular}

Fonte: Criado pela autora a partir das informações da PNAD.

Legenda - 1 Nível fundamental; 2 - Nível médio; 3 - Nível Superior

\footnotetext{
${ }^{17}$ As tabelas com os resultados para casamentos inter-raciais, colocadas no Anexo deste trabalho, apresentam resultados semelhantes.
} 


\subsection{Descrição dos dados dos filhos - 18 a 25 anos}

Os dados a seguir dizem respeito aos filhos de 18 a 25 anos. A Tabela 18 ilustra a classificação racial dos filhos por tipo de casamento. Vale destacar dois pontos importantes: primeiro cerca de $90 \%$ dos filhos de casamento branco-branco são classificados como brancos. Já no casamento entre branco e pardo, e branco e preto, por exemplo, cerca de $30 \%$ dos filhos são classificados como branco, bem como cerca de $50 \%$ são classificados como pardos. Outro ponto relevante é a classificação de $4 \%$ dos filhos de casais de raça preta como branco em 2012.

Tabela 18 - Classificação racial dos filhos - 18 a 25 anos

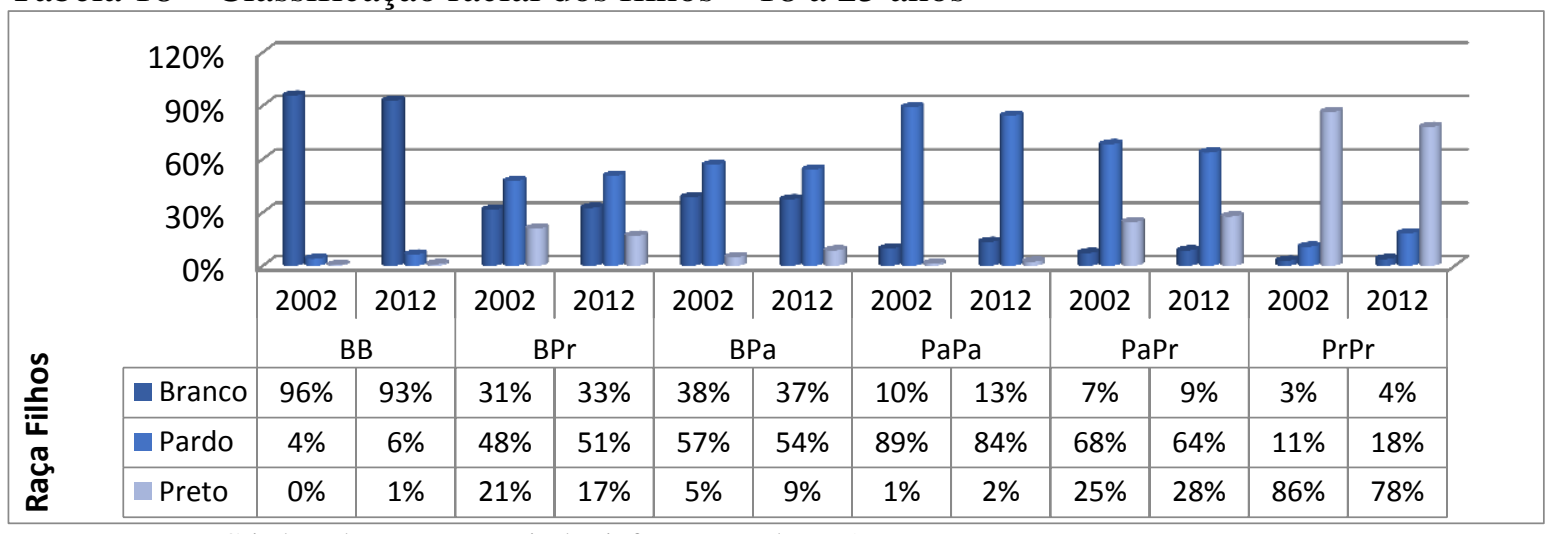

Fonte: Criado pela autora a partir das informações da PNAD.

Legenda: $\mathrm{B}$ - raça branca; $\mathrm{Pr}$ - raça preta; $\mathrm{Pa}$ - raça parda

Os resultados que serão apresentados a seguir, mostram dados sobre atraso escolar dos jovens entre 18 e 25 anos. Ao analisar os valores absolutos, verifica-se que houve uma queda $39 \%$ nos anos de atraso escolar entre os anos de 2002 e 2012, apresentando, portanto uma melhoria no nível educacional desses jovens.

Os próximos seis gráficos, sobre atraso escolar ${ }^{18}$, irão exibir os resultados de jovens entre 18 e $25 \operatorname{anos}^{19}$, separados por tipo de casamento e classificação racial dos filhos. A Tabela 19 mostra os anos de atraso escolar, separado pela classificação racial dos filhos, para os casamentos entre brancos. Verifica-se que cerca de $60 \%$ dos valores concentram-se entre 3 e 5 anos de atraso. O ano de 2002 não apresenta nenhum resultado, pois neste ano, não houve filho de casamento intra-racial branco-branco classificado de raça preta.

\footnotetext{
${ }^{18}$ Nos anexos apresentamos os valores totais por classificação racial e tipo de casamento.

${ }^{19}$ Neste caso, consideramos apenas os filhos que moram com os pais, que estejam estudando ou não.
} 
Tabela 19 - Atraso escolar dos filhos de casamento intra-racial Branco-Branco de 18 a 25 anos

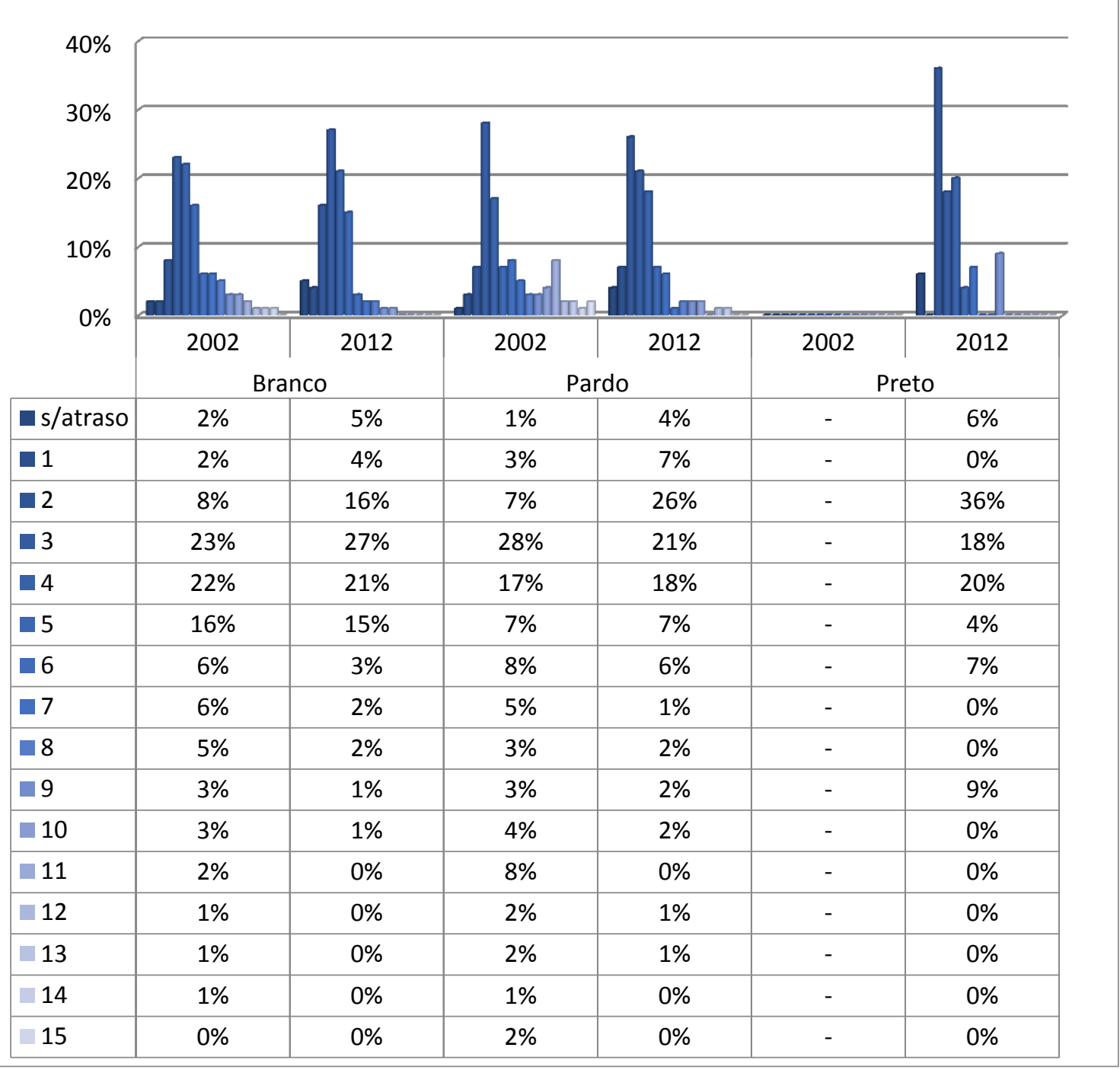

Fonte: Criado pela autora a partir das informações da PNAD.

Nota: Tamanho da Amostra - 2002 = Ba - 1231, Pa - 1182, Pr - 123; $2012=\mathrm{Ba}-1424, \mathrm{~Pa}-1156, \mathrm{Pr}-126$

A Tabela 20 ilustra os resultados do casamento intra-racial pardo-pardo. Verifica-se na tabela que apenas $1 \%$ dos filhos pardos e pretos não estão com os estudos atrasados no ano de 2012. Outro ponto relevante é o percentual de jovens com 4 anos de atraso. Em 2012, $23 \%$ dos filhos classificados como brancos, $21 \%$ dos pardos e $19 \%$ dos pretos estavam em atraso escolar. Além disso, 13\% dos jovens de raça preta, em 2012, estavam com 10 anos de atraso escolar ${ }^{20}$.

${ }^{20}$ Os resultados para anos de estudo desses jovens encontram-se nos Anexos. A Tabela A14 mostra que cerca de $47 \%$ dos jovens tem entre 1 e 8 anos de estudo. E apenas 10\% tem mais de 12 anos de estudo. Estes resultados nos permite inferir que esses jovens não estão mais estudando. 
Tabela 20 - Atraso escolar dos filhos de casamento intra-racial Pardo-Pardo de 18 a 25 anos

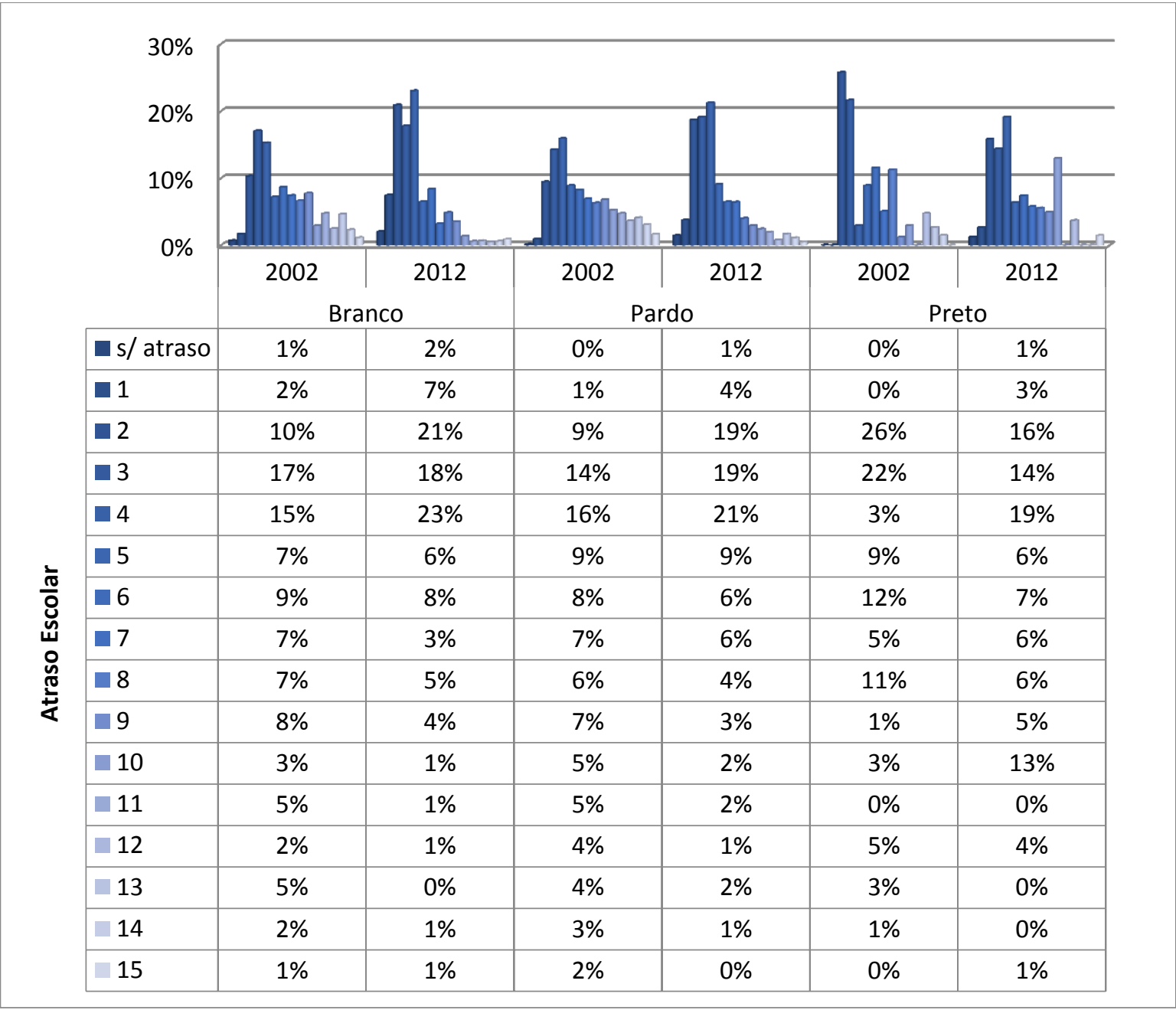

Fonte: Criado pela autora a partir das informações da PNAD.

Nota: Tamanho da Amostra $-2002=\mathrm{Ba}-1277, \mathrm{~Pa}-1223, \mathrm{Pr}-1103 ; 2012=\mathrm{Ba}-1302, \mathrm{~Pa}-1294, \mathrm{Pr}-1109$

$\mathrm{O}$ atraso escolar dos filhos de casamento intra-racial preto-preto pode ser visto na Tabela 21. É possível notar que cerca de $70 \%$ e $80 \%$ do atraso escolar está concentrado entre 2 e 6 anos de atraso. Se compararmos os desempenho dos jovens no ano de 2012, por exemplo, os filhos classificados como pretos apresentam $22 \%$ para 3 anos de atraso escolar, enquanto que o filho classificado como branco apresenta $28 \%$ para o mesmo tempo de atraso. Entretanto, enquanto os valores para os demais anos de atraso estão reduzindo para os filhos brancos, os valores permanecem estáveis até o $5^{\circ}$ ano de atraso, para os filhos classificados como preto. Diante disso, em um cenário geral, os filhos brancos estão em melhor situação quanto a escolaridade que os filhos pretos, do casamento intra-racial pretopreto. 
Tabela 21 - Atraso escolar dos filhos de casamento intra-racial Preto-Preto de 18 a 25 anos

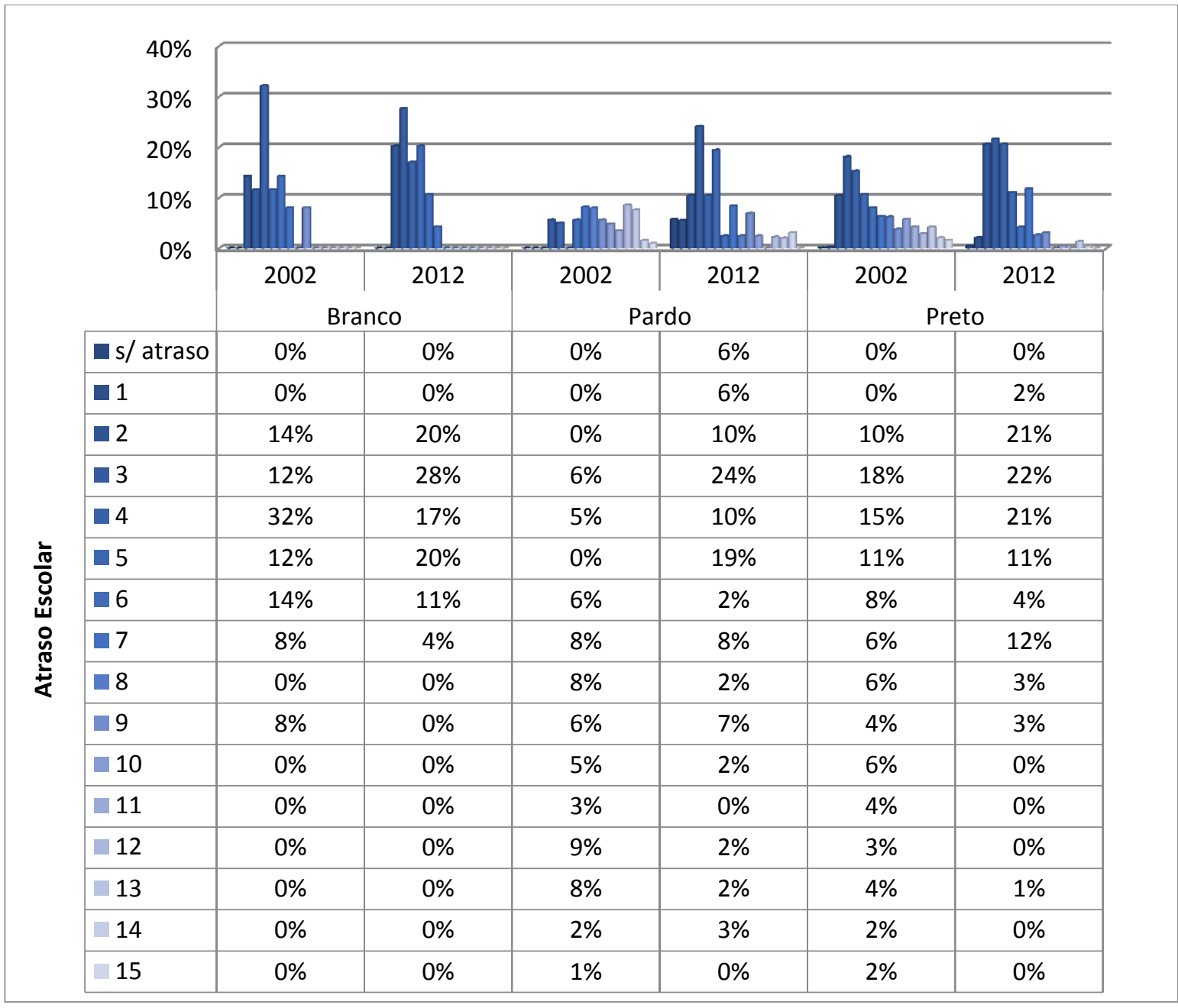

Fonte: Criado pela autora a partir das informações da PNAD.

Nota: Tamanho da Amostra $-2002=\mathrm{Ba}-151, \mathrm{~Pa}-151, \mathrm{Pr}-1201 ; 2012=\mathrm{Ba}-169, \mathrm{~Pa}-155, \mathrm{Pr}-1254$

As próximas 3 tabelas mostram os resultados para casamento inter-racial. Percebe-se pelos gráficos que os filhos brancos do casamento inter-racial branco-pardo tem menor percentual de atraso escolar entre os três primeiros anos, ao compará-lo com o filho branco do casamento inter-racial branco-preto. A mesma comparação pode ser feita com os demais.

Se comparar os filhos por tipo de casamento, verifica-se na Tabela 22 que o maior grau de atraso está em quatro anos. Isto é, 35\% dos filhos classificados como preto em 2012 tem 4 anos de atraso escolar, enquanto que $18 \%$ dos filhos pardos tem 4 anos de atraso. Se analisarmos o percentual de jovens sem atraso escolar, verifica-se $3 \%$ dos brancos, $4 \%$ dos pretos e $2 \%$ dos pardos não estão em atraso no ano de 2012.

Já na Tabela 23, se verificarmos os valores sem atraso escolar, percebe-se que não há nenhum filho classificado como preto sem atraso, ou seja, dentro dos jovens avaliados neste estudo, eles estão com pelo menos um ano de atraso escolar. 
Tabela 22 - Atraso escolar dos filhos de casamento inter-racial BrancoPardo de 18 a 25 anos

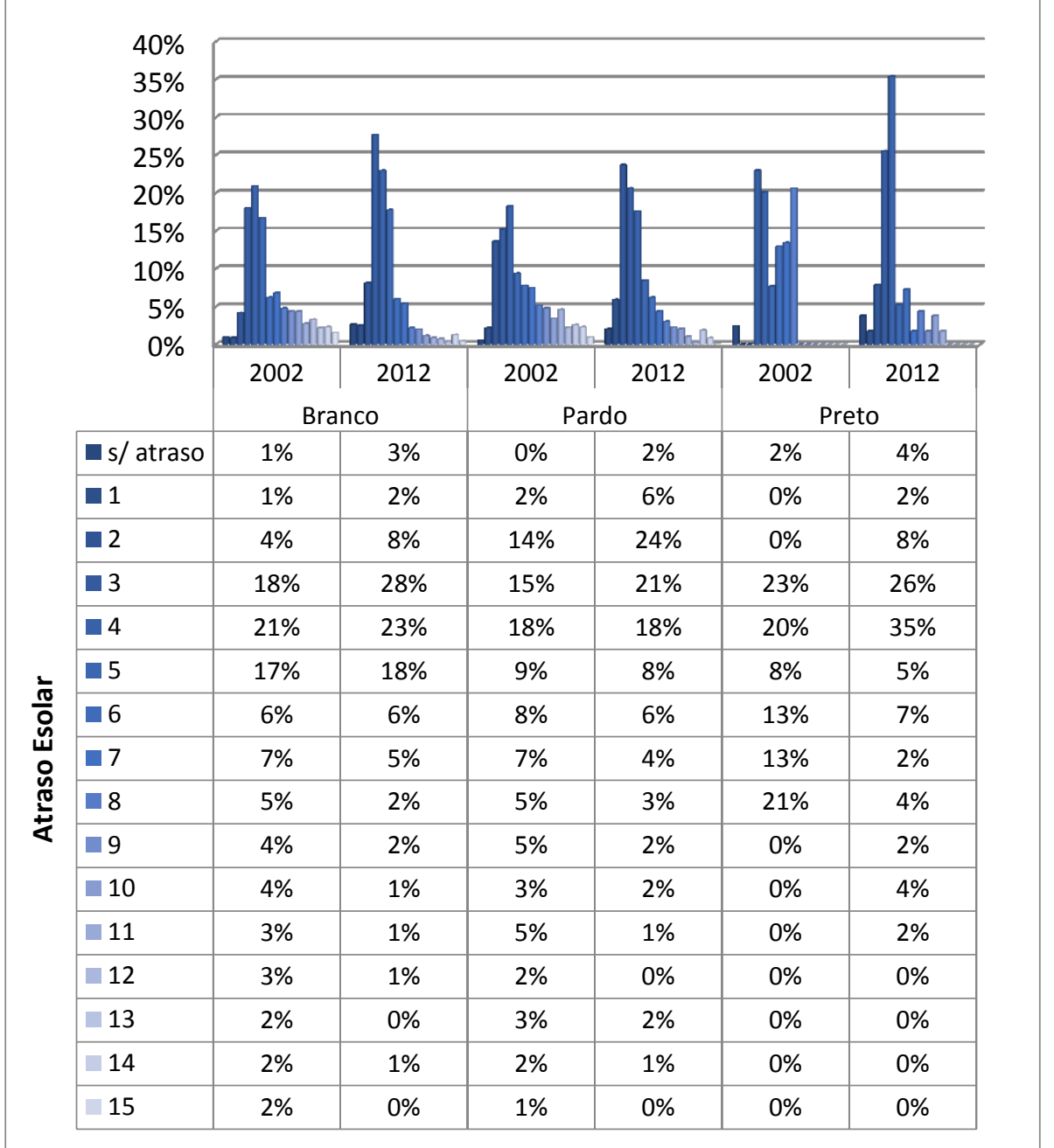

Fonte: Criado pela autora a partir das informações da PNAD.

Nota: Tamanho da Amostra $-2002=\mathrm{Ba}-1131, \mathrm{~Pa}-1114, \mathrm{Pr}-169 ; 2012=\mathrm{Ba}-1283, \mathrm{~Pa}-$ 1126, $\operatorname{Pr}-175$
Tabela 23 - Atraso escolar dos filhos de casamento inter-racial BrancoPreto de 18 a 25 anos

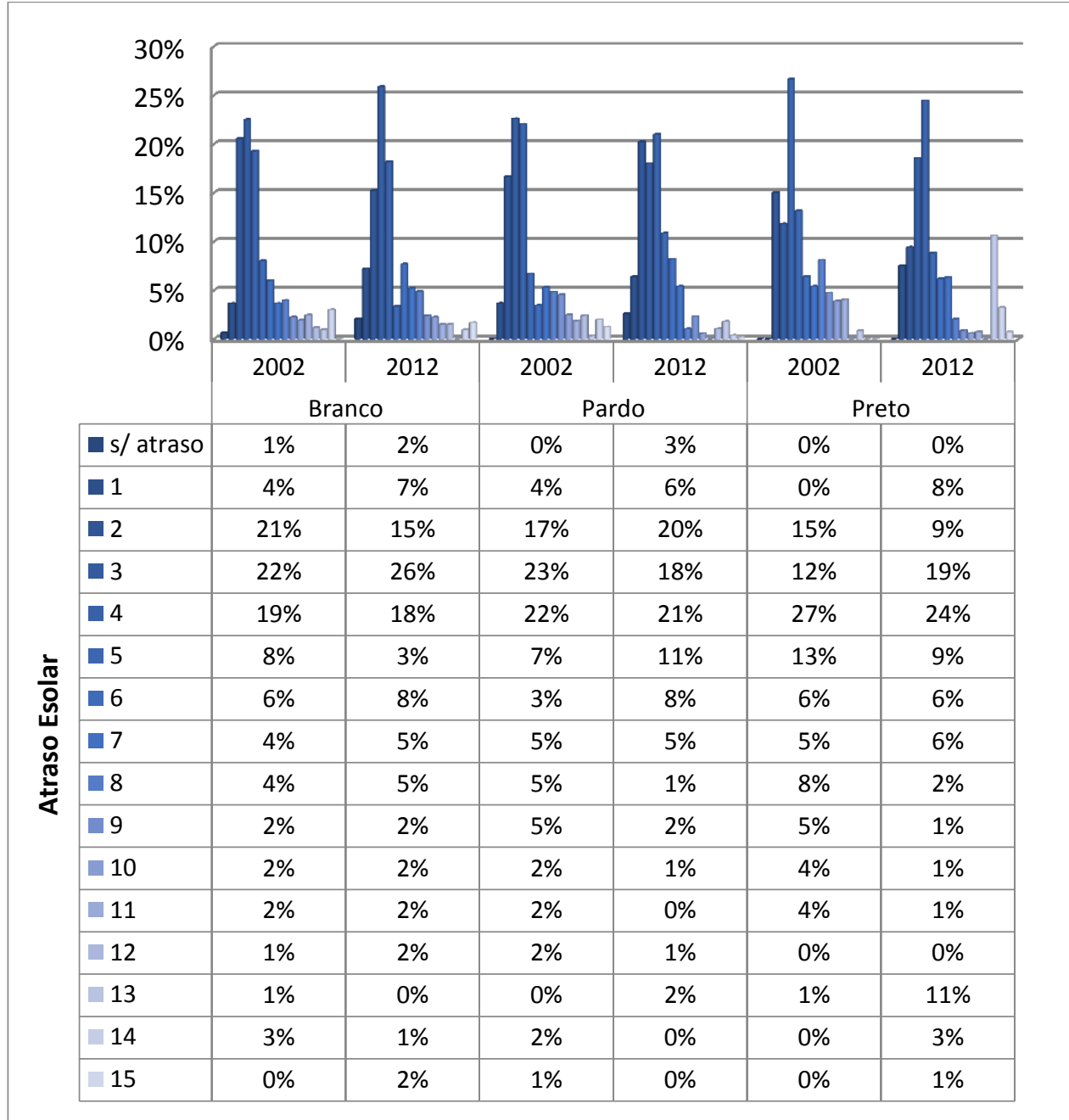

Fonte: Criado pela autora a partir das informações da PNAD.

Nota: Tamanho da Amostra $-2002=\mathrm{Ba}-193, \mathrm{~Pa}-1145, \mathrm{Pr}-163 ; 2012=\mathrm{Ba}-1124, \mathrm{~Pa}-$ 1211, $\operatorname{Pr}-172$ 
$\mathrm{O}$ atraso escolar dos filhos de casamento inter-racial preto-pardo pode ser visto na Tabela 24. É possível notar que 60\% do atraso escolar está concentrado entre 2 e 4 anos de atraso. Se compararmos o desempenho dos jovens no ano de 2012, por exemplo, os filhos classificados como pretos apresentam $24 \%$ para 3 anos de atraso escolar, enquanto que o filho classificado como branco apresenta $31 \%$ para o mesmo tempo de atraso. A partir do $4^{\circ}$ ano de atraso, os percentuais começam a reduzir, e neste caso, os filhos brancos apresentam menor percentual de atraso que os filhos pretos.

Tabela 24 - Atraso escolar dos filhos de casamento inter-racial Preto-Pardo de 18 a 25 anos

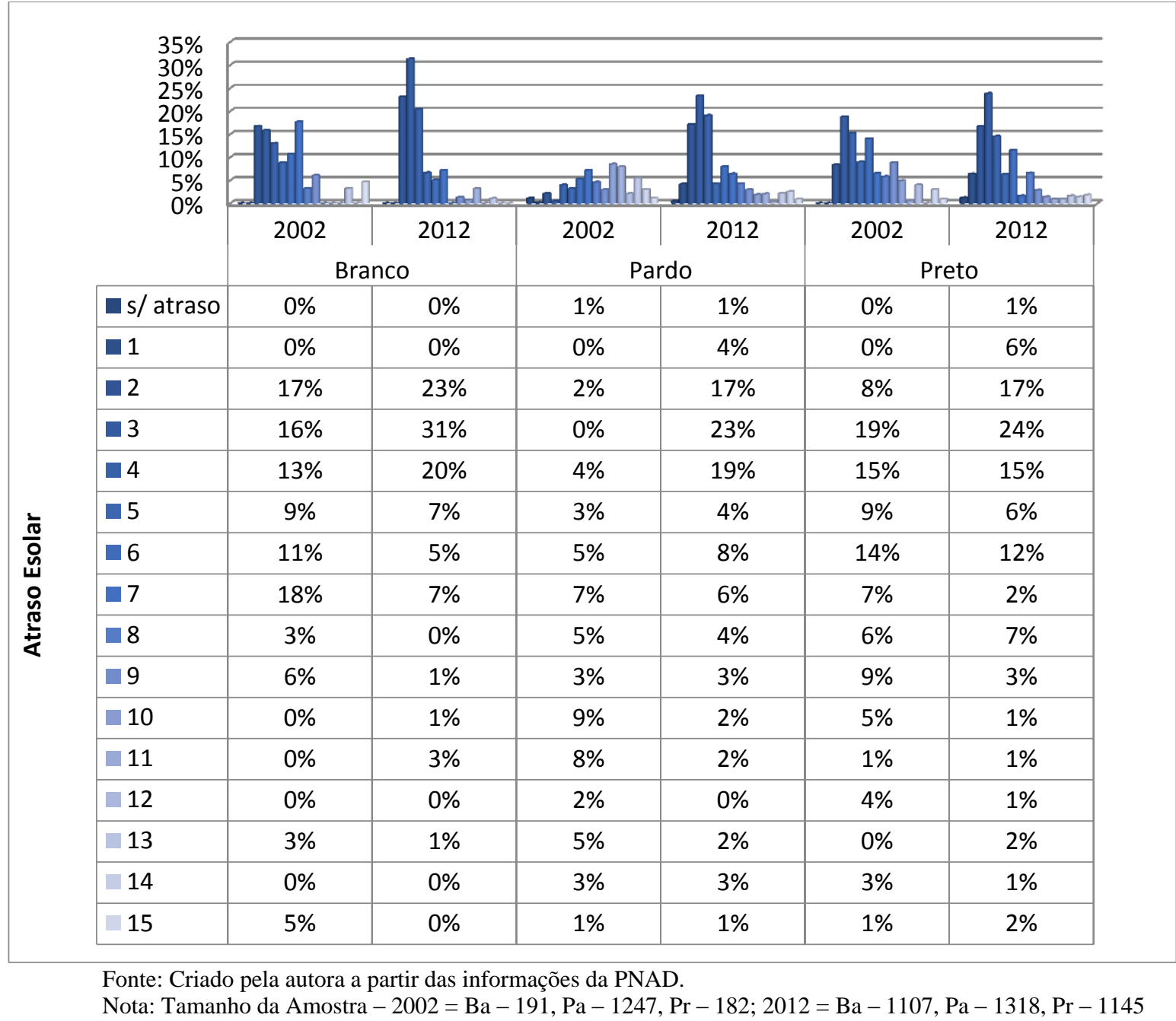

A partir dos gráficos apresentados para jovens entre 18 e 25 anos, sobre atraso escolar, verifica-se que filhos brancos apresentam menos anos de atraso escolar do que os demais. Rangel (2007), já havia comentando esse resultado em seu trabalho. O autor afirma que as famílias tendem a investir mais em filhos com peles mais claras, ao perceberem maior possibilidade de retorno. $\mathrm{O}$ autor também destaca que os determinantes das diferenças salariais entre brancos e negros por exemplo, surgem durante a infância de uma criança, 
devido à decisão de investimento que os pais tomam em relação à educação de seus filhos. Os resultados apresentados, tanto para jovens entre 14 e 17 como para jovens entre 18 e 25 anos ilustram essa diferença entre filhos de raça branca e preta. Filhos de raça branca, em que pelo menos um dos pais é de raça branca apresentam resultado educacional melhor que filhos de raça preta.

Becker (1974) afirma que o conhecimento adquirido entre os membros das famílias podem ser transferidas, apenas entre membros da mesma família. Barros et al. (2001) alega a que há uma associação importante entre o desempenho educacional dos filhos e o nível de escolaridade dos pais. Diante desses argumentos verifica-se a importância de avaliar o nível de escolaridade dos pais. As informações a seguir mostram o nível de escolaridade dos pais em conjunto (pai e mãe), de acordo com a classificação racial do filho e por tipo de casamento, isto é, intra-racial ou inter-racial.

Assim como na seção anterior, avaliarmos apenas três categorias de escolaridade dos pais: fundamental, médio e superior. Nas tabelas 25 a 27, apresentaremos como o nível de escolaridade dos pais está relacionado com a forma como eles classificam a raça de seus filhos. Na Tabela 18 verificamos que mais de $90 \%$ dos casais de casamento inter-racial branco-branco classificam seus filhos como branco, $6 \%$ dos filhos são classificados como pardos e apenas $1 \%$ como preto, no ano de 2012. Na Tabela 25 verifica-se cerca de $61 \%$ dos cônjuges de casamento branco-branco que classificaram seus filhos de raça branca, possuem o nível fundamental (pelo menos um dos cônjuges), 74\% deles classificaram seus filhos de raça parda e $72 \%$ de raça preta. Se verificarmos o nível superior (em que pelo menos um deles possui ensino superior), $17 \%$ dos casais branco-branco classificam seus filhos como brancos, $7 \%$ como pardo e apenas $4 \%$ como preto.

No casamento intra-racial pardo, a Tabela 18 mostrou que em 2012 13\% dos filhos foram classificados como branco, $84 \%$ dos como pardos e apenas $2 \%$ como preto. Ao verificar o nível de escolaridade dos pais e a forma como eles classificam seus filhos na Tabela 26, nota-se que $73 \%$ dos pais de casamento pardo-pardo, em que pelo menos um deles tem o ensino fundamental classificaram seus filhos como branco, $80 \%$ classificou seu filho como pardo e $84 \%$ classificaram seus filhos de raça preta. Se fizermos a mesma análise para os pais com níveis médio e superior (incompleto), $27 \%$ dos pais de casamento classificam os filhos como brancos, $20 \%$ como pardos, e por fim $16 \%$ classificam os filhos de raça preta. 
Tabela 25 - Nível educacional de pais de casamento intra-racial Branco-Branco de filhos de 18 a 25 anos

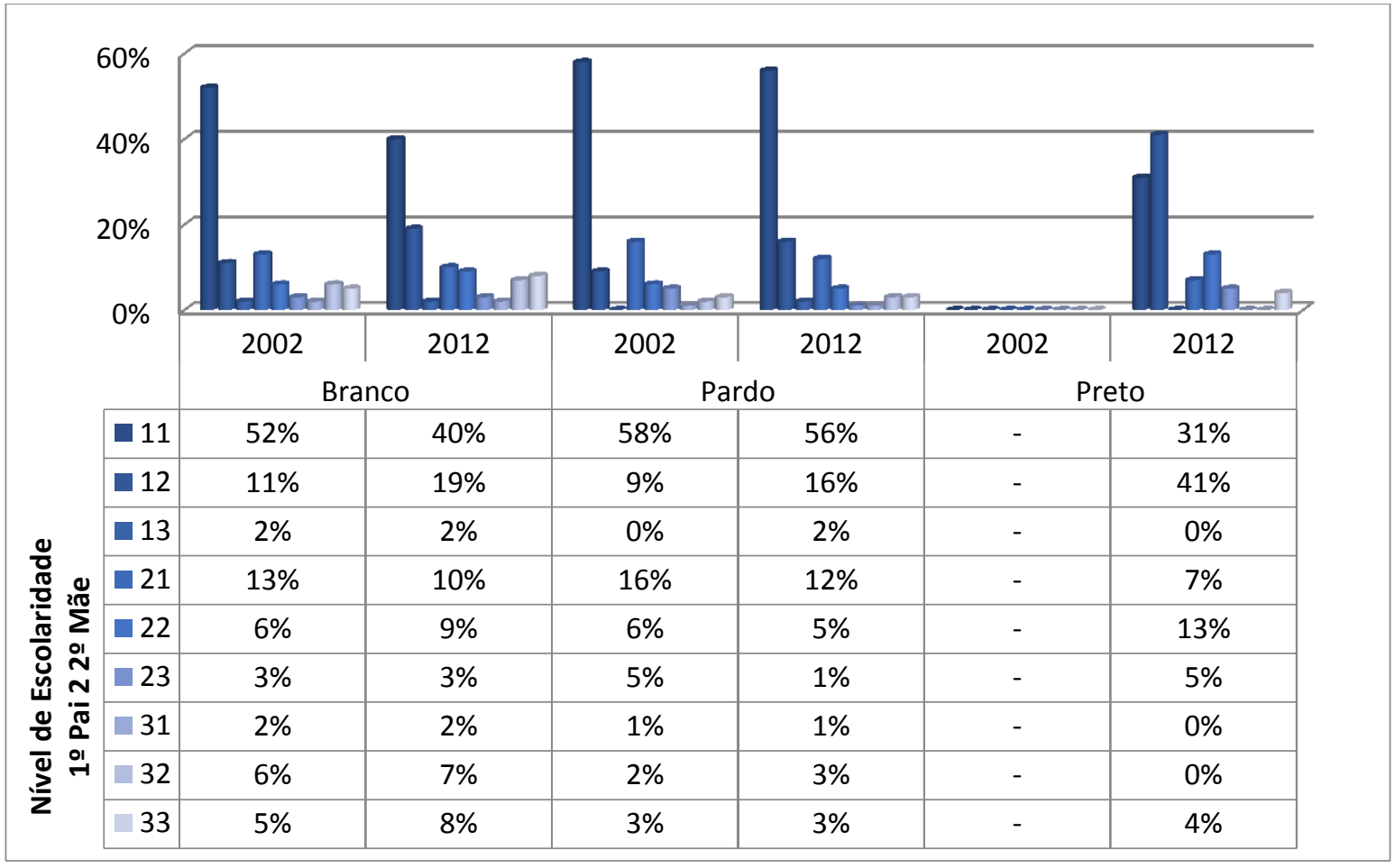

Fonte: Criado pela autora a partir das informações da PNAD.

Legenda - 1 Nível fundamental; 2 - Nível médio; 3 - Nível Superior

Tabela 26 - Nível educacional de pais de casamento intra-racial Pardo-Pardo de filhos de 18 a 25 anos

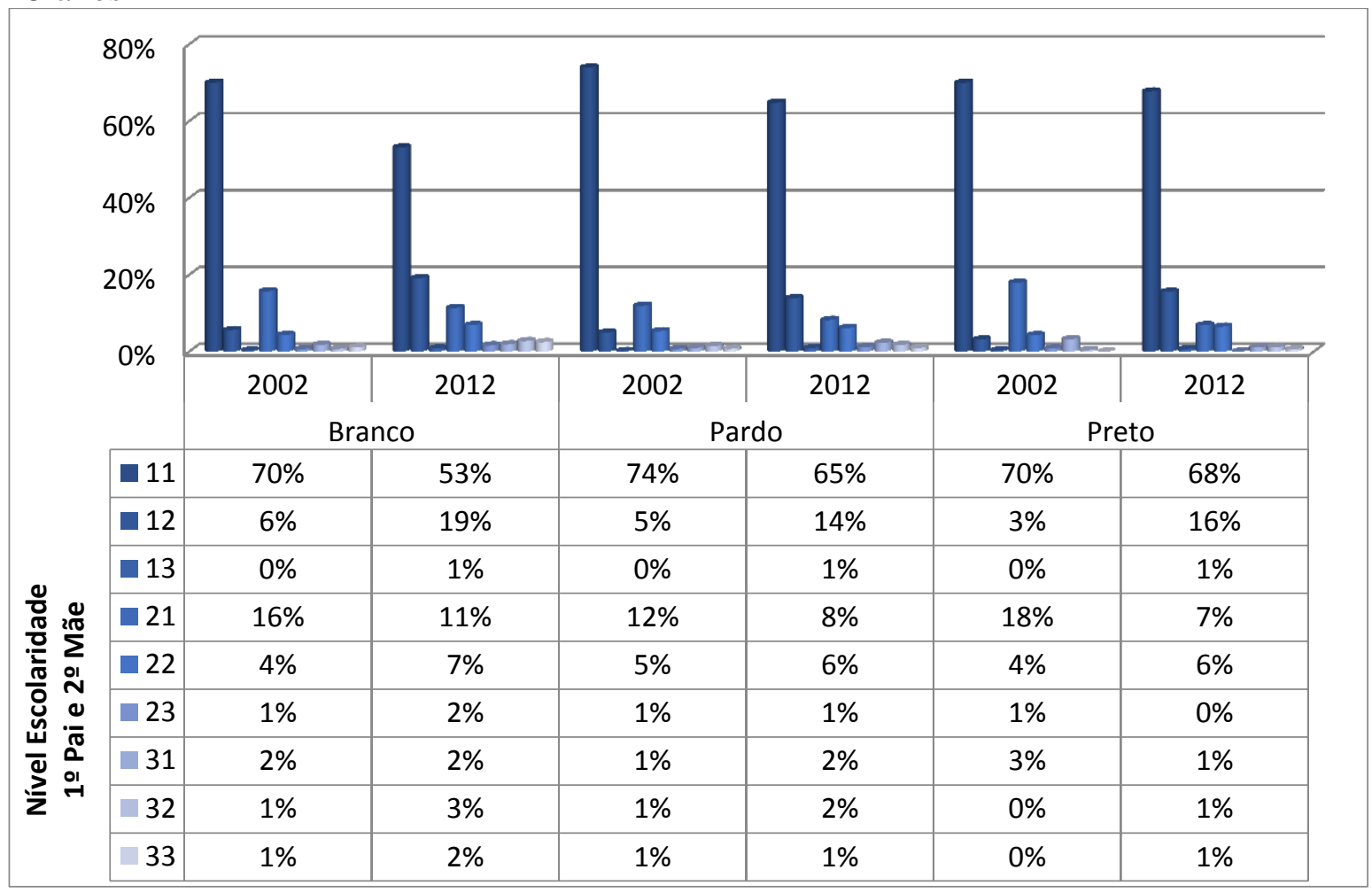

Fonte: Criado pela autora a partir das informações da PNAD.

Legenda - 1 Nível fundamental; 2 - Nível médio; 3 - Nível Superior 
A análise não muda muito na Tabela 27. De acordo com os resultados vistos anteriormente na Tabela 18 , dos $4 \%$ dos casais de casamento preto-preto que classificaram seus filhos de raça branca em 2012 , em $61 \%$ deles pelo menos um tem ensino fundamental, e $30 \%$ deles, pelo menos um tem o ensino médio, e $9 \%$ o superior. Já dos $18 \%$ que classificaram seus filhos de raça parda, $84 \%$ tem pelo menos o ensino fundamental, $15 \%$ pelo menos o médio e apenas $2 \%$ o ensino superior. Por fim, daqueles $78 \%$ que classificaram o filho de raça preta, $84 \%$ deles pelo menos um tem nível fundamental, $11 \%$ o nível médio e apenas $5 \%$ o nível superior.

Tabela 27 - Nível educacional de pais de casamento intra-racial Preto-Preto de filhos de 18 a 25 anos

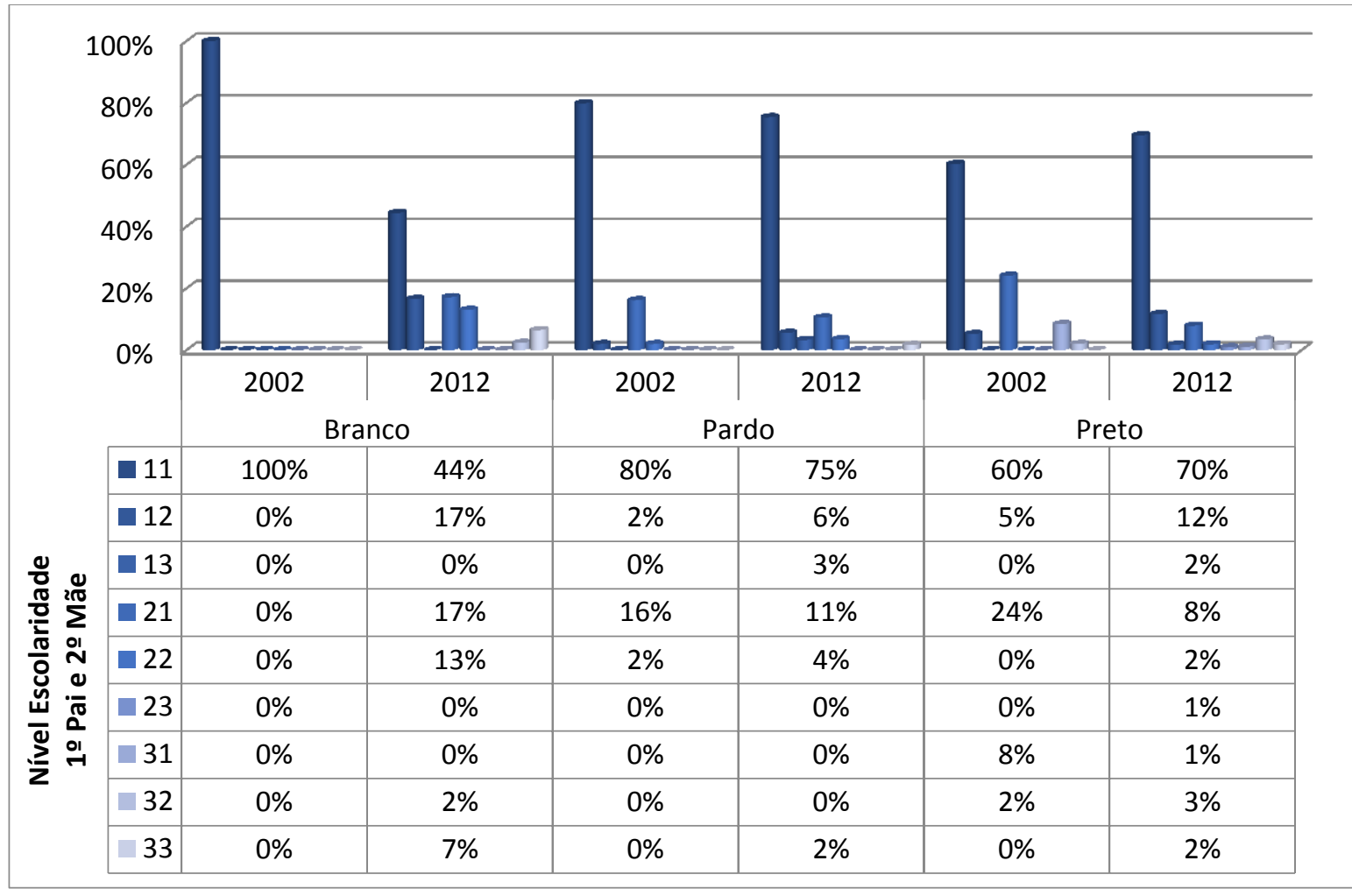

Fonte: Criado pela autora a partir das informações da PNAD.

Legenda - 1 Nível fundamental; 2 - Nível médio; 3 - Nível Superior

Assim como Marteleto (2012), Schwartzman (2007) verifica o comportamento dos pais quanto à classificação racial dos filhos ao longo do tempo. $\mathrm{O}$ autor também comenta o fato "escurecimento" na classificação racial dos jovens, ou seja, pais com nível maior de escolaridade tendem a classificar a raça de seus filhos mais próximos de suas raças ${ }^{21}$. Fatos esses que podem ser vistos nas tabelas Tabela 25, Tabela 26 eTabela 27.

\footnotetext{
${ }^{21}$ As tabelas com os resultados para casamentos inter-raciais, colocadas no Anexo deste trabalho, apresentam resultados semelhantes.
} 
Para finalizar as estatísticas descritivas, a Tabela 28 apresenta a descrição da amostra. Os valores para educação do pai e da mãe foram avaliados em anos de estudo. As variáveis utilizadas no presente trabalho que não estão descritas na tabela, são variáveis binárias.

Tabela 28 - Descrição da Amostra

\begin{tabular}{l|c|c|c|c}
\multicolumn{1}{c|}{ Variável } & \multicolumn{2}{c|}{ Ano 2002 } & \multicolumn{2}{c}{ Ano 2012 } \\
& Média & $\begin{array}{c}\text { Desvio } \\
\text { Padrão }\end{array}$ & Média & $\begin{array}{c}\text { Desvio } \\
\text { Padrão }\end{array}$ \\
\hline Atraso_escF & 6.68 & 3.63 & 6.60 & 3.47 \\
Pchefejovem* & 0.017 & 0.007 & 0.0174 & 0.007 \\
Renda familiar média (R\$) & 1131,21 & 1,081 & 2700,00 & 1,93 \\
Educação_pai & 5.96 & 4.49 & 7.28 & 4.64 \\
Educação_mãe & 6.26 & 4.33 & 8.89 & 4.47 \\
IdadeP & 43.59 & 5.39 & 45.13 & 6.18 \\
IdadeM & 41.33 & 5.40 & 41.64 & 5.98 \\
\hline Número de observações & \multicolumn{2}{|c|}{13519} & \multicolumn{2}{c}{17891} \\
\hline
\end{tabular}

Fonte: Criado pela autora, a partir dos dados da PNAD 2002 e 2012.

* Apenas para jovens entre 18 e 25 anos.

\subsection{Metodologia}

Identificar como características sócio-econômicas e familiares podem impactar na desigualdade educacional racial, tem ganhado cada vez mais atenção na literatura envolvendo estudos raciais (Schwartzman, 2007). Métodos de regressão são extremamente importantes nessas pesquisas e por vezes pesquisadores recorrem a modelos econômicos empíricos para identificar se há algum efeito imediato nas variáveis analisadas que podem causar alguma desigualdade educacional. Uma das abordagens utilizada para identificar tais causas é a técnica da decomposição contrafactual para verificar diferenças nas características e diferenças nos retornos a essas características entre grupos.

As decomposições utilizadas com maior frequência por pesquisadores são as de Blinder (1973) e Oaxaca (1973), bem como a decomposição proposta por Juhn, Murphy e Pierce (1993 e 1991). A decomposição de Blinder (1973) e Oaxaca (1973) é útil em identificar as diferenças entre grupos com características possíveis de mensurar, tais como educação, experiência, estado civil e região geográfica, por exemplo. Essa decomposição é utilizada em regressões lineares que explicam as médias condicionais das variáveis independentes utilizadas nas regressões. Já a decomposição de Juhn, Murphy e Pierce (1993 e 1991), é uma ampliação da técnica de decomposição de Oaxaca-Blinder. Os autores incorporaram à decomposição a posição que o indivíduo ocupa na distribuição residual, assim como a própria dispersão da distribuição residual (Monsueto, 2003). 
A principal inovação dessa metodologia é que ela permite operacionalizar decomposições para a distribuição educacional como um todo. Assim, com a simulação feita através de uma transformação preservadora da ordem, os autores viabilizaram a transposição da distribuição dos resíduos de um grupo para o outro. Logo, isso torna factível o estudo das disparidades das distribuições como um todo, assim como embute mais um termo na decomposição das diferenças, isto é, a distribuições dos resíduos (Crespo, 2003).

Tendo em vista que o objetivo deste trabalho é identificar se pode haver uma redução da desigualdade racial em educação com o aumento do casamento inter-racial, a metodologia proposta permitirá avaliar as variações entre grupos sujeitos a algum tipo de desigualdade, que no nosso caso será a desigualdade educacional racial. Além de avaliar as variações entre grupos, o uso dessa decomposição nos permitirá averiguar a distribuição dos resíduos, que desempenha papel importante neste caso, pois ele responde pelas características não observadas no presente estudo.

Diante disso, o método proposto faz uma decomposição que utiliza variáveis de controle (quantidade), coeficientes estimados (preços) e resíduos da regressão (não observados) para reconstruir sequencialmente a distribuição dos anos de atraso escolar dos jovens entre 14 e 25 anos. A partir desse procedimento é possível obter distribuições contrafactuais que nos permitem identificar a contribuição de cada um desses elementos na desigualdade educacional racial total. A seção a seguir apresentará a metodologia de Juhn, Murphy e Pierce (1993 e 1991), detalhando os elementos que medem a desigualdade educacional racial total.

\subsection{Decomposição entre duas distribuições}

A decomposição de Juhn, Murphy e Pierce (1993) calcula a diferença entre duas distribuições (jovens brancos e não-brancos) de resultados (atraso escolar) com o objetivo de medir a desigualdade educacional racial. Os coeficientes utilizados na decomposição para medir tal desigualdade serão estimados por Mínimo Quadrado Ordinário (MQO).

A metodologia permite decompor qualquer medida em três partes: quantidade, preço e não observáveis. A quantidade mede os efeitos de uma variação nas características observáveis dos indivíduos sobre a variação da diferença entre os grupos analisados em um determinado período de tempo. Já o preço mede a mudança no diferencial em decorrência de uma mudança na forma como o mercado valoriza os atributos observáveis, ou seja, avalia a diferença nos parâmetros. Enquanto que o terceiro mede o "efeito gap", ou seja, a diferença dos resíduos capta uma mudança na posição relativa dos indivíduos do grupo minoritário 
(avaliado) na distribuição do grupo majoritário (referência). Para melhor compreender essa decomposição, de acordo com Juhn, Murphy e Pierce (1993) e Foguel et. al. (2006), considere a equação abaixo:

$$
y_{i t}=X_{i t} \beta_{t}+u_{i t}
$$

em que $i$ representa o indivíduo, $t$ o tempo e $y$ os anos de atraso escolar do indivíduo, $X_{i t} \mathrm{o}$ vetor de características observáveis do indivíduo ${ }^{22}, \beta_{t}$ o vetor de coeficientes para o período $t$, e $u_{i t}$ o termo de erro da regressão ${ }^{23}$. Para o presente estudo é útil avaliar esse resíduo como dois componentes: o primeiro composto por $\theta_{i t}$ sendo o percentil do indivíduo $i$ no tempo $t$ na distribuição residual e o segundo composto por $F_{t}\left(. \mid X_{i t}\right)$ sendo a distribuição acumulada condicional dos resíduos no tempo $t$. Por definição temos:

$$
u_{i t}=F_{t}^{-1}\left(\theta_{i t} \mid X_{i t}\right)
$$

em que $F_{t}^{-1}\left(\theta_{i t} \mid X_{i t}\right)$ é a função inversa de distribuição acumulada dos indivíduos com características $X_{i t}$ no ano $t$.

Conforme Juhn, Murphy e Pierce (1993), mudanças estruturais na desigualdade podem vir de três fontes: mudança na distribuição das características dos indivíduos, que neste caso é uma mudança na distribuição dos X's (raça dos fillhos, renda da família, nível educacional dos pais, dummy de região, por exemplo), alteração no preço das habilidades observáveis, isto é, mudança nos parâmetros ( $\beta$ 's) e mudança na distribuição dos resíduos.

Se definirmos $\bar{\beta}$ como o vetor de preços das características observáveis da regressão para todos os períodos conjuntamente e $\bar{F}_{t}\left(\theta_{i t} \mid X_{i t}\right)$ a distribuição condicional dos resíduos dessa regressão conjunta, podemos então, decompor o nível de desigualdade nos seguintes componentes:

$$
y_{i t}=X_{i t} \bar{\beta}+X_{i t}\left(\beta_{t}-\bar{\beta}\right)+\bar{F}^{-1}\left(\theta_{i t} \mid X_{i t}\right)+\left[F_{t}^{-1}\left(\theta_{i t} \mid X_{i t}\right)-\bar{F}^{-1}\left(\theta_{i t} \mid X_{i t}\right)\right]
$$

\footnotetext{
${ }^{22} \mathrm{O}$ subscrito it não denota um painel de dados. O termo é usado para caracterizar um agrupamento de dados cross section para diferentes períodos de tempo. Isso se faz necessário, pois a metodologia de JMP é baseada em uma série de dados cross section.

${ }^{23} \mathrm{O}$ termo de erro deve ter média condicional nula, ou seja $E\left[u_{i t} \mid X_{i t}\right]=0$. Forgel et. al (2006) afirmam que essa hipótese é muito forte, pois assume a inexistência de correlação entre as covariadas e o termo de erro da regressão.
} 
O primeiro termo capta o efeito das variáveis a preços fixos. O segundo termo capta os efeitos das variações de preços de habilidade para os X's observáveis fixos, e o termo final capta os efeitos de mudanças na distribuição residual.

A partir da equação (3) podemos simular a distribuição dos anos de atraso escolar do indivíduo $i$ no período $t$ utilizando os X's observados em $t$ e em um tempo fixo de referência $s$, porém mantendo constantes os preços e a distribuição dos resíduos, conforme a seguir:

$$
y_{i t}^{1}=X_{i t} \bar{\beta}_{S}+\bar{F}_{S}^{-1}\left(\theta_{i t} \mid X_{i t}\right)
$$

Verifica-se que tanto os preços como os resíduos estão fixos, portanto a distribuição de $y_{i t}^{1}$ só muda ao longo do tempo se os X's variarem temporariamente.

Conforme Foguel et. al. (2006) a equação (4) simula os anos de atraso escolar permitindo que a distribuição das quantidades varie ao longo do tempo, porém mantendo constantes o vetor de preços e a distribuição dos não observáveis do período $s$. Em outras palavras, ela cria uma distribuição contra factual dos anos de atraso escolar caso os preços e os não observáveis fossem os do período $s$, porém com as quantidades observadas em cada $t$.

Da mesma forma, podemos simular a distribuição $y_{i t}$ variando tanto a quantidade como o preço, mantendo constante a distribuição dos não observáveis do período $s$. Neste caso teremos:

$$
y_{i t}^{2}=X_{i t} \beta_{t}+\bar{F}_{S}^{-1}\left(\theta_{i t} \mid X_{i t}\right)
$$

E por fim, permitindo variação de todos os componentes, ou seja, a variação da quantidade, preço e resíduo pode ser descrita como:

$$
y_{i t}^{3}=X_{i t} \beta_{t}+F_{t}^{-1}\left(\theta_{i t} \mid X_{i t}\right)=X_{i t} \beta_{t}+u_{i t}=y_{i t}
$$

que retorna a distribuição observada no período $t$.

A decomposição tem por objetivo calcular a distribuição de $y_{i t}^{1}, y_{i t}^{2}$ e $y_{i t}^{3}$ para cada grupo do presente estudo, ou seja, para os filhos de casamento entre cônjuges de raça branca e entre cônjuges de raça preta (casamento intra-racial) e casamento entre cônjuges de raça branca, parda e/ou preta (casamento inter-racial). Será atribuído como desigualdade: mudanças ao longo do tempo em $y_{i t}^{1}$, ou seja, alterações nas quantidades observáveis; qualquer alteração adicional em $y_{i t}^{2}$, isto é, mudança nos parâmetros observáveis e por fim qualquer alteração adicional em $y_{i t}^{3}$, ou seja, uma alteração na distribuição dos resíduos. 
Para compreender melhor esse processo, seja $\mathrm{D}($.$) uma medida de desigualdade$ qualquer. Denote $Y_{i t}^{k}=\exp \left(y_{i t}^{k}\right)$, em que $k=1,2$ e 3, então podemos definir a contribuição das quantidades $(k=1)$, dos preços $(k=2)$ e não observáveis $(\mathrm{k}=3)$ para a desigualdade total no período $t$, entre o grupo avaliado $i$ e o grupo de referência $s$, respectivamente como:

$$
\begin{gathered}
Q_{t}=D\left(Y_{i t}^{1}\right) \\
P_{t}=D\left(Y_{i t}^{2}\right)-D\left(Y_{i t}^{1}\right) \\
U_{t}=D\left(Y_{i t}^{3}\right)-D\left(Y_{i t}^{2}\right)
\end{gathered}
$$

Perceba que: $Q_{t}+P_{t}+U_{t}=D\left(y_{i t}^{3}\right)=D\left(Y_{i t}\right)=T_{t}$, ou seja, a desigualdade educacional total $\left(T_{t}\right)$, no período $t$ entre o grupo avaliado $i$ e o grupo de referência $s$, pode ser decomposta pelos componentes: mudança nas características (quantidade), mudança de preços (parâmetros) e mudança nos atributos não observáveis (resíduos). Foguel et. al. (2006) observa que essa metodologia só permite interpretações contra factuais dos efeitos quantidade, preços e não observáveis em um período de tempo $t$ para os diversos grupos em relação ao grupo de referência $s$. Isso significa que não podemos utilizá-la para calcular a contribuição desses efeitos entre dois outros períodos quaisquer, isto é, entre períodos diferentes do utilizado para o grupo de referência s.

A variável explicada neste estudo será os anos de atraso escolar de filhos. Para avaliar mudanças estruturais na desigualdade educacional de filhos de casamentos inter-raciais, consideraremos o casamento entre cônjuges de raça branca $(\mathrm{BB})$ como referência $(s)$ e o casamento entre cônjuges de raça preta $(\operatorname{PrPr})$ e casamento inter-racial $(\mathrm{BPaPr})$ a serem comparados ( $i$ ). A partir da equação (4), ao considerar $t=2012, i=\mathrm{BPaPr}$ e $s=\mathrm{BB}$, podemos escrever o seguinte:

$$
y_{B P a P r, 2012}^{1}=X_{B P a P r, 2012} \bar{\beta}_{B B, 2012}+\bar{F}_{2012}^{-1}\left(\theta_{B B} \mid X_{B B}\right)
$$

A equação (10) cria uma distribuição contra factual dos anos de atraso escolar dos filhos de casamento inter-racial $(\mathrm{BPaPr})^{24}$ caso os preços e os não observáveis ${ }^{25}$ fossem os resultados de casamento entre brancos $(\mathrm{BB})^{26}$, porém com as quantidades observadas ${ }^{27}$ para os filhos de casamento inter-racial.

\footnotetext{
${ }^{24} \mathrm{O}$ termo BPaPr corresponde ao casamento inter-racial: $\mathrm{BPa}, \mathrm{BPr}, \mathrm{PaPr}$

${ }^{25}$ Preços e não observáveis do casamento inter-racial corresponde aos termos: $\bar{\beta}_{i t}$ e $\bar{F}_{t}^{-1}\left(\theta_{i} \mid X_{i}\right)$, respectivamente.

${ }^{26} \mathrm{O}$ termo BB corresponde ao casamento entre pessoas brancas.

${ }^{27}$ Quantidades Observadas corresponde ao termo: $X_{i t}$
} 
A partir da equação (5) podemos simular a distribuição $y_{i t}$ variando tanto a quantidade como o preço, mantendo constante a distribuição dos não observáveis do casamento interracial.

$$
y_{B P a P r, 2012}^{2}=X_{B P a P r, 2012} \beta_{B P a P r, 2012}+\bar{F}_{2012}^{-1}\left(\theta_{B B} \mid X_{B B}\right)
$$

E a partir da equação (6) podemos simular a variação de todos os componentes para casamento inter-racial e com isso obter a distribuição $y_{B P a P r, 2012}^{3}$.

$$
y_{B P a P r, 2012}^{3}=X_{B P a P r, 2012} \beta_{B P a P r, 2012}+F_{2012}^{-1}\left(\theta_{B P a P r} \mid X_{B P a P r}\right)
$$

Agora podemos definir a contribuição das quantidades $\left(y_{B P a P r, 2012}^{1}\right)$, dos preços $\left(y_{B P a P r, 2012}^{2}\right)$ e não observáveis $\left(y_{B P a P r, 2012}^{3}\right)$ para a desigualdade total do filhos de casamento inter-racial (BPaPr) no ano de 2012 tendo casamento entre brancos (BB) como referência, conforme abaixo:

$$
\begin{gathered}
Q_{B P a P r}=D\left(Y_{B P a P r, 2012}^{1}\right) \\
P_{B P a P r}=D\left(Y_{B P a P r, 2012}^{2}\right)-D\left(Y_{B P a P r, 2012}^{1}\right) \\
U_{B P a P r}=D\left(Y_{B P a P r, 2012}^{3}\right)-D\left(Y_{B P a P r, 2012}^{2}\right)
\end{gathered}
$$

Perceba que: $Q_{B P a P r}+P_{B P a P r}+U_{B P a P r}=D\left(Y_{B P a P r, 2012}\right)=D_{T_{B P a P r, 2012}}$, ou seja, $\left(D_{T_{B P a P r}, 2012}\right)$ representa a desigualdade educacional total entre os filhos de casamento interracial (BPaPr) e os filhos de casamento intra-racial (BB) para o ano 2012.

$$
D_{T_{B P a P r, 2012}}=Q_{B P a P r, 2012}+P_{B P a P r, 2012}+U_{B P a P r, 2012}
$$

A equação (16) pode ser decomposta pelos componentes: mudança nas características - $Q_{B P a P r, 2012}$ (quantidade), mudança de preços - $P_{B P a P r, 2012}$ (parâmetros) e mudança nos atributos não observáveis - $U_{B P a P r, 2012}$ (resíduos). As mudanças estruturais na desigualdade do nível de atraso educacional para casamentos entre pretos, tendo como referência o casamento entre brancos para o ano de 2012, podem ser feita de forma análoga. A partir das equações (4), (5) e (6), considerando $t=2012, i=\operatorname{PrPr}$ e $s=\mathrm{BB}$, podemos escrever, respectivamente, as seguintes equações:

$$
\begin{aligned}
& y_{P r P r, 2012}^{1}=X_{P r P r, 2012} \bar{\beta}_{B B, 2012}+\bar{F}_{2012}^{-1}\left(\theta_{B B} \mid X_{B B}\right) \\
& y_{P r P r, 2012}^{2}=X_{P r P r, 2012} \beta_{P r P r, 2012}+\bar{F}_{2012}^{-1}\left(\theta_{B B} \mid X_{B B}\right)
\end{aligned}
$$




$$
y_{\operatorname{Pr} P r, 2012}^{3}=X_{\operatorname{PrPr}, 2012} \beta_{\operatorname{Pr} P r, 2012}+F_{2012}^{-1}\left(\theta_{\operatorname{PrPr}} \mid X_{\operatorname{Pr} P r}\right)
$$

A equação (17) cria uma distribuição contra factual dos anos de atraso escolar dos filhos de casamento entre pessoas de raça preta $(\operatorname{PrPr})^{28}$ caso os preços e os não observáveis fossem os resultados de casamento entre brancos (BB), porém com as quantidades observadas no casamento entre pessoas de raça preta. Já a equação (18) simula a distribuição do nível de atraso educacional variando tanto a quantidade como o preço, mantendo constante a distribuição dos não observáveis do casamento intra-racial entre pessoas de raça preta. E por fim, a equação (19) simula a variação de todos os componentes para casamento intra-racial $(\operatorname{PrPr})$.

A partir disso, podemos definir desigualdade total dos filhos de casamento intra-racial (PrPr) no ano de 2012, tendo casamento entre brancos (BB) como referência, de acordo com as equações abaixo:

$$
\begin{gathered}
Q_{P r P r}=D\left(Y_{P r P r, 2012}^{1}\right) \\
P_{P r P r}=D\left(Y_{P r P r, 2012}^{2}\right)-D\left(Y_{P r P r, 2012}^{1}\right) \\
U_{P r P r}=D\left(Y_{P r P r, 2012}^{3}\right)-D\left(Y_{P r P r, 2012}^{2}\right)
\end{gathered}
$$

$Q_{P r P r}+P_{P r P r}+U_{P r P r}=D\left(Y_{P r P r, 2012}\right)=D_{T_{P r P r}, 2012}$, representa a desigualdade educacional total entre os filhos de casamento intra-racial $(\operatorname{PrPr})$ e os filhos de casamento intra-racial (BB) para o ano $2012^{29}$.

$$
D_{T_{P r P r, 2012}}=Q_{P r P r, 2012}+P_{P r P r, 2012}+U_{P r P r, 2012}
$$

\subsection{Decomposição entre período de tempo e grupos específicos}

Além da decomposição das distribuições educacionais dos diversos grupos para medir as desigualdades em um período de tempo, Juhn, Murphy e Pierce (1991) também desenvolveram um método de decomposição que nos permite decompor como as mudanças nas distribuições educacionais diferem para os grupos raciais ao longo do tempo. Os autores fizeram a decomposição dos rendimentos salariais entre os anos de 1979 e 1988 e entre os

\footnotetext{
${ }^{28} \mathrm{O}$ termo PrPr corresponde ao casamento intra-racial entre pessoas de raça preta.

${ }^{29}$ Os estudos feitos para o ano de 2002 podem ser feitos de forma análoga à descrita em 2012.
} 
gêneros, homem e mulher ${ }^{30}$. O objetivo foi avaliar o nível global de desigualdade salarial ( $g a p$ salarial) entre homens e mulheres nos anos de 1979 e 1988 e sua evolução ao longo do tempo. O uso dessa metodologia em nosso trabalho tem como objetivo avaliar se houve uma mudança no gap educacional racial ao longo do tempo e como as características observáveis, preços e resíduos contribuíram para isso. Para tanto, considere os anos de atraso escolar dos filhos nossa variável $y$ para um ano $t$ qualquer.

$$
Y_{i t}=X_{i t} \beta_{t}+\sigma_{t} \theta_{i t}
$$

em que $X_{i t}$ é o vetor da variáveis explicativas, $\beta_{t}$ é o vetor de coeficientes, $\theta_{i t}$ é o termo de erro normalizado da regressão ${ }^{31}$, e $\sigma_{i}$ é o desvio padrão dos anos de atraso escolar dentro do grupo estudado para o ano $t$ (ou seja, o seu nível de desigualdade residual). De acordo com a metodologia apresentada por Juhn, Murphy e Pierce (1991), não há imposição de normalidade do erro. O procedimento de decomposição sugerido pelos autores é descrito conforme a seguir:

$$
D_{t}=Y_{b}-Y_{n b}=\left(X_{b, t} \beta_{t}+u_{b, t}\right)-\left(X_{n b, t} \beta_{t}+u_{n b, t}\right)=\Delta X_{t} \beta_{t}+\sigma_{t} \Delta \theta_{t}
$$

em que o subscrito $b$ representa filhos de casamento intra-racial com ambos os cônjuges da raça branca, e $n b$ filhos de casamento inter-racial em que nenhum ou pelo menos um dos cônjuges são da raça banca ${ }^{32}, \Delta X_{t}$ é a diferença média das características (variáveis explicativas) entre brancos e não brancos e $\Delta \theta_{t}$ é a diferença média do termo de erro para o grupo branco e não branco.

A equação (25) mostra que a diferença dos anos de atraso escolar dos filhos de casamento inter-racial pode ser decomposta inicialmente devido à diferença nas características medidas em $\Delta X_{t}$, ponderados pelos retornos $\beta_{t}$, ou seja, $\Delta X_{t} \beta_{t}$ é o gap nas características entre os grupos analisados. Em seguida, o termo $\sigma_{t} \Delta \theta_{t}$ é a diferença dos

\footnotetext{
${ }^{30} \mathrm{O}$ gênero homem e mulher são mencionados como grupo pelos autores, que também relatam que esses grupos podem ser, por exemplo, diferentes países, branco e preto, etc.

${ }^{31}$ Segundo Junh, Murphy e Pierce (1991), $\theta_{i t}$ tem média zero e variância igual a 1.

${ }^{32}$ Neste caso permanecem os grupos formados na seção anterior: o casamento inter-racial com a seguinte combinação de raça entre os cônjuges, $\mathrm{BPa}, \mathrm{BPr}$, PaPr; ou o casamento intra-racial, BB e PrPr. A partir disso, pode-se afirmar que o diferencial será calculado da seguinte forma, para grupo de casamento entre brancos (BB) e casamento inter-racial (BPaPr):
}

$$
D_{t}=Y_{b}-Y_{n b}=Y_{B B}-Y_{B P a P r}=\left(X_{B B, t} \beta_{t}+u_{B B, t}\right)-\left(X_{B P a P r, t} \beta_{t}+u_{B P a P r b, t}\right) ;
$$

E para grupo de casamento entre brancos $(\mathrm{BB})$ e casamento entre pessoas de raça preta $(\mathrm{Pr} P r)$ :

$$
\left.D_{t}=Y_{b}-Y_{n b}=Y_{B B}-Y_{P r P r}=\left(X_{B B, t} \beta_{t}+u_{B B, t}\right)-\left(X_{P r P r, t} \beta_{t}\right)+u_{P r P r, t}\right)
$$


resíduos normalizados a partir da equação para branco e não branco, multiplicada pela diferença do resíduo padronizado. O termo $\sigma_{t}$ captura o efeito de mudança na desigualdade enquanto que $\Delta \theta_{t}$ captura mudanças relativas na posição dos grupos branco e não branco, isto é, se os brancos estão mudando para cima ou para baixo dentro da distribuição dos não brancos (Juhn, Murphy e Pierce, 1991).

Sabendo-se como é feita a decomposição por grupos, agora vamos definir a diferença dos anos de atraso escolar dos filhos para os grupos branco e não branco ${ }^{33}$, considerando dois anos: 2002 e 2012. Para tanto, considere a equação de desigualdade a seguir:

$$
\begin{gathered}
D_{2012}-D_{2002}=\left(\Delta X_{2012}-\Delta X_{2002}\right) \beta_{2012}+\Delta X_{2002}\left(\beta_{2012}-\beta_{2002}\right)+ \\
+\left(\Delta \theta_{2012}-\Delta \theta_{2002}\right) \sigma_{2012}+\Delta \theta_{2002}\left(\sigma_{2012}-\sigma_{2002}\right)
\end{gathered}
$$

O primeiro termo depois do sinal de igualdade da equação (26) é o efeito dos X's observados, ou seja, representa o impacto das diferenças nas características dos grupos raciais sobre a trajetória temporal do gap educacional racial. Já o segundo termo é o efeito "preços" observados, ele reflete o impacto das diferenças de preços entre as raças ao longo do tempo sobre a trajetória temporal do gap educacional racial para os anos de atraso escolar dos filhos. Para compreender o resultado do segundo termo basta pensar no seguinte: se os anos de atraso escolar dos filhos do grupo $b$ - os cônjuges são da raça branca - reduzir, isso pesa no resultado deficitário dos anos de atraso escolar dos filhos do grupo $n b$, e com isso aumenta a disparidade entre os grupos, portanto aumenta a desigualdade.

O terceiro termo, o "efeito gap", mede o efeito sobre a mudança dos anos de atraso escolar dos filhos dos grupos brancos e não brancos após o controle de características observadas. Ou seja, ele dá a contribuição para a mudança do hiato dos grupos que resultaria se o nível de desigualdade residual do grupo branco tivesse permanecido o mesmo e somente os rankings de percentis dos resíduos do grupo não branco tivessem mudado.

E por fim, o quarto termo da equação (26), o "efeito de preços não observados," reflete o efeito de diferenças na desigualdade residual entre os 2 anos. Ele mede a contribuição que resultaria de uma mudança no hiato dos grupos se os rankings de percentis dos resíduos dos anos de atraso escolar dos filhos que pertencem ao grupo não branco tivesse permanecido o mesmo e só o grau de desigualdade do grupo branco tivesse mudado, ou seja, reduzindo os anos de atraso escolar.

\footnotetext{
${ }^{33} \mathrm{O}$ grupo não branco é definido pelo grupo de filhos de casamento inter-racial (BPaPr) ou também pelo grupo de filhos de casamento intra-racial (PrPr).
} 


\section{Resultados}

Os resultados a seguir serão divididos por idade dos jovens, assim, primeiramente apresentaremos os resultados para os jovens entre 14 e 17 anos e em seguida os resultados dos jovens entre 18 e 25 anos. A partir disso, os dados ilustrarão a decomposição entre duas distribuições, que tem como objetivo verificar as mudanças estruturais na desigualdade educacional de filhos de casamento inter-racial e intra-racial entre pretos, tanto para o ano de 2002 como para o ano de 2012, tomando os filhos de casamento intra-racial entre brancos como referência. Em seguida apresentaremos as decomposições que avaliam a evolução temporal do gap educacional entre período de tempo e entre grupos específicos, ou seja, iremos aferir o nível global de desigualdade educacional entre brancos e não brancos comparando os anos de 2002 e 2012.

\subsection{Decomposição da desigualdade educacional para jovens de 14 a 17 anos}

A Tabela 29 apresenta os resultados da decomposição e está separada da seguinte forma: a primeira coluna mostra as variáveis de controle utilizadas na regressão ${ }^{34}$; a segunda coluna mostra os resultados da decomposição do ano de 2002, comparando os filhos de casamento intra-racial entre brancos (referência) e filhos de casamento inter-racial; a terceira coluna faz a mesma decomposição, no entanto os dados são de 2012; a quarta coluna ilustra a decomposição do ano de 2002, comparando os filhos de casamentos intra-racial entre brancos (referência) e filhos de casamento intra-racial entre pessoas de raça preta; e por fim a quinta coluna apresenta a mesma decomposição anterior, porém com dados de 2012.

Inicialmente verificaremos o resultado dos grupos: intra-racial branco-branco e interracial (BB x BPaPr). O nível de desigualdade educacional total entre filhos de casamento inter-racial tendo intra-racial branco-branco como referência em 2002 foi de -0.806 , enquanto que em 2012 a desigualdade educacional foi de -0.538. Os resultados negativos mostram que o atraso escolar para jovens de 14 a 17 anos é maior entre aos filhos de casamento inter-racial do que para os jovens filhos de casamento intra-racial branco. Isso significa dizer que se houver um aumento de atraso escolar, aumentará a desigualdade entre os jovens de casamento intra-racial e inter-racial. Esse fator pode contribuir, por exemplo, para a persistência da diferença salarial entre brancos e não-brancos ao longo do tempo, conforme relatos de Becker et al. (1976), uma vez que o nível de escolaridade é um fator relevante para a definição de salário.

\footnotetext{
${ }^{34}$ As regressões que geram os resultados das decomposições encontra-se no Anexo.
} 
Tabela 29 - Decomposição das desigualdades educacionais para jovens de 14 a 17 anos

\begin{tabular}{|c|c|c|c|c|}
\hline \multirow{2}{*}{$\begin{array}{l}\text { Casamento } \\
\text { Ano }\end{array}$} & \multicolumn{2}{|c|}{$B B \times B P a P r$} & \multicolumn{2}{|c|}{$B B \times P r P r$} \\
\hline & 2002 & 2012 & 2002 & 2012 \\
\hline $\begin{array}{l}\text { 1. Características Individuais } \\
\qquad X_{i t} \bar{\beta}_{S}+\bar{F}_{S}^{-1}\left(\theta_{i t} \mid X_{i t}\right)\end{array}$ & -0.59 & -0.44 & -0.73 & -0.89 \\
\hline 1.1. Raça Filho - Pardo & $\begin{array}{l}-0.21 \Delta \\
(0.00)\end{array}$ & $\begin{array}{l}-0.19 \Delta \\
(0.00)\end{array}$ & $\begin{array}{c}-0.031 \Delta \\
(0.02)\end{array}$ & $\begin{aligned}-0.04 \Delta \\
(0.02)\end{aligned}$ \\
\hline 1.2. Raça Filho - Preto & $\begin{array}{c}-0.028 \Delta \\
(0.00)\end{array}$ & $\begin{array}{r}-0.06 \Delta \\
(0.00)\end{array}$ & $\begin{array}{l}-0.32 \triangle \\
(0.01)\end{array}$ & $\begin{array}{r}-0.63 \Delta \\
(0.01)\end{array}$ \\
\hline 1.3. Renda & $\begin{array}{c}-0.058 \Delta \\
(0.00)\end{array}$ & $\begin{array}{c}-0.006 \Delta \\
(0.00)\end{array}$ & $\begin{array}{r}-0.11 \Delta \\
(0.00)\end{array}$ & $\begin{array}{r}-0.02 \Delta \\
(0.00)\end{array}$ \\
\hline 1.4. Idade Pai & $\begin{array}{c}-0.013 \Delta \\
(0.02)\end{array}$ & $\begin{array}{l}0.014 \nabla \\
(0.00)\end{array}$ & $\begin{array}{c}-0.011 \Delta \\
(0.00)\end{array}$ & $\begin{array}{r}0.013 \Delta \\
(0.01)\end{array}$ \\
\hline 1.5. Educação Pai - Primário & $\begin{array}{c}-0.018 \Delta \\
(0.00)\end{array}$ & $\begin{array}{c}-0.003 \Delta \\
(0.00)\end{array}$ & $\begin{array}{c}-0.016 \Delta \\
(0.00)\end{array}$ & $\begin{array}{r}-0.002 \Delta \\
(0.00)\end{array}$ \\
\hline 1.6. Educação Pai - Médio & $\begin{array}{c}-0.007 \Delta \\
(0.00)\end{array}$ & $\begin{array}{c}-0.018 \Delta \\
(0.00)\end{array}$ & $\begin{array}{c}-0.009 \Delta \\
(0.00)\end{array}$ & $\begin{array}{r}-0.024 \\
(0.00)\end{array}$ \\
\hline 1.7. Educação Pai - Superior & $\begin{array}{c}-0.020 \Delta \\
(0.00)\end{array}$ & $\begin{array}{c}-0.038 \Delta \\
(0.00)\end{array}$ & $\begin{array}{c}-0.025 \Delta \\
(0.00)\end{array}$ & $\begin{array}{r}-0.049 \Delta \\
(0.00)\end{array}$ \\
\hline 1.8. Idade Mãe & $\begin{array}{c}-0.030 \Delta \\
(0.00)\end{array}$ & $\begin{array}{c}-0.025 \Delta \\
(0.00)\end{array}$ & $\begin{array}{c}-0.020 \Delta \\
(0.00)\end{array}$ & $\begin{array}{r}-0.021 \\
(0.00)\end{array}$ \\
\hline 1.9. Educação Mãe - Primário & $\begin{array}{c}-0.042 \Delta \\
(0.02)\end{array}$ & $\begin{array}{c}-0.019 \Delta \\
(0.00)\end{array}$ & $\begin{array}{c}-0.041 \Delta \\
(0.02)\end{array}$ & $\begin{array}{r}-0.016 \Delta \\
(0.00)\end{array}$ \\
\hline 1.10. Educação Mãe - Médio & $\begin{array}{c}-0.015 \Delta \\
(0.00)\end{array}$ & $\begin{array}{c}-0.012 \triangle \\
(0.00)\end{array}$ & $\begin{array}{c}-0.023 \Delta \\
(0.00)\end{array}$ & $\begin{array}{r}-0.011 \wedge \\
(0.00)\end{array}$ \\
\hline 1.11. Educação Mãe - Superior & $\begin{array}{c}-0.022 \Delta \\
(0.00)\end{array}$ & $\begin{array}{c}-0.017 \Delta \\
(0.00)\end{array}$ & $\begin{array}{c}-0.015 \Delta \\
(0.00)\end{array}$ & $\begin{array}{r}-0.019 \wedge \\
(0.00)\end{array}$ \\
\hline 1.12. Horas Trabalhadas - Mãe & $\begin{array}{c}-0.001 \Delta \\
(0.39)\end{array}$ & $\begin{array}{c}-0.0001 \Delta \\
(0.00)\end{array}$ & $\begin{array}{c}-0.007 \Delta \\
(0.00)\end{array}$ & $\begin{array}{r}0.0003 \\
(0.00)\end{array}$ \\
\hline 1.13. Região Norte & $\begin{array}{c}-0.037 \\
(0.02)\end{array}$ & $\begin{array}{c}-0.0420 \Delta \\
(0.00)\end{array}$ & $\begin{array}{c}-0.020 \Delta \\
(0.02)\end{array}$ & $\begin{array}{r}-0.020 \Delta \\
(0.00)\end{array}$ \\
\hline 1.14. Região Nordeste & $\begin{array}{c}-0.071 \text { ム } \\
(0.00)\end{array}$ & $\begin{array}{c}-0.054 \Delta \\
(0.00)\end{array}$ & $\begin{array}{c}-0.067 \Delta \\
(0.00)\end{array}$ & $\begin{array}{r}-0.076 \Delta \\
(0.00)\end{array}$ \\
\hline 1.15. Região Sul & $\begin{array}{c}-0.015 \Delta \\
(0.00)\end{array}$ & $\begin{array}{c}0.026 \nabla \\
(0.00)\end{array}$ & $\begin{array}{c}-0.011 \Delta \\
(0.00)\end{array}$ & $\begin{array}{r}0.031 \text { ₹ } \\
(0.00)\end{array}$ \\
\hline 1.16. Região Centro Oeste & $\begin{array}{c}-0.004 \Delta \\
(0.00)\end{array}$ & $\begin{array}{c}0.0001 \nabla \\
(0.00)\end{array}$ & $\begin{array}{c}0.003 \nabla \\
(0.00)\end{array}$ & $\begin{array}{r}-0.0002 \Delta \\
(0.00)\end{array}$ \\
\hline 1.17. Urbana & $\begin{array}{c}-0.005 \Delta \\
(0.00) \\
\end{array}$ & $\begin{array}{c}0.003 \nabla \\
(0.00)\end{array}$ & $\begin{array}{c}0.003 \nabla \\
(0.00) \\
\end{array}$ & $\begin{array}{c}0.002 \\
(0.00) \\
\end{array}$ \\
\hline $\begin{array}{l}\text { 2. Diferença nas respostas (parâmetros) } \\
\qquad X_{i t} \beta_{t}+\bar{F}_{S}^{-1}\left(\theta_{i t} \mid X_{i t}\right) \\
\end{array}$ & -0.22 & -0.099 & -0.18 & -0.05 \\
\hline $\begin{array}{l}\text { 3. Diferença em não observados (resíduos) } \\
\qquad X_{i t} \beta_{t}+F_{t}^{-1}\left(\theta_{i t} \mid X_{i t}\right)\end{array}$ & 0.004 & 0.001 & 0.01 & 0.01 \\
\hline 4. Desigualdade Educacional Total $(1+2+3)$ & -0.806 & -0.538 & -0.90 & -0.93 \\
\hline
\end{tabular}


Outro ponto interessante nos resultados da tabela acima é a queda de $33 \%{ }^{35}$ da desigualdade entre os grupos de filhos inter-raciais e intra-raciais branco-branco, mostrando que a desigualdade educacional está caindo ao longo do tempo. O mesmo não ocorre para os grupos de filhos de casamento intra-racial branco-branco e preto-preto, neste caso, houve um aumento de $3 \%$ da desigualdade entre eles. (discutiremos essa informação com mais detalhes na Tabela 30).

Fazendo uma análise comparativa dos resultados apresentados na Tabela 29 é possível inferir que as características individuais em ambos os anos, tem maior participação dentro da desigualdade total, ou seja, ela representa $73 \%$ (-0.59 / -0.806) do total da desigualdade educacional no ano de 2002, já em 2012 esse valor passa para 82\% (-0.44 / -0.538). Medeiros et al. (2013) alega que as características individuais é um fator importante na desigualdade educacional, pois parte dessa desigualdade é observada e pode ser alterada ao longo do tempo.

O resultado negativo das características mostra que elas são desfavoráveis aos filhos de casamento inter-racial e preto-preto. Isso quer dizer que se houver uma melhoria nas variáveis de controle dos filhos de casamento branco-branco ao longo do tempo, elas contribuirão para aumentar o gap, entre os grupos. No ano de 2002, todas variáveis apresentam resultados negativos, por isso, para entender melhor o significado disso, vejamos um exemplo com a variável Educação Mãe - Superior: caso haja um aumento de mães de casamento branco-branco com ensino superior, o resultado negativo mostra que haverá um aumento do gap educacional entre jovens de 14 a 17 anos filhos de casamento inter-racial e preto-preto, e isso pode ser motivado pelo fato de o nível de escolaridade dos pais impactarem positivamente no desempenho escolar dos filhos (Barros et al. 2001).

As regiões Norte e Nordeste também apresentam resultados menos favoráveis a redução do gap educacional entre os grupos analisados. Isso pode ser observado pelas diferenças regionais que Medeiros et. al. (2013) comenta em seu trabalho. Ao usar o estado de São Paulo como referência, o autor mostra que todas as regiões do Brasil apresentam desigualdade educacional quando comparada ao estado de referência. E que a única forma de reduzir essa desigualdade seria todas as regiões, e neste caso principalmente Norte e Nordeste, pois apresentam maior desigualdade, convergir em direção ao estado de São Paulo ${ }^{36}$.

O resultado positivo mostra que as características individuais são mais favoráveis aos filhos de casamento inter-racial e preto-preto do que para filhos de casamento BB, pois

\footnotetext{
${ }^{35}[(-0.538-(-0.806) /-0.806) * 100]=33 \%$

36 Medeiros et. al. (2013) é categórico ao inferir sobre a convergência das regiões. Os autores afirmam que se todas as regiões do Brasil seguissem o padrão de São Paulo, a desigualdade seria entre um décimo e um quinto menor do que a atualmente observada nas regiões Norte, Nordeste e Sudeste sem São Paulo.
} 
ajudam a reduzir o gap entre eles de 2002 a 2012. No ano de 2012, por exemplo, o fato de o jovem, filho de casamento inter-racial, morar na região sul, contribui para a redução do gap educacional. De acordo com o estudo feito por Medeiros et. al. (2013), ao avaliar a desigualdade regional em educação, tomando o estado de São Paulo como referência, a região sul foi a região que mostrou melhor desempenho, isto é, ela apresentou menor desigualdade em anos de estudo, quando comparada à São Paulo.

Deste modo podemos inferir dos resultados, que as características individuais (raça do filho, educação do pai, educação da mãe, renda, região norte e nordeste) usadas neste estudo, contribuem para aumentar o gap educacional entre o grupo de filhos de casamento inter-racial e grupo de filhos de casamento branco-branco.

Além das características individuais, os retornos observados (diferença nas respostas) também são negativos, revelando que o retorno das características individuais são maiores para o grupo de referência, ou seja, para os filhos de casamento branco-branco. Em outras palavras, se houver um aumento na renda da família, por exemplo, os retornos gerados por esse aumento trará maior benefício aos filhos de casamento intra-racial do que aos filhos de casamento inter-racial, aumentando portanto, o gap entre eles. Percebe-se que os retornos observados representavam em 2002, cerca de $27 \%$ da defasagem do gap educacional entre os grupos. Já em 2012 passou a representar apenas 18\% do diferencial. Logo, mesmo os retornos contribuindo para aumentar a desigualdade educacional entre os grupos, a tabela mostra que o papel dos retornos vem se reduzindo ao longo do tempo.

Finalmente, o efeito na diferença nos resíduos apresenta um resultado positivo, sugerindo, em média, que contribuem para reduzir a desigualdade entre os filhos de casamento inter-racial e filhos de casais preto-preto relativamente aos filhos de casais brancobranco. Este resultado representa uma espécie de prêmio ao nível educacional dos jovens que não podem ser explicado pelas variáveis de controle. Entretanto, em termos absolutos, como os resultados são baixos, isso nos permite inferir que mesmo sendo favorável aos grupos, ele é pouco relevante, neste caso, para queda do gap educacional.

Avaliando agora o resultado dos grupos: intra-racial branco-branco e intra-racial pretopreto (BB x PrPr). A diferença educacional total entre filhos de casamento intra-racial pretopreto tendo intra-racial branco-branco como referência em 2002 foi de -0.90, enquanto que em 2012 a diferença total foi de -0.93. Isso significa que houve um pequeno aumento na desigualdade educacional entre os grupos analisados no período de 2002 e 2012, mas que não parece ser significante. 
Dentre os pontos avaliados, as características individuais dos grupos são os principais responsáveis pelo aumento desse gap. As características individuais, no ano de 2002, representam $81 \%$ do total da desigualdade educacional entre os grupos de filhos de casamento intra-racial branco-branco e preto-preto, já em 2012 esse valor passa para 95\%.

Assim como na análise dos grupos anteriores os valores positivos das variáveis apresentadas nas características individuais contribuem para reduzir o gap educacional entre os grupos. O fato de o jovem morar na região sul bem como morar em área urbana, contribui para a redução do gap educacional entre filhos de casamento intra-racial branco-branco e intra-racial preto-preto.

O resultado negativo das características mostra que elas são desfavoráveis aos filhos de casamento intra-racial preto-preto. Ou seja, caso ocorra uma melhora nas variáveis de controle ao longo do tempo, elas contribuirão para aumentar o gap, entre os grupos. No ano de 2012, a variável renda da família apresentou resultado negativo, isso significa que um aumento na renda das famílias causará aumento do gap educacional entre jovens de 14 a 17 anos filhos de casamento preto-preto relativamente a branco-branco. Kaushal et al. (2011) afirmam em seus estudos que o investimento na educação dos filhos pode ser afetada pela restrição orçamentária da família. Vimos nas estatísticas descritivas que as famílias de casamento intra-racial branco-branco tem uma situação financeira melhor do que as famílias de casamento intra-racial preto-preto, cerca $80 \%$ das famílias de casamento entre pessoas de raça preta estão na classe baixa, enquanto que cerca de $60 \%$ das famílias de casamento entre brancos são de classe baixa. Logo, uma elevação na renda desses grupos, poderá gerar maior benefício aos filhos de casamento entre brancos, pois possibilitará maior capacidade de investimento educacional, e com isso aumentar o gap educacional entre jovens de 14 a 17 anos filhos de casamento intra-racial.

O efeito nos retornos observados também é negativo, revelando que o retorno das características individuais são maiores para os filhos de casamento branco-branco. Isto é, permanecendo com o exemplo de aumento na renda da família, os retornos gerados por esse aumento trará maior benefício aos filhos de casamento branco-branco do que aos filhos de casamento preto-preto. Percebe-se que os retornos observados representavam em 2002, cerca de 19,9\% do gap educacional entre os grupos. Já em 2012 passou a representar apenas 4,9\% do diferencial, mostrando portanto, que a diferença de retornos ficou menor ao longo do tempo. Isso mostra que o retorno aos atributos observados neste estudo, mesmo que ainda negativo, estão diminuindo ao longo do tempo, isto é, a diferença dos coeficientes observados 
entre os grupos estão menores, e este resultado contribui para que a desigualdade educacional seja menor com o passar do tempo.

Por fim, o efeito na diferença nos resíduos entre os grupos apresenta um resultado positivo, sugerindo que os resultados são favoráveis a ambos. No entanto, os valores representam menos de $1 \%$ do valor total da diferença, permitindo inferir que mesmo sendo favorável aos grupos, ele é pouco relevante na queda do gap educacional.

$\mathrm{Na}$ próxima tabela iremos analisar decomposições que nos permite avaliar evolução temporal do gap educacional entre período de tempo e entre grupos específicos. O objetivo aqui é aferir o nível global de desigualdade educacional entre brancos ${ }^{37}$ e não brancos ${ }^{38}$. Os resultados serão apresentados em quatro termos: o primeiro representa o efeito das variáveis de controle observadas, ou seja, representa como mudanças das características observadas dos grupos ao longo do tempo contribuem para a evolução da desigualdade educacional; o segundo é o efeito "preços" observado, o qual reflete como a variação dos retornos às características dos grupos impactou a evolução temporal da desigualdade educacional; o terceiro termo "efeito gap", mede o efeito da mudança na posição dos grupos analisados após o controle de características observadas, ou seja, ele captura o que aconteceria se a desigualdade residual do grupo de referência branco (filhos de casamento intra-racial) fosse mantida constante, mas o ranking percentil do grupo não branco (filhos de casamento interracial) se modificasse. Desta forma, os indivíduos do grupo não branco deveriam se mover em direção ao topo da distribuição, caso estivessem menos sujeitos desigualdade nos períodos analisados; e por fim o quarto termo o "efeito de preços não observados," reflete o efeito de diferenças na desigualdade residual entre os 2 anos, ou seja 2002 e 2012.

A Tabela 30 mostra os resultados para a decomposição entre o período de 2002 e 2012 para o grupo branco e não branco de jovens entre 14 e 17 anos. A tabela está divida em três colunas: a primeira mostra as variáveis de controle utilizadas na regressão; a segunda mostra os resultados da decomposição entre o período de 2002 e 2012, comparando os filhos de casamento intra-racial entre brancos - grupo branco - (referência) e filhos de casamento interracial ; a terceira coluna faz a decomposição entre o mesmo período de tempo, porém comparando os filhos de casamentos intra-racial entre brancos - grupo branco - (referência) e filhos de casamento intra-racial entre pessoas de raça preta.

Os resultados da Tabela 29 mostraram que houve uma queda de $33 \%$ da desigualdade entre os grupos de filhos inter-raciais e intra-raciais branco-branco e uma aumento de $3 \%$ na

\footnotetext{
${ }^{37} \mathrm{O}$ grupo branco representa o casamento intra-racial entre brancos (BB)

${ }^{38} \mathrm{O}$ grupo não branco representa o casamento inter-racial (BPrPa) ou casamento intra-racial entre pretos $(\mathrm{PrPr})$
} 
desigualdade educacional entre os grupos de filhos de casamento intra-racial branco-branco e preto-preto. Para o grupo de filhos inter-raciais e intra-raciais branco-branco, essa queda foi representada por uma queda de $25 \%$ na diferença das características individuais e uma queda de $55 \%$ nos retornos observados. Para o grupo de filhos de casamento intra-racial brancobranco e preto-preto, o aumento do gap, de apenas 3\%, foi representado principalmente pelo aumento de $22 \%$ na diferença das características individuais. Logo, os resultados apresentados na Tabela 30, ajudará a compreender melhor esses resultados.

Vejamos inicialmente os resultados para os filhos de casamento inter-raciais e intraraciais branco-branco. Resultados positivos sugerem que as variáveis de controle utilizadas colaboraram para a redução do gap do nível educacional ao longo do tempo, enquanto que resultados negativos sugerem aumento da desigualdade educacional ao longo do tempo.

O resultado da diferença na característica observada foi de -0.028 , ou seja, o resultado negativo ilustra que as características individuais não contribuíram para a redução do gap educacional, no entanto, ela corresponde apenas $10 \%(-0.028 /-0.27)$ do total da desigualdade educacional. Diante disso, vejamos quais as variáveis utilizadas nas características individuais que colaboraram e quais não colaboraram para a redução da desigualdade educacional.

Dentro do grupo de filhos de casamento inter-racial, com filhos de casamento brancobranco como referência, nota-se que o fato do filho ter classificação racial parda, contribuiu para a queda na desigualdade educacional total, bem como o fato de o filho ser classificado de raça preta contribuiu para aumentar o gap educacional entre o grupo. Este fato pode ser explicado com a maximização da utilidade dos pais em relação ao investimento na educação dos filhos, pois conforme resultado encontrado no trabalho de Rangel (2007), os pais a fim de maximizar o bem estar da família escolhem investir na educação de filhos com a pele mais clara.

Diante disso, nossos resultados reforçam os resultados de Rangel (2007), uma vez que famílias com composição de casamento inter-racial (os pais tem classificação racial diferente) ao perceberem a existência de diferenças no retorno para investimentos em capital humano (de acordo com a cor da pele) tendem a investir mais em filhos com peles mais claras. E neste caso, isso pode contribuir para o aumento do gap educacional entre os filhos dos grupos em estudo. Outro ponto de vista a ser considerado é o fato de os pais anteciparem a discriminação em relação aos seus filhos, por já terem tido essa experiência no mercado de trabalho. Logo, os efeitos da discriminação ocorrida no passado, persistem ao longo do tempo. Segundo Hoff et al. (2006) a desigualdade tende a persistir ao longo de gerações, uma vez os membros destes grupos investem menos em si próprio e isso afeta o investimento nos filhos. 
Tabela 30 - Decomposição da mudança do hiato de anos de estudo de jovens entre 14 e 17 anos

\begin{tabular}{|c|c|c|}
\hline Casamento & $B B \times B P a P r$ & $B B \times P r P r$ \\
\hline $\begin{array}{l}\text { 1. Diferença na característica observada } \\
\qquad\left(\Delta X_{2012}-\Delta X_{2002}\right) \beta_{2012}\end{array}$ & -0.028 & -0.03 \\
\hline 1.1. Raça Filho - Pardo & $0.001 \nabla$ & $0.015 \nabla$ \\
\hline 1.2. Raça Filho - Preto & $-0.001 \Delta$ & $-0.045 \Delta$ \\
\hline 1.3. Renda & $-0.001 \wedge$ & $-0.002 \wedge$ \\
\hline 1.4. Idade Pai & $-0.002 \Delta$ & -0.003 \\
\hline 1.5. Educação Pai - Primário & $-0.001 \wedge$ & $-0.0016 \Delta$ \\
\hline 1.6. Educação Pai - Médio & $0.005 \nabla$ & $0.008 \nabla$ \\
\hline 1.7. Educação Pai - Superior & $0.006 \nabla$ & $0.010 \nabla$ \\
\hline 1.8. Idade Mãe & $0.0002 \nabla$ & -0.003 \\
\hline 1.9. Educação Mãe - Primário & $-0.024 \Delta$ & $-0.025 \Delta$ \\
\hline 1.10. Educação Mãe - Médio & $-0.003 \wedge$ & $-0.012 \wedge$ \\
\hline 1.11. Educação Mãe - Superior & $0.006 \nabla$ & $0.012 \nabla$ \\
\hline 1.12. Horas Trabalhadas - Mãe & $-0.0004 \Delta$ & $0.001 \nabla$ \\
\hline 1.13. Região Norte & $-0.010 \wedge$ & $-0.007 \wedge$ \\
\hline 1.14. Região Nordeste & -0.005 & $-0.020 \wedge$ \\
\hline 1.15. Região Sul & $0.003 \nabla$ & $-0.008 \wedge$ \\
\hline 1.16. Região Centro Oeste & 0.000000 & $-0.00006 \Delta$ \\
\hline 1.17. Situação Censitária & -0.003 & $-0.003 \wedge$ \\
\hline $\begin{array}{l}\text { 2. Diferença nos preços observados } \\
\qquad\left(\beta_{2012}-\beta_{2002}\right) \Delta X_{2002}\end{array}$ & -0.12 & 0.19 \\
\hline $\begin{array}{l}\text { 3. Efeito gap } \\
\qquad\left(\Delta \theta_{2012}-\Delta \theta_{2002}\right) \sigma_{2012}\end{array}$ & -0.058 & -0.07 \\
\hline $\begin{array}{l}\text { 4. Diferença nos preços não observados } \\
\qquad\left(\sigma_{2012}-\sigma_{2002}\right) \Delta \theta_{2002}\end{array}$ & -0.069 & -0.06 \\
\hline $\begin{array}{l}\text { 5. Diferença Desigualdade Educacional Total }(1+2+3+4) \\
\qquad D=D_{2012}-D_{2002}\end{array}$ & -0.27 & 0.03 \\
\hline
\end{tabular}

A renda assim como o baixo nível de escolaridade dos pais (ensino primário), que gera baixos ganhos salariais, colabora para aumentar a desigualdade educacional. Como já discutido antes, a falta de recursos financeiros da família, fará com que ela decida investir naquele que apresentar maior dotação, e com isso, possibilitar maior retorno à família. E neste caso, de acordo com Becker et al. (1976), prevalecerá efeito preço, uma vez que os pais contribuirão para a melhorar a habilidade dos filhos com melhor dotação, dado a escassez de recursos.

Considerando o segundo termo da Tabela 30, diferença nos preços observados (também chamado de efeito preço), esse resultado reflete o impacto da variação dos retornos às características, que ocorreu entre 2002 e 2012, sobre a variável atraso escolar para os 
grupos em debate. Em termos gerais, este resultado informa sobre a variação na sensibilidade do atraso escolar em relação às características observáveis incluídas no modelo de regressão. O sinal negativo deste componente indica que houve uma queda na sensibilidade do atraso escolar em relação às características observáveis, e isso pesa no resultado deficitário da desigualdade educacional dos filhos de casamento inter-racial, ou seja, aumenta a desigualdade em cerca de $12 \%$ entre o grupo. Dito de outra forma, se os coeficientes estimados de 2002 forem maior que os de 2012, isso contribui para o aumento da desigualdade entre o grupo, e neste caso este aumento é de $12 \%$.

O efeito gap ilustrado na Tabela 30, que corresponde ao terceiro termo, mede o efeito da mudança dos anos de atraso escolar dos jovens após o controle de características observadas. Este resultado mostra a contribuição para a mudança do hiato dos grupos caso o nível de desigualdade residual do grupo branco (filhos de casamento intra-racial) tivesse permanecido o mesmo e somente os rankings de percentis dos resíduos do grupo não branco (filhos de casamento inter-racial) tivesse mudado. Como o efeito gap apresentou resultado negativo, então houve um aumento na desigualdade entre os grupos.

O efeito preços não observados, apresentado no item 4 da Tabela 30 , mede a contribuição que resultaria de uma mudança no hiato dos grupos se os rankings de percentis dos resíduos do atraso escolar dos filhos que pertencem ao grupo não branco de casamentos inter-raciais tivessem permanecido o mesmo e só o grau de desigualdade do grupo branco tivesse mudado. Como esse resultado apresenta valor negativo, isso significa que variáveis não observadas neste estudo podem contribuir para aumentar o diferencial de educação entre os dois grupos em cerca de $6 \%$.

Diante dos resultados apresentados, pode-se concluir que o efeito preço e o efeito gap foram os principais fatores que contribuíram para a desigualdade educacional entre os grupos de filhos de casamento inter-racial e intra-racial branco-branco no período de 2002 e 2012 . Os valores negativos sugerem que as variáveis contribuem para a desigualdade educacional, porém ao longo do período analisado a diferença entre os dois grupos vem caindo. Esse fato ocorre, pois as características individuais observadas colaboraram para isso. Variáveis como: educação do pai, educação da mãe (nível superior) e filho classificado de raça parda foram as principais responsáveis para que houvesse uma redução da desigualdade educacional entre os grupos.

A Tabela 30 mostra os resultados para os filhos de casamento intra-raciais preto-preto relativamente aos branco-branco. O resultado da diferença na característica observada foi de 0.03 mostrando que as características individuais não contribuíram para a redução do gap 
educacional, no entanto, variáveis como filho de raça parda, educação do pai e educação da mãe cooperaram para que a desigualdade entre os grupos não fosse maior.

Assim como no caso anterior, o fato do filho ter classificação racial parda contribuiu para a queda na desigualdade educacional total entre o ano de 2002 e 2012, assim como o fato de o filho ser classificado de raça preta aumentou o gap educacional entre o grupo. Diante disso, pode-se concluir novamente que os pais a fim de maximizar o bem estar da família, investirá maiores recursos nos filhos de pele mais clara. Neste caso, os pais de casamento intra-racial preto optam por investir em filhos de pele mais clara, pois conforme estudos de Hoff et al. (2006) os mecanismos de discriminação operam, em parte, dentro de indivíduos que já foram discriminados. Pais que sofreram algum tipo de descriminação racial no mercado de trabalho acabam tendo maior incentivo a investir em filhos com peles mais claras, pois eles acreditam que haverá uma probabilidade menor dos filhos de pele mais clara passar por algum tipo de preconceito. Logo, os efeitos da discriminação ocorrida no passado, persistem ao longo do tempo e influenciam no investimento intra-familiar.

Além disso, tanto Hoff et al. (2006) como Carneiro et al. (2005) alegam que se as habilidades não são justamente recompensadas, os membros destes grupos têm menos incentivos para investir em si próprio e com isso diferenças de desempenho do mercado de trabalho persistirão ao longo de gerações, pois quanto menor for a oportunidade econômica, menor será a renda da família para investir nos filhos.

Analisando agora o segundo termo, efeito preços observados, seu resultado positivo indica que houve um aumento na sensibilidade do atraso escolar em relação às características observáveis, e com isso uma queda desigualdade (medida pelo atraso escolar) em cerca de $19 \%$ entre o grupo. Ou seja, a variação positiva na sensibilidade do atraso escolar em relação às características observáveis contribuiu para a redução do gap educacional entre os filhos de casamento intra-racial branco-branco e preto-preto.

Já o terceiro termo: o efeito gap, que mede o efeito da mudança dos anos de atraso escolar dos jovens após o controle de características observadas apresentou resultado negativo, contribuindo, portanto, para o aumento na desigualdade entre os grupos ao longo do tempo.

O último termo, efeito preços não observados apresentou valor negativo, logo se conclui que variáveis não observadas neste estudo podem contribuir para aumentar o diferencial de educação entre os dois grupos em cerca de $6 \%$.

Perante os resultados apresentados, infere-se que as características individuais, o efeito preço observado e o não observado foram os principais fatores que contribuíram para o 
aumento de $3 \%$ da desigualdade educacional entre os grupos de filhos de casamento interracial branco-branco e preto-preto no de período de 2002 e 2012. Os valores positivos das características individuais sugerem que as variáveis contribuem para queda da desigualdade educacional. Variáveis como: educação do pai, educação da mãe (nível superior) e filho classificado de raça parda, foram as principais responsáveis para que a desigualdade educacional entre os grupos não fosse maior.

A Tabela 31 tem o objetivo de avaliar quais características individuais pesam mais na desigualdade educacional: perfil racial dos casamentos ou educação dos pais. Por isso, não houve separação por grupo, foi feito apenas uma decomposição entre os anos de 2002 e 2012, tomando 2012 como referência. Neste caso específico, os tipos de casamento inter-racial e intra-racial preto-preto entraram como variável de controle, pois queremos entender o que pesa mais na desigualdade educacional dos filhos, o tipo de casamento dos pais, ou o nível de escolaridade deles.

De acordo com os dados da Tabela $31^{39}$ as características individuais contribuíram para o aumento da desigualdade educacional dos jovens de 14 a 17 anos, entre os anos de 2002 e 2012, uma vez que seu resultado é negativo. Já os retornos observados (diferença nas respostas) são positivos, revelando que o retorno das características individuais são maiores em 2012, ou seja, o retorno das características foi maior no ano de referência 2012, do que no ano de 2002, significando, portanto redução do gap educacional ao longo dos anos.

Sabendo que as características individuais cooperaram para ampliar a desigualdade educacional, vamos analisar qual tem maior impacto sobre o resultado. A terceira coluna da Tabela 31 mostra a contribuição de cada componente da decomposição no diferencial da desigualdade educacional. É possível verificar que a educação dos pais é o fator que mais colabora para o aumento da desigualdade educacional, ou seja, do valor total da desigualdade educacional, a educação dos pais representa $23,26 \%$.

Se fizermos essa mesma análise para o tipo de casamento dos pais, intra-racial pretopreto e inter-racial, ele é responsável por apenas 2,33\% da desigualdade educacional. Logo, podemos inferir que o nível educacional dos pais tem maior relevância no gap educacional do que o tipo de casamento dos pais.

\footnotetext{
${ }^{39}$ Nos anexos, a Tabela A9 apresenta o resultado dessa mesma decomposição de forma mais detalhada.
} 
Tabela 31 - Decomposição das desigualdades educacionais com casamento inter-racial para jovens de 14 a 17 anos

\begin{tabular}{|c|c|c|}
\hline Grupo & $2002 \times 2012$ & $\%$ \\
\hline $\begin{array}{l}\text { 1. Características Individuais } \\
\qquad X_{i t} \overline{\boldsymbol{\beta}}_{S}+\overline{\boldsymbol{F}}_{S}^{-1}\left(\theta_{i t} \mid X_{i t}\right)\end{array}$ & $-\mathbf{0 . 1 0}$ & $23,26 \%$ \\
\hline 1.1. Renda & $\begin{array}{c}-0.02 \Delta \\
(0.00)\end{array}$ & $4,65 \%$ \\
\hline 1.2. Raça Filho & $\begin{array}{l}0.03 \nabla \\
(0.00)\end{array}$ & $-6,98 \%$ \\
\hline 1.3. Casamento inter-racial e intra-racial preto-preto & $\begin{array}{c}-0.01 \Delta \\
(0.00)\end{array}$ & $2,33 \%$ \\
\hline 1.4. Educação dos pais & $\begin{array}{c}-0.10 \Delta \\
(0.02)\end{array}$ & $23,26 \%$ \\
\hline 1.5. Região & $\begin{array}{c}-0.0003 \\
(0.00)\end{array}$ & $0,07 \%$ \\
\hline $\begin{array}{l}\text { 2. Diferença nas respostas (parâmetros) } \\
\qquad X_{i t} \beta_{t}+\bar{F}_{S}^{-1}\left(\theta_{i t} \mid X_{i t}\right)\end{array}$ & 0.53 & $-123,24 \%$ \\
\hline $\begin{array}{l}\text { 3. Diferença em não observados (resíduos) } \\
\qquad X_{i t} \beta_{t}+F_{t}^{-1}\left(\theta_{i t} \mid X_{i t}\right)\end{array}$ & 0.0001 & $-0,02 \%$ \\
\hline 4. Desigualdade Educacional Total $(1+2+3)$ & $\mathbf{0 . 4 3}$ & $100 \%$ \\
\hline
\end{tabular}

Fonte: Criado pela autora, a partir dos dados da PNAD 2002 e 2012.

Nota: os valores em \% indicam a contribuição de cada um dos componentes na desigualdade educacional total. Erros padrão entre parênteses.

$\Delta$ - As setas vermelhas indicam que as variáveis contribuem para aumentar o diferencial entre os grupos.

$\nabla$ - As setas azuis indicam que as variáveis contribuem para reduzir o diferencial entre os grupos.

Francis (2014), em suas análises afirma que o casamento inter-racial pode reduzir a desigualdade educacional, no entanto os efeitos do casamento sobre a desigualdade são relativamente pequenos. Contudo, essa desigualdade deve persistir no futuro se os padrões socioeconômicos e educacionais atuais continuarem. Diante disso, é possível afirmar que o nível educacional dos pais tem maior influência sobre a desigualdade educacional dos filhos do que o casamento inter-racial.

Portanto, por meio dos resultados apresentados, tanto a renda como o nível educacional dos pais contribuem para aumentar a desigualdade educacional entre os jovens de 14 a 17 anos filhos de casamento intra-racial preto-preto e inter-racial relativamente aos de casamentos branco-branco. Contudo, é importante frisar que pais com nível de escolaridade superior tem efeito contrário, ou seja, pais que possuam ou estejam cursando nível de escolaridade superior colaboram para a redução da desigualdade educacional. 


\subsection{Decomposição da desigualdade educacional para jovens de 18 a 25 anos}

A Tabela 32 apresenta os resultados da decomposição da desigualdade educacional para jovens de 18 a 25 anos e está separada da seguinte forma: a primeira coluna mostra as variáveis de controle utilizadas na regressão ${ }^{40}$; a segunda coluna mostra os resultados da decomposição do ano de 2002, comparando os filhos de casamento intra-racial entre brancos (referência) e filhos de casamento inter-racial; a terceira coluna mostra a mesma decomposição, no entanto os dados são de 2012; a quarta coluna ilustra a decomposição do ano de 2002, comparando os filhos de casamentos intra-racial entre brancos (referência) e filhos de casamento intra-racial entre pessoas de raça preta; e por fim a quinta coluna apresenta a mesma decomposição, porém com dados de 2012.

Inicialmente verificaremos o resultado dos grupos: intra-racial branco-branco e interracial (BB x BPaPr). A desigualdade educacional total entre filhos de casamento inter-racial tendo intra-racial branco-branco como referência em 2002 foi de -1.13, enquanto que em 2012 a desigualdade educacional foi de -0.95 . Os resultados negativos mostram que o atraso escolar para jovens de 18 a 25 anos é maior para os filhos de casamento inter-racial do que para os jovens filhos de casamento intra-racial branco. Isso significa dizer que se houver um aumento de atraso escolar, aumentará a desigualdade educacional entre os jovens de casamento intraracial e inter-racial. Logo, os resultados negativos pesam mais para os jovens filhos de casamento inter-racial uma vez que eles se distanciam mais dos jovens filhos de casamento intra-racial branco.

Em uma análise comparativa dos resultados apresentados na Tabela 32 verifica-se que as características individuais em ambos os anos, tem maior peso na desigualdade educacional total, ou seja, ela representa 85\% (-0.96 / -1.13) do total da desigualdade em 2002, já em 2012 esse valor cai para $80 \%$ (-0.44 / -0.538). Rangel (2014) afirma que as características individuais são um fator importante para mensurar resultados da desigualdade educacional. Segundo o autor, o baixo pagamento de salários para pessoas de pele mais escura, por exemplo, pode estar associado ao baixo nível de escolaridade, causado pelo baixo investimento em capital humano. Isso pode ocorrer logo na infância, quando a responsabilidade de investimento em educação é dos pais, quanto na fase adulta em que o baixo nível educacional pode estar associado pela escassez de oportunidade. Estes fatos, não são mutuamente excludentes.

Os valores positivos das características individuais contribuem para reduzir o gap educacional entre os grupos. No ano de 2002, por exemplo, o fato de o jovem morar na região

\footnotetext{
${ }^{40}$ As regressões que geraram os resultados das decomposições encontram-se no Anexo.
} 
sul, contribuiu para a redução do gap educacional entre filhos de casamento intra-racial branco-branco e inter-racial. Já no ano de 2012, o fato de a mãe possuir nível superior também contribuiu para reduzir a desigualdade. A variável Pchefejovem - proporção de domicílios chefiada por jovens entre 18 e 25 anos - assim como as horas trabalhadas da mãe, também são fatores relevantes para reduzir o gap educacional entre os jovens filhos de casamento intra-racial branco-branco e inter-racial.

O resultado negativo das características mostra que elas são desfavoráveis aos filhos de casamento inter-racial. Havendo uma melhora nas variáveis de controle ao longo do tempo, elas contribuirão para aumentar a desigualdade educacional. Tanto em 2002 como em 2012, a variável renda da família apresentou resultado negativo, isso significa que um aumento na renda das famílias aumentará a desigualdade educacional entre os jovens, ampliando, portanto a diferença entre eles. Kaushal et al. (2011) afirmam em seus estudos que o investimento na educação dos filhos pode ser afetada pela restrição orçamentária da família. Se a família tiver restrições de renda, ela escolherá o filho com melhor dotação, contribuindo assim, com a desigualdade.

Assim sendo, podemos observar que as características individuais usadas neste estudo, contribuem para aumentar o gap educacional entre o grupo de filhos de casamento inter-racial e grupo de filhos de casamento intra-racial branco-branco. Avaliando o resultado da desigualdade educacional, elas são o principal responsável pela desigualdade entre os grupos. Corroborando, portanto com as conclusões do trabalho de Medeiros et. al. (2013), que argumenta a relevância das características individuais na desigualdade educacional.

Assim como as características individuais, os retornos observados também são negativos, revelando que o retorno de tais características individuais são maiores para os filhos de casamento intra-racial branco-branco. Isto é, se houver um aumento na renda da família, por exemplo, os retornos gerados por esse aumento trará maior benefício aos filhos de casamento branco-branco do que aos filhos de casamento inter-racial, e com isso aumentar o gap entre eles. De acordo com Alves, et al. (2007), a origem social tem um peso relevante no desempenho educacional de crianças e jovens, e isso contribui para a desigualdade educacional no Brasil. Percebe-se que os retornos observados contribuíam, em 2002, com cerca de 16\% do gap educacional entre os grupos, e em 2012 passou a representar $21 \%$ do diferencial. Com isso, percebe-se que retornos às características aumentaram mais para os filhos de casamento branco-branco entre os anos estudados, contribuindo assim para o aumento do gap educacional. 
Tabela 32 - Decomposição das desigualdades educacionais para jovens de 18 a 25 anos

\begin{tabular}{|c|c|c|c|c|}
\hline \multirow{2}{*}{$\begin{array}{l}\text { Casamento } \\
\text { Ano }\end{array}$} & \multicolumn{2}{|c|}{$B a \times B a P a P r$} & \multicolumn{2}{|c|}{$B a x P r$} \\
\hline & 2002 & 2012 & 2002 & 2012 \\
\hline $\begin{array}{l}\text { 1. Características Individuais } \\
\qquad X_{i t} \overline{\boldsymbol{\beta}}_{S}+\overline{\boldsymbol{F}}_{S}^{-1}\left(\theta_{i t} \mid X_{i t}\right)\end{array}$ & -0.96 & -0.76 & -2.25 & -2.05 \\
\hline 1.1. Raça Filho Pardo & $\begin{array}{c}-0.42 \Delta \\
(0.01)\end{array}$ & $\begin{array}{c}-0.18 \Delta \\
(0.00)\end{array}$ & $\begin{array}{c}-0.053 \wedge \\
(0.08)\end{array}$ & $\begin{array}{c}-0.03 \Delta \\
(0.02)\end{array}$ \\
\hline 1.2. Raça Filho Preto & $\begin{array}{c}-0.13 \Delta \\
(0.05)\end{array}$ & $\begin{array}{c}-0.16 \Delta \\
(0.00)\end{array}$ & $\begin{array}{c}-1.69 \Delta \\
(0.10)\end{array}$ & $\begin{array}{c}-1.49 \Delta \\
(0.01)\end{array}$ \\
\hline 1.3. Renda & $\begin{array}{c}-0.055 \Delta \\
(0.00)\end{array}$ & $\begin{array}{c}-0.008 \Delta \\
(0.00)\end{array}$ & $\begin{array}{c}-0.12 \Delta \\
(0.00)\end{array}$ & $\begin{array}{c}-0.05 \Delta \\
(0.00)\end{array}$ \\
\hline 1.4. Pchefejovem & $\begin{array}{c}0.0001 \nabla \\
(0.00)\end{array}$ & $\begin{array}{c}0.029 \nabla \\
(0.00)\end{array}$ & $\begin{array}{c}0.004 \nabla \\
(0.01)\end{array}$ & $\begin{array}{c}0.002 \nabla \\
(0.03)\end{array}$ \\
\hline 1.5. Idade Pai & $\begin{array}{c}-0.018 \text { A } \\
(0.00)\end{array}$ & $\begin{array}{c}-0.11 \Delta \\
(0.00)\end{array}$ & $\begin{array}{c}-0.014 \Delta \\
(0.00)\end{array}$ & $\begin{array}{c}-0.04 \Delta \\
(0.00)\end{array}$ \\
\hline 1.6. Educação Pai Primário & $\begin{array}{c}-0.019 \\
(0.00)\end{array}$ & $\begin{array}{c}0.013 \vee \\
(0.00)\end{array}$ & $\begin{array}{c}-0.012 \wedge \\
(0.00)\end{array}$ & $\begin{array}{c}0.015 \nabla \\
(0.01)\end{array}$ \\
\hline 1.7. Educação Pai Médio & $\begin{array}{c}-0.011 \Delta \\
(0.00)\end{array}$ & $\begin{array}{c}-0.026 \Delta \\
(0.00)\end{array}$ & $\begin{array}{c}0.015 \nabla \\
(0.00)\end{array}$ & $\begin{array}{c}-0.038 \Delta \\
(0.00)\end{array}$ \\
\hline 1.8. Educação Pai Superior & $\begin{array}{c}-0.015 \\
(0.00)\end{array}$ & $\begin{array}{c}-0.06 \Delta \\
(0.00)\end{array}$ & $\begin{array}{c}-0.016 \Delta \\
(0.01)\end{array}$ & $\begin{array}{c}-0.11 \Delta \\
(0.00)\end{array}$ \\
\hline 1.9. Idade Mãe & $\begin{array}{c}-0.061 \Delta \\
(0.01)\end{array}$ & $\begin{array}{l}0.07 \nabla \\
(0.00)\end{array}$ & $\begin{array}{c}-0.037 \Delta \\
(0.01)\end{array}$ & $\begin{array}{l}0.03 \nabla \\
(0.00)\end{array}$ \\
\hline 1.10. Educação Mãe Primário & $\begin{array}{c}-0.062 \Delta \\
(0.04)\end{array}$ & $\begin{array}{c}-0.003 \wedge \\
(0.00)\end{array}$ & $\begin{array}{c}-0.052 \wedge \\
(0.03)\end{array}$ & $\begin{array}{c}-0.005 \text { A } \\
(0.00)\end{array}$ \\
\hline 1.11. Educação Mãe Médio & $\begin{array}{c}-0.066 \text { ه } \\
(0.00)\end{array}$ & $\begin{array}{c}-0.05 \Delta \\
(0.00)\end{array}$ & $\begin{array}{c}-0.10 \Delta \\
(0.00)\end{array}$ & $\begin{array}{c}-0.04 \Delta \\
(0.00)\end{array}$ \\
\hline 1.12. Educação Mãe Superior & $\begin{array}{c}-0.099 \text { A } \\
(0.01)\end{array}$ & $\begin{array}{l}0.05 \nabla \\
(0.00)\end{array}$ & $\begin{array}{c}-0.10 \wedge \\
(0.02)\end{array}$ & $\begin{array}{c}-0.07 \Delta \\
(0.00)\end{array}$ \\
\hline 1.13. Horas Trabalhadas - Mãe & $\begin{array}{c}0.003 \nabla \\
(0.00)\end{array}$ & $\begin{array}{c}0.0006 \text { ₹ } \\
(0.00)\end{array}$ & $\begin{array}{c}-0.018 \Delta \\
(0.41)\end{array}$ & $\begin{array}{c}0.002 \nabla \\
(0.00)\end{array}$ \\
\hline 1.14. Região Norte & $\begin{array}{c}-0.009 \Delta \\
(0.02)\end{array}$ & $\begin{array}{c}-0.07 \wedge \\
(0.00)\end{array}$ & $\begin{array}{c}-0.0002 \Delta \\
(0.01)\end{array}$ & $\begin{array}{c}-0.02 \Delta \\
(0.00)\end{array}$ \\
\hline 1.15. Região Nordeste & $\begin{array}{c}-0.066 \text { ـ } \\
(0.00)\end{array}$ & $\begin{array}{c}-0.09 \Delta \\
(0.00)\end{array}$ & $\begin{array}{c}-0.076 \Delta \\
(0.00)\end{array}$ & $\begin{array}{c}-0.14 \Delta \\
(0.00)\end{array}$ \\
\hline 1.16. Região Sul & $\begin{array}{c}0.082 \nabla \\
(0.00)\end{array}$ & $\begin{array}{c}-0.013 \wedge \\
(0.00)\end{array}$ & $\begin{array}{c}0.070 \nabla \\
(0.00)\end{array}$ & $\begin{array}{c}-0.01 \Delta \\
(0.00)\end{array}$ \\
\hline 1.17. Região Centro Oeste & $\begin{array}{c}-0.002 \text { ه } \\
(0.00)\end{array}$ & $\begin{array}{c}-0.0004 \text { ـ } \\
(0.00)\end{array}$ & $\begin{array}{c}-0.0008 \Delta \\
(0.00)\end{array}$ & $\begin{array}{c}-0.004 \Delta \\
(0.00)\end{array}$ \\
\hline 1.18. Situação Censitária & $\begin{array}{c}-0.0005 \text { ॥ } \\
(0.01)\end{array}$ & $\begin{array}{c}-0.011 \wedge \\
(0.00)\end{array}$ & $\begin{array}{c}-0.033 \wedge \\
(0.01)\end{array}$ & $\begin{array}{c}-0.02 \Delta \\
(0.00)\end{array}$ \\
\hline $\begin{array}{l}\text { 2. Diferença nas respostas (parâmetros) } \\
\qquad X_{i t} \beta_{t}+\bar{F}_{s}^{-1}\left(\theta_{i t} \mid X_{i t}\right)\end{array}$ & -0.18 & -0.20 & 0.32 & 0.63 \\
\hline $\begin{array}{l}\text { 3. Diferença em não observados (resíduos) } \\
\qquad X_{i t} \beta_{t}+F_{t}^{-1}\left(\theta_{i t} \mid X_{i t}\right)\end{array}$ & 0.008 & 0.009 & 0.04 & 0.05 \\
\hline 4. Desigualdade Educacional Total $(1+2+3)$ & -1.13 & -0.95 & -1.89 & -1.37 \\
\hline
\end{tabular}


Por fim, o efeito na diferença nos resíduos apresenta um resultado positivo, sugerindo, em média, que os resultados são favoráveis aos grupos. Entretanto, como os resultados são baixos (representam menos de $1 \%$ do total da desigualdade educacional), infere-se que mesmo sendo favorável, ele é pouco relevante para queda da desigualdade educacional.

Sendo assim, verifica-se que as características individuais são os fatores que mais pesam na desigualdade educacional entre filhos de casamento entre brancos e casamento inter-racial. Fatores como renda, raça do filho, educação dos pais e região, favorecem o aumento do gap educacional, bem como retornos observados de tais características. Os efeitos não observados neste estudo, pouco contribui para redução da desigualdade.

Vejamos agora o resultado dos grupos: intra-racial branco-branco e intra-racial pretopreto (BB x PrPr). A desigualdade educacional total entre filhos de casamento intra-racial preto-preto tendo intra-racial branco-branco como referência em 2002 foi de -1.89, enquanto que em 2012 foi de -1,37. Mostrando, portanto que houve uma queda na desigualdade educacional entre os grupos no período de 2002 e 2012.

Novamente, verifica-se que as características individuais dos grupos são os principais responsáveis pelo gap educacional. As características individuais, no ano de 2002, representa $119 \%(-2,25 /-1,89)$ do total da desigualdade educacional entre os grupos de filhos de casamento intra-racial branco-branco e preto-preto, já em 2012 esse valor passa para 149\% (2,05/-1,37). Esses valores apresentam resultados acima de $100 \%$, pois foram maiores que o resultado total do gap. O valor total da desigualdade educacional corresponde ao somatório das características individuais, mais o efeito preço, mais as características não observadas. Como o efeito preço e as características não observadas apresentaram resultados positivos, isso reduziu o valor da desigualdade educacional total, mostrando, portanto que as características individuais dos jovens de 18 a 25 pesam no resultado do gap, e que só não foi mais alto, porque os retornos do efeito preço contribuíram para redução da desigualdade. $\mathrm{O}$ efeito preço, mede a mudança no diferencial em decorrência de mudanças na forma como o mercado valoriza os atributos observáveis, mostrando, portanto que os retornos das variáveis observadas neste estudo estão melhorando ao longo do tempo e com isso beneficiando os jovens filhos de casamento preto-preto.

Assim como na análise dos grupos anteriores os valores positivos de algumas características individuais colaboram para reduzir o gap educacional entre os grupos. $\mathrm{O}$ fato de o jovem morar na região sul, no ano de 2002, assim como as horas trabalhadas da mãe, em 2012, contribuiu para a redução do gap educacional. A proporção de domicílios chefiadas por jovens também são fatores relevantes para reduzir o gap educacional entre os jovens filhos de 
casamento intra-racial branco-branco e preto-preto. Ou seja, em regiões com maior proporção de domicílios chefiados por jovens a diferença educacional racial é menor.

O resultado negativo das de algumas características mostra que elas contribuem para aumentar a diferença entre os filhos de casamento intra-racial branco-branco e preto-preto. $\mathrm{Ou}$ seja, caso ocorra uma melhora nas variáveis de controle ao longo do tempo, elas contribuirão para aumentar o gap, entre os grupos. No ano de 2012, por exemplo, as variáveis relacionadas e educação da mãe, apresentaram resultado negativo, isso significa que o nível educacional das mães de casamentos branco-branco aumentou mais que o das mães de casamento pretopreto.

Vimos nas estatísticas descritivas que as mulheres classificadas como brancas possuem maior nível educacional que as mulheres classificadas como pardas ou pretas. Logo, uma melhora no nível educacional de todas elas não mudaria o cenário atual. Diante disso, para que houvesse uma queda na desigualdade educacional dos filhos, considerando que os benefícios são transferidos entre membros da família conforme argumentado por Becker et. al (1976), o ideal seria melhorar o nível educacional para mães classificadas como pretas, fazendo com que eles atingissem o mesmo nível educacional de mães classificadas como brancas.

Avaliando agora o segundo termo da Tabela 32, a diferença nas respostas, o resultado positivo revela que o retorno das características individuais geram maior benefício aos filhos de casamento intra-racial preto-preto. Verificando o nível educacional dos pais por exemplo, os retornos à educação dos pais preto-preto aumentaram mais do que os dos pais branco dos jovens de 18 a 25 anos.

Por fim, o efeito na diferença nos resíduos entre os grupos apresenta um resultado positivo, com isso, os resultados são favoráveis tanto aos filhos de casamento intra-racial branco-branco e preto-preto. No entanto, a diferença nos resíduos representa apenas $1 \%$ do valor total da diferença, permitindo inferir que mesmo sendo favorável aos grupos, ele é pouco relevante na queda do gap educacional.

A Tabela 33 mostra os resultados para a decomposição entre período de tempo, 2002 e 2012, para grupos específicos branco e não branco de jovens entre 18 e 25 anos. A tabela está divida em três colunas: a primeira mostra as variáveis de controle utilizadas na regressão; a segunda mostra os resultados da decomposição entre o período de 2002 e 2012, comparando os filhos de casamento intra-racial entre brancos - grupo branco - (referência) e filhos de casamento inter-racial; a terceira coluna faz a decomposição entre o mesmo período de tempo, 
porém comparando os filhos de casamentos intra-racial entre brancos - grupo branco (referência) e filhos de casamento intra-racial entre pessoas de raça preta.

Os resultados da Tabela 32 mostraram que houve uma queda de 19\% (0.95 1.13/0.95) da desigualdade entre os grupos de filhos de casamento inter-raciais e intra-raciais branco-branco e uma queda de $38 \%$ (1.37 - 1.89/1.37) na desigualdade educacional entre os grupos de filhos de casamento intra-racial branco-branco e preto-preto, no período de 2002 e 2012. Para o grupo de filhos inter-raciais e intra-raciais branco-branco, essa queda foi representada por uma queda de $26 \%$ na diferença das características individuais e uma queda de $10 \%$ nos retornos observados. Para o grupo de filhos de casamento intra-racial brancobranco e preto-preto, a queda do gap, de $38 \%$, foi representado principalmente pelo queda de $10 \%$ na diferença das características individuais e por um aumento de $49 \%$ no retorno das características individuais (diferença nos parâmetros).

Como a diferença nos parâmetros apresentou resultado positivo, o fato de aumentar $49 \%$ entre 2002 e 2012, contribui para a queda na desigualdade educacional entre os grupos analisados, pois os retornos às características foram maior em 2012 do que em 2002. Os resultados apresentados na Tabela 33, ajudará a compreender melhor esses resultados.

O efeito da diferença nas características observadas foi de -0.015 , ou seja, as características individuais contribuíram para a redução do gap educacional entre 2002 e 2012, no entanto, ela corresponde apenas $8 \%(-0.015 /-0.18)$ do total da desigualdade educacional. Diante disso, vejamos quais as variáveis que colaboraram e quais não colaboraram para a redução da desigualdade educacional.

Dentro do grupo de filhos de casamento inter-racial, o fato do filho ser de raça parda, contribuiu para a queda na desigualdade educacional total, bem como o fato de o filho ser de raça preta contribuiu para aumentar o gap educacional entre o grupo. Novamente, nossos resultados estão de acordo com o trabalho de Rangel (2007) uma vez que os pais, a fim de maximizar o bem estar da família, escolhem investir na educação de filhos com a pele mais clara.

Se analisarmos o nível educacional da mãe, notamos que na Tabela 32 os valores foram negativos, porém comparando a evolução entre os anos, conforme Tabela 33, os resultados indicam que a educação da mãe para jovens de 18 a 25 anos contribuíram para a queda na desigualdade educacional entre 2002 e 2012. Mostrando assim que a melhora no nível educacional, ilustrada nas estatísticas descritivas, gerou benefícios aos jovens de casamento inter-racial, contribuindo para a queda no gap. 
Tabela 33 - Decomposição da mudança do hiato de anos de estudo de jovens entre 18 e 25 anos

\begin{tabular}{|c|c|c|}
\hline Casamento & $B B \times B P a P r$ & $B B \times P r P r$ \\
\hline 1. Diferença na característica observada $\left(\Delta X_{2012}-\Delta X_{2002}\right) \beta_{2012}$ & -0.015 & -0.39 \\
\hline 1.1. Raça Filho Pardo & $0.001 \nabla$ & $0.02 \nabla$ \\
\hline 1.2. Raça Filho Preto & $-0.002 \wedge$ & $-0.045 \Delta$ \\
\hline 1.3. Renda & $-0.004 \Delta$ & $-0.05 \Delta$ \\
\hline 1.4. Pchefejovem & $0.003 \nabla$ & $-0.002 \Delta$ \\
\hline 1.5. Idade Pai & $-0.002 \Delta$ & $-0.07 \Delta$ \\
\hline 1.6. Educação Pai Primário & $-0.008 \Delta$ & $-0.006 \Delta$ \\
\hline 1.7. Educação Pai Médio & $-0.001 \wedge$ & $0.02 \nabla$ \\
\hline 1.8. Educação Pai Superior & $0.0002 \nabla$ & $-0.05 \Delta$ \\
\hline 1.9. Idade Mãe & $0.009 \nabla$ & $-0.08 \Delta$ \\
\hline 1.10. Educação Mãe Primário & $-0.009 \Delta$ & $-0.022 \wedge$ \\
\hline 1.11. Educação Mãe Médio & $0.006 \nabla$ & $0.05 \nabla$ \\
\hline 1.12. Educação Mãe Superior & $0.04 \nabla$ & $0.003 \nabla$ \\
\hline 1.13. Horas Trabalhadas - Mãe & $-0.0024 \Delta$ & $-0.08 \wedge$ \\
\hline 1.14. Região Norte & $-0.003 \wedge$ & $-0.040 \wedge$ \\
\hline 1.15. Região Nordeste & $-0.0026 \Delta$ & $-0.008 \Delta$ \\
\hline 1.16. Região Sul & $-0.004 \Delta$ & $-0.00009 \Delta$ \\
\hline 1.17. Região Centro Oeste & $-0.003 \wedge$ & $-0.003 \wedge$ \\
\hline 1.18. Situação Censitária & $-0.003 \wedge$ & $-0.03 \wedge$ \\
\hline 2. Diferença nos preços observados $\left(\beta_{2012}-\beta_{2002}\right) \Delta X_{2002}$ & -0.12 & 0.10 \\
\hline 3. Efeito gap $\left(\Delta \theta_{2012}-\Delta \theta_{2002}\right) \sigma_{2012}$ & -0.04 & -0.14 \\
\hline 4. Diferença nos preços não observados $\left(\sigma_{2012}-\sigma_{2002}\right) \Delta \theta_{2002}$ & -0.007 & -0.09 \\
\hline $\begin{array}{l}\text { 5. Diferença Desigualdade Educacional Total }(1+2+3+4) \\
\qquad D=D_{2012}-D_{2002}\end{array}$ & -0.18 & -0.52 \\
\hline
\end{tabular}

Considerando o segundo termo, diferença nos preços observados (também chamado de efeito preço), esse resultado reflete a variação do preço, que ocorreu entre 2002 e 2012, para as características dos grupos analisados. Em termos gerais, este resultado informa sobre a variação na sensibilidade do atraso escolar em relação às características observáveis entre 2002 e 2012, o resultado negativo aumenta a desigualdade educacional dos filhos de casamento inter-racial em cerca de $12 \%$.

O efeito gap, que corresponde ao terceiro termo, mede o efeito da mudança dos anos de atraso escolar dos jovens após o controle de características observadas. Este resultado mostra a contribuição para a mudança do hiato dos grupos caso o nível de desigualdade residual do grupo branco tivesse permanecido o mesmo e somente os rankings de percentis dos resíduos do grupo não branco (filhos de casamento inter-racial) tivesse mudado. Como o 
efeito gap apresentou resultado negativo, então houve um aumento na desigualdade entre os grupos.

O último termo, efeito preços não observados, mede a contribuição que resultaria de uma mudança no hiato dos grupos se os rankings de percentis dos resíduos do atraso escolar dos filhos que pertencem ao grupo não branco tivessem permanecido o mesmo e só o grau de desigualdade do grupo branco tivesse mudado. Como esse resultado apresenta valor negativo, isso significa que variáveis não observadas neste estudo podem contribuir para aumentar o diferencial de educação entre os dois grupos em cerca de $7 \%$.

Diante dos resultados apresentados, pode-se concluir que a diferença nas características, o efeito preço e o efeito gap foram os principais fatores que contribuíram para a desigualdade educacional entre os grupos de filhos de casamento inter-racial e intra-racial branco-branco entre o período de 2002 e 2012. Os valores negativos sugerem que as variáveis contribuem para a desigualdade educacional, porém ao longo do período analisado a diferença entre os dois grupos vem caindo. Esse fato ocorre, pois as características individuais observadas colaboraram para isso. Variáveis como: educação do pai, educação da mãe (nível superior), jovens chefe de família e filho classificado de raça parda, foram as principais responsáveis para que houvesse uma redução da desigualdade educacional entre os grupos.

A coluna 3 da Tabela 33 mostra os resultados para os filhos de casamento intra-raciais branco-branco e preto-preto. O resultado da diferença na característica observada foi de -0.39 mostrando que as características individuais pesa mais para os filhos de casamento intra-racial preto, contribuindo assim, para o aumento do gap educacional. Contudo, verifica-se que houve uma queda de $10 \%$ entre os anos de 2002 e 2012, e por isso, podemos afirmar que a desigualdade educacional está reduzindo ao longo do tempo.

Assim como no caso anterior, o fato do filho ter classificação racial parda contribuiu para a queda na desigualdade educacional total entre o ano de 2002 e 2012, bem como o fato de o filho ser classificado de raça preta aumentou o gap educacional entre o grupo. Neste caso, confirmando os resultados de Rangel (2014), os pais de casamento intra-racial preto optam por investir em filhos de pele mais clara, pois podem obter maior retorno sobre o investimento e com isso, maximizar a utilidade das famílias.

Um dos fatos que podem explicar isso, por exemplo, é o fato de os pais que já terem sofrido algum tipo de descriminação racial no mercado de trabalho acabam tendo maior incentivo a investir em filhos com peles mais claras, dado que os pais consideram que haverá uma probabilidade menor dos filhos de pele mais clara sofrerem algum tipo de preconceito. Logo, os efeitos da discriminação ocorrida no passado, persistem ao longo do tempo. Além 
disso, tanto Hoff et al. (2006) como Carneiro et al. (2005) afirmam que em casos que as habilidades não são justamente recompensadas, os membros destes grupos têm menos incentivos para investir em si próprio, persistindo ao longo de gerações as diferenças de desempenho do mercado de trabalho, gerando menor renda na família, impactando portanto, o investimento nos filhos.

Analisando o efeito dos preços observados, verifica-se que o resultado foi positivo, ou seja, as características individuais de filhos de casamento preto-preto são mais bem remuneradas que as de filhos de casamentos branco-branco, isso pesa no resultado da desigualdade educacional dos filhos de casamento intra-racial branco-branco, e com isso haverá queda na desigualdade entre os grupos em cerca de $10 \%$.

Já o efeito gap, que mede o efeito da mudança dos anos de atraso escolar dos jovens após o controle de características observadas apresentou resultado negativo, contribuindo, portanto, para o aumento na desigualdade entre os grupos ao longo do tempo.

O último termo, efeito preços não observados apresentou valor negativo, com isso conclui-se que variáveis não observadas neste estudo podem contribuir para aumentar o diferencial de educação entre os dois grupos em cerca de $9 \%$.

Perante os resultados apresentados, infere-se que as características individuais, o efeito gap e o preço não observado foram os principais fatores que contribuíram para manter a desigualdade educacional entre os grupos de filhos de casamento inter-racial branco-branco e preto-preto no de período de 2002 e 2012. Os valores positivos das características individuais indicam queda da desigualdade educacional. Variáveis como: educação do pai (nível médio), educação da mãe (nível médio e superior) e filho classificado de raça parda, bem como o efeito dos preços observados, foram as principais responsáveis para que a desigualdade educacional entre os grupos não fosse maior.

A próxima tabela tem o objetivo de avaliar quais características individuais pesam mais na desigualdade educacional para os jovens de 18 a 25 anos, por isso, não houve separação por grupo de casamento, fizemos apenas uma decomposição entre os anos de 2002 e 2012, usando 2012 como referência. Nesta decomposição, os tipos de casamento inter-racial e intra-racial preto-preto entraram como variável de controle, pois queremos entender o que pesa mais na desigualdade educacional dos filhos, o tipo de casamento dos pais, ou o nível de escolaridade deles. 
Os dados da Tabela $34^{41}$ indicam que as características individuais, pelo fato de terem apresentado resultado negativo, contribuíram para o aumento da desigualdade educacional em $39,3 \%$, entre os anos de 2002 e 2012. Enquanto que os retornos observados, pelo fato de serem positivos, contribuíram para a redução do gap educacional. Este resultado ilustra que o retorno das características individuais são maiores no ano de referência 2012, do que no ano de 2002, por isso podemos concluir quem vem ocorrendo uma redução do gap educacional ao longo dos anos para os jovens de 18 a 25 anos.

Tabela 34 - Decomposição das desigualdades educacionais com casamento inter-racial para jovens de 18 a 25 anos

\begin{tabular}{|c|c|c|}
\hline Grupo & $2002 \times 2012$ & $\%$ \\
\hline $\begin{array}{l}\text { 1. Características Individuais } \\
\qquad X_{i t} \bar{\beta}_{S}+\bar{F}_{S}^{-1}\left(\theta_{i t} \mid X_{i t}\right)\end{array}$ & -0.16 & $39,3 \%$ \\
\hline 1.1. Renda & $\begin{array}{c}-0.03 \wedge \\
(0.00)\end{array}$ & $7 \%$ \\
\hline 1.2. Raça Filho & $\begin{array}{l}0.04 \nabla \\
(0.00)\end{array}$ & $-10 \%$ \\
\hline 1.3. Casamento inter-racial e intra-racial preto-preto & $\begin{array}{c}-0.02 \Delta \\
(0.00)\end{array}$ & $5 \%$ \\
\hline 1.4. Educação dos pais & $\begin{array}{c}-0.09 \Delta \\
(0.00)\end{array}$ & $22 \%$ \\
\hline 1.5. Região & $\begin{array}{c}-0.0007 \\
(0.00)\end{array}$ & $0,3 \%$ \\
\hline 1.6. Pchefejovem & $\begin{array}{r}-0.06 \Delta \\
(0.00)\end{array}$ & $15 \%$ \\
\hline $\begin{array}{l}\text { 2. Diferença nas respostas (parâmetros) } \\
\qquad X_{i t} \beta_{t}+\bar{F}_{S}^{-1}\left(\theta_{i t} \mid X_{i t}\right)\end{array}$ & 0.57 & $-139 \%$ \\
\hline $\begin{array}{l}\text { 3. Diferença em não observados (resíduos) } \\
\qquad X_{i t} \beta_{t}+F_{t}^{-1}\left(\theta_{i t} \mid X_{i t}\right)\end{array}$ & 0.0001 & $-0,03 \%$ \\
\hline 4. Desigualdade Educacional Total $(1+2+3)$ & 0.41 & $100 \%$ \\
\hline
\end{tabular}

Sabendo que as características individuais cooperaram para ampliar a desigualdade educacional, vejamos quais são as variáveis que geram maior impacto sobre este resultado. A terceira coluna da Tabela 34 mostra a contribuição de cada componente da decomposição na desigualdade educacional. É possível verificar que, dentro das características individuais, a educação dos pais é o fator que mais colabora para o aumento da desigualdade educacional, ou seja, do valor total da desigualdade educacional, a educação dos pais representa $22 \%$. Em

\footnotetext{
${ }^{41}$ Nos anexos, a Tabela A24 apresenta o resultado dessa mesma decomposição de forma mais detalhada.
} 
seguida, representando $15 \%$ do gap é a proporção de domicílios chefiada por jovens. Este fato pode ocorrer, pois de acordo com Emerson e Souza (2002) pessoas que tiveram experiências no mercado de trabalho ainda jovens tem impacto direto no investimento da educação, pois eles enfrentam um trade off entre trabalho e estudo. Logo, iniciar ainda jovem no mercado de trabalho afeta o nível de escolaridade do indivíduo, bem como contribui para a desigualdade educacional para as próximas gerações.

Se fizermos essa mesma análise para o tipo de casamento dos pais, intra-racial pretopreto e inter-racial, ele é responsável por apenas $5 \%$ da desigualdade educacional. Logo, podemos inferir que o nível educacional dos pais tem maior relevância no gap educacional do que o tipo de casamento dos pais. Divergindo com os resultados de Francis (2014), em que o autor assegura que o casamento inter-racial reduz a desigualdade educacional. Não obstante, em sua conclusão, o autor infere que essa desigualdade deve persistir ao longo do tempo se os padrões socioeconômicos e educacionais atuais continuarem.

A única variável, dentro das características individuais, que apresentou resultado positivo foi raça do filho. Mas é importante destacar que este fato ocorre para o filho classificado como pardo e não para ambos, pardo e preto. O filho classificado como pardo apresentou redução da desigualdade, pois os pais, conforme discussão abordada na literatura, preferem investir em filhos de pele mais clara, uma vez que acreditam que esses trarão maior retorno às famílias do que os filhos de pele mais escura.

Portanto, por meio dos resultados apresentados, o nível educacional dos pais assim como o fato de o jovem ser chefe de família contribuem para aumentar a desigualdade educacional entre os jovens de 18 a 25 anos filhos de casamento intra-racial preto-preto e inter-racial. Contudo, é importante frisar que pais com nível de escolaridade superior tem efeito contrário, ou seja, pais que possuam ou estejam cursando nível de escolaridade superior colaboram para a redução do gap educacional.

Diante de todas as análises expostas no trabalho, verifica-se que os resultados não divergem entre os jovens de 14 a 17 anos e jovens entre 18 a 25 anos. O nível de escolaridade dos pais assim como renda são fatores importantes, que colaboram com a desigualdade educacional entre eles. $\mathrm{O}$ fato de essas variáveis terem apresentado resultado negativo nas decomposições realizadas, significa que qualquer melhoria que ocorra para os filhos de casamentos inter-raciais e preto-preto, tanto na educação como renda, provocará uma aproximação dos jovens de referência (filhos de casamento entre brancos) e os demais (filhos de casamento intra-racial entre pretos e inter-racial), com isso uma redução do gap educacional entre eles. Entretanto, a análise para os pais que possuem nível superior não 
entram no resultado descrito. $\mathrm{O}$ fato de os pais terem maior nível de escolaridade contribui para reduzir a desigualdade entre os grupos estudados, independentemente da idade. Também não foi diferente quanto ao fato de o casamento inter-racial contribuir para a desigualdade educacional dos filhos. Tanto casamento entre diferentes raças como casamento entre pessoas de raça preta, contribuem para o aumento do gap educacional entre os filhos, contudo este fator não é mais relevante que o nível educacional dos pais.

A única variável que apresenta resultado diferente entre os grupos de jovens analisados é o fato de eles morarem na região sul. Para jovens de 14 a 17 anos, isso contribui para a redução da desigualdade entre os grupos analisados. Já para os jovens de 18 a 25 anos, o fato de morar na região sul aumentam a desigualdade. Medeiros et. al. (2013) mostraram que a região sul está mais próxima do estado de São Paulo, referência no estudo, do que as demais regiões. No entanto, seus estudos consideraram apenas jovens de 14 a 17 anos, com isso podemos inferir que o ensino básico (primário, fundamental e médio) na região sul é melhor que nas demais regiões e por isso, contribui para a redução da desigualdade educacional para os jovens de 14 a 17. Já para os jovens de 18 a 25 anos, que geralmente estão finalizando o ensino médio ou iniciando / cursando o ensino superior, o fato de morar na região sul não contribui para reduzir o gap educacional, pelo contrário, aumenta a diferença entre os grupos analisados. 


\section{Conclusão}

O objetivo proposto pelo trabalho foi identificar se pode haver uma redução da desigualdade educacional inter-geracional com o aumento do casamento inter-racial. Para realizar esse objetivo, utilizamos dados da PNAD de 2002 e 2012, aplicando a metodologia de Juhn, Murphy e Pierce (1993 e 1991).

Diante dos resultados apresentados, pode-se concluir para os jovens de 14 a 17 anos que houve uma queda na desigualdade entre os filhos de casamento intra-racial branco e interracial de $37 \%$ entre os períodos analisados. Os valores negativos sugerem que as variáveis contribuem para a desigualdade educacional, porém ao longo do período analisado a diferença entre os dois grupos vem caindo. Esse fato ocorre, pois as características individuais observadas colaboraram para isso. Variáveis como: educação do pai, educação da mãe (nível superior) e filho classificado de raça parda, foram as principais responsáveis para que houvesse uma redução da desigualdade educacional entre os grupos.

Já para os filhos de casamento intra-racial branco-branco e preto-preto infere-se que as características individuais, o efeito preço observado e o não observado foram os principais fatores que contribuíram para o aumento de $3 \%$ da desigualdade educacional no de período de 2002 e 2012. Os valores positivos das características individuais sugerem que as variáveis contribuem para queda da desigualdade educacional. Variáveis como: educação do pai, educação da mãe (nível superior) e filho classificado de raça parda, foram os principais responsáveis para que a desigualdade educacional entre os grupos não fosse maior.

Nas análises da decomposição entre os anos de 2002 e 2012, tomando 2012 como referência, verificamos como os componentes usados como variável de controle contribuem para a desigualdade educacional dos jovens. É possível verificar que a educação dos pais é o fator que mais colabora para o aumento da desigualdade educacional, ou seja, do valor total da desigualdade educacional, a educação dos pais representa $23,26 \%$. Se fizermos essa mesma análise para o tipo de casamento dos pais, intra-racial preto-preto e inter-racial, ele é responsável por apenas $2,33 \%$ da desigualdade educacional. Logo, podemos inferir que o nível educacional dos pais tem maior relevância no gap educacional do que o tipo de casamento dos pais. Salientando, no entanto, que pais que possuem nível superior contribuem para a redução do gap educacional.

Já para os jovens entre 18 e 25, os resultados não alteram muito. Os resultados encontrados mostraram que houve uma queda de $19 \%$ da desigualdade entre os grupos de filhos de casamento inter-raciais e intra-raciais branco-branco e uma queda de $38 \%$ na 
desigualdade educacional entre os grupos de filhos de casamento intra-racial branco-branco e preto-preto, no período de 2002 e 2012.

Para o grupo de filhos inter-raciais e intra-raciais branco-branco, essa queda foi representada por uma queda de $26 \%$ na diferença das características individuais e uma queda de $10 \%$ nos retornos observados. Enquanto que para o grupo de filhos de casamento intraracial branco-branco e preto-preto, a queda do gap, de 38\%, foi representado principalmente pelo queda de $10 \%$ na diferença das características individuais e por um aumento de $49 \%$ no retorno das características individuais (diferença nos parâmetros).

O nível educacional dos pais e o fato de o jovem ser chefe de família contribuem para aumentar a desigualdade educacional. Contudo, é necessário salientar que pais com nível de escolaridade superior colaboram para a redução do gap educacional. Filhos classificados como pretos também contribuem para o aumento do gap, enquanto que filho de classificação racial parda contribui para a redução da desigualdade, pois os pais preferem investir em filhos de pele mais clara, uma vez que acreditam que esses trarão maior retorno às famílias do que os filhos de pele mais escura (Rangel, 2014).

Comparando os jovens de 14 a 17 anos e jovens entre 18 a 25 anos, verifica-se que os resultados são parecidos, entretanto vale destacar que as magnitudes dos gaps são diferentes, porém com conclusões semelhantes. O nível de escolaridade dos pais assim como renda são fatores importantes, que colaboram com a desigualdade educacional entre eles. $\mathrm{O}$ fato de essas variáveis terem apresentado resultado negativo nas decomposições realizadas, significa que qualquer melhoria que ocorra, tanto na educação como renda, provocará um distanciamento entre os jovens de referência (observados) e os contra factuais. Entretanto, a análise para os pais que possuem nível superior não entram no resultado descrito. $O$ fato de os pais terem maior nível de escolaridade contribui para reduzir a desigualdade entre os grupos estudados, independentemente da idade. Com isso, pode-se inferir que para que haja uma redução da desigualdade educacional entre os grupos analisados, é necessário que os pais de casamento inter-racial bem como de casamento intra-racial preto-preto alcance o nível superior, para que isso influencie de forma positiva no nível educacional dos filhos. Com isso, os resultados encontrados no presente trabalho, corroboram com os estudos de Becker et. al. (1976), quando os autores afirmam que há transferência de benefícios (conhecimento) entre membros da mesma família.

O casamento inter-racial também contribuir para a desigualdade educacional dos filhos. Tanto casamento entre diferentes raças como casamento entre pessoas de raça preta contribuem para o aumento do gap educacional entre os filhos, contudo este fator não é mais 
relevante que o nível educacional dos pais. Este resultado contradiz os estudos de Francis (2013) que alega que o casamento inter-racial colabora para a redução da desigualdade educacional.

O único resultado diferente é o fato de os jovens morarem na região sul. Para jovens de 14 a 17 anos, isso contribui para que a queda da desigualdade, enquanto que para os jovens de 18 a 25 anos, o fato de morar na região sul aumenta a desigualdade. Medeiros et. al. (2013) mostraram que a região sul está mais próxima do estado de São Paulo, do que as demais regiões. Não obstante, seus estudos consideraram apenas jovens de 14 a 17 anos, com isso podemos inferir que os ensinos fundamental e médio na região sul são melhores que nas demais regiões e por isso, contribui para a redução da desigualdade educacional para os jovens de 14 a 17. Já para os jovens de 18 a 25 anos, que geralmente estão finalizando o ensino médio ou iniciando / cursando o ensino superior, o fato de morar na região sul não contribui para reduzir o gap educacional, pelo contrário, aumenta a diferença entre os grupos analisados. 


\section{Referência}

ALDERMAN, Harold; KING, ELIZABETH M. Gender differences in parental investment in education. Structural Change and Economic Dynamics, v. 9, n. 4, p. 453-468, 1998.

ALVES, F.; ORTIGÃO, I.; FRANCO, C. Origem social e risco de repetência: interação raça capital econômico. Cadernos de pesquisa, v. 37, p. 161-180, 2007.

BAILEY, Stanley R.; Legacies of Race: Identities, Attitudes, and Politics in Brazil. Stanford: Stanford University Press, 2009.

BARROS, R. P. D., MENDONÇA, R., SANTOS, D. D. D., \& QUINTAES, G.; Os determinantes do desempenho educacional no Brasil. Pesquisa e planejamento econômico, Rio de Janeiro, v. 31, n. 1, p. 1-42, 2001.

BECKER, Gary S.; A Theory of Marriage: Part I. Journal of Political Economy, 81(4): 813846, 1973.

1974.

. A Theory of Marriage: Part II. Journal of Political Economy, 82(2): S11-S26,

A Treatise on the Family, Enlarged Edition (Cambridge, Mass.: Harvard University Print). 1991.

BECKER, G.; N. TOMES; Child Endowments and the Quantity and Quality of Childre. The Journal of Political Economy, Vol. 84(4), Part 2: Essays in Labor Economics in Honor of H. Gregg Lewis, pp. S143-S162, 1976.

BEHRMAN, J.; R. POLLAK; P. TAUBMAN.; Parental Preferences and Provision for Progeny, Journal of Political Economy, University of Chicago Press, Vol. 90(1), pp. 52-73, 1982.

BLACK, Sandra E.; DEVEREUX, Paul J.; SALVANES, Kjell G. The more the merrier? The effect of family size and birth order on children's education. The Quarterly Journal of Economics, p. 669-700, 2005.

BREEN, Richard., Luijkx, R., Müller, W., \& Pollak, R. Nonpersistent Inequality in Educational Attainment: Evidence from Eight European Countries1. American Journal of Sociology, v. 114, n. 5, p. 1475-1521, 2009.

BREEN, Richard; SIGNE Hald Andersen. Educational Assortative Mating and Income Inequality in Denmark. Demography, 49(3): 867-887, 2012.

BROWNING, Martin; CHIAPPORI, Pierre-Andre; WEISS, Yoram.; Family economics. Tel Aviv University, unpublished textbook manuscript, 2011.

CARNEIRO, P.; J. HECKMAN and D. MASTEROV; Labor Market Discrimination and Racial Differences in Premarket Factors, Journal of Law and Economics, Vol. 48(1), pp. 140, 2005.

CESAR, C. C.; SOARES, J. F. Desigualdades acadêmicas induzidas pelo contexto escolar. Revista brasileira de estudos de população, v. 18, n. 1-2, p. 97-110, 2001.

CRESPO, Anna Risi Vianna; FERREIRA, Francisco H. G. Desigualdade entre Raças e Gêneros: uma análise com simulações contra-factuais. Dissertação de Mestrado Departamento de Economia, Pontifícia Universidade Católica do Rio de Janeiro. Rio de Janeiro. 2003. 
DUNCAN, Brian; STEPHEN J. Trejo. 2011. Intermarriage and the Intergenerational Transmission of Ethnic Identity and Human Capital for Mexican Americans. Journal of Labor Economics, 29(2): 195-227, 2011.

EMERSON, Patrick M.; SOUZA, Andre Portela. Bargaining over Sons and Daughters: Child labor, school attendance and intra-household gender bias in Brazil. Working Paper, 2002.

FRANCIS, Andrew M.; Can interracial marriage eliminate racial inequality? How marriage patterns of one generation affect educational outcomes of the next. Working Paper, Emory University, 2014.

FRANCIS, Andrew M.; PIANTO, Maria Tannuri. The Redistributive Equity of Affirmative Action: Exploring the Role of Race, Socioeconomic Status, and Gender in College Admissions. Economics of Education Review, 31(1): 45-55, 2012.

FISMAN, Raymond Iyengar, S. S., KAMENICA, E., \& SIMONSON, I.; Gender differences in mate selection: Evidence from a speed dating experiment. The Quarterly Journal of Economics, p. 673-697, 2006.

FOGUEL, M. N. \& AZEVEDO, J. P. Uma Decomposição da Desigualdade de Rendimentos do Trabalho no Brasil: 1984-2005, Texto de Discussão 1247, Instituto de Pesquisa Econômica Aplicada - IPEA, 2006.

FU, Xuanning. Interracial marriage and family socio-economic well-being: Equal status exchange or caste status exchange?, Social Science Journal, 45(1): 132-155, 2008.

FU, X. e HEATON, T. B.; Racial and Educational Homogamy: 1980 to 2000. Sociological Perspectives, Vol. 51, No. 4 pp. 735-758, 2008.

FURTADO, Delia. Human capital and interethnic marriage decisions. Economic inquiry, v. 50, n. 1, p. 82-93, 2012.

GONÇALVES, F. de O.; FRANÇA, M. T. A. Transmissão intergeracional de desigualdade e qualidade educacional: avaliando o sistema educacional brasileiro a partir do SAEB 2003. Ensaio: avaliação e políticas públicas em educação, v. 16, n. 61, p. 639-662, 2008.

HECKMAN, J.; Detecting Discrimination. The Journal of Economic Perspectives, Vol. 12(2), Spring, pp. 101-116, 1998.

HOFF, Karla; PANDEY, Priyank.; Discrimination, Social Identity, and Durable Inequalities. The American Economic Review, Vol. 96, No. 2, pp. 206-211, 2006.

IBGE. Pesquisa Nacional de Amostra por Domicílio, (Banco de dados) Rio de Janeiro: 2002. Disponível em:

<ftp://ftp.ibge.gov.br/Trabalho_e_Rendimento/Pesquisa_Nacional_por_Amostra_de_Domicil ios_anual/>. Acesso em: 10 maio 2014.

IBGE. Pesquisa Nacional de Amostra por Domicílio, (Banco de dados) Rio de Janeiro: 2012. Disponível em:

<ftp://ftp.ibge.gov.br/Trabalho_e_Rendimento/Pesquisa_Nacional_por_Amostra_de_Domicil ios_anual/>. Acesso em: 10 maio 2014.

JUHN, c., MURPHY, K. M. and PIERCE, B.; Accounting for the slowdown in black-white wage convergence.; Workers and their Wages. Washington DC: AEI Press, pp. 107-43, 1991.

.; Wage inequality and the rise in returns to skill. Journal of Political Economy, 101(3):410 - 442, 1993. 
KALMIJN, Matthijs.; Intermarriage and homogamy: Causes, patterns, trends. Annual Review of Sociology, 24: 395-421, 1998.

KAUSHAL, Neeraj; MAGNUSON, Katherine; WALDFOGEL, Jane.; How is family income related to investments in children's learning?. Russell Sage Foundation, 2011.

LAM, David.; Marriage markets and assortative mating with household public goods: Theoretical results and empirical implications. Journal of Human resources, p. 462-487, 1988.

LEWIS, Susan K.; Valerie K. OPPENHEIMER, Educational Assortative Mating across Marriage Markets: Non-Hispanic Whites in the United States, Demography, (37) - 29-40, 2000 .

MARTELETO, Leticia J. Educational Inequality by Race in Brazil, 1982-2007: Structural Changes and Shifts in Racial Classification. Demography, 49(1): 337-358, 2012.

MEDEIROS, Marcelo; OLIVEIRA, Luis Felipe Batista de.; Potencial de convergência regional em educação no Brasil. Texto de Discussão 1888, Instituto de Pesquisa Econômica Aplicada - IPEA, 2013.

MONSUETO, Sandro Eduardo. Distribuição de renda no Brasil: a situação dos $25 \%$ mais pobres. Dissertação apresentada ao curso de mestrado do Centro de Desenvolvimento e Planejamento Regional da Faculdade de Ciências Econômicas da Universidade Federal de Minas Gerais, 2003.

NEAL, D.; e W. JOHNSON; The Role of Premarket Factors in Black-White Wage Differences, Journal of Political Economy, University of Chicago Press, Vol. 104(5), October, pp. 869-895, 1996.

OSÓRIO, R. A desigualdade racial de renda no Brasil: 1976-2006. Brasília, tese de doutorado em Sociologia, UnB, 2009.

QIAN, Z.; .Changes in Assortative Mating: The Impact of Age and Education. Demography, 35(3):279.292, 1998.

RANGEL, Marcos A. Is parental love colorblind?: allocation of resources within mixed families. Chicago: Harris School of Public Policy, University of Chicago, 2007.

RIBEIRO, C. A. C.; SILVA, N. V. Cor, educação e casamento: tendência da seletividade marital no Brasil, 1960 a 2000. Dados: revista de ciências sociais, Rio de Janeiro, v. 52, n. 1, p.7-51, 2009.

SCHWARTZ, Christine R.; ROBERT D. Mare. Trends in educational assortative marriage from 1940 to 2003. Demography, 42(4): 621-646, 2003.

SCHWARTZMAN, L. F.; Does Money Whiten? Intergenerational Changes in Racial Classification in Brazil. American Sociological Review, VOL. 72 (December: 940-963), 2007.

SILVA, N. V. Duas Décadas de Seletividade Marital Educacional no Brasil", in C. Hasenbalg e N. do V. Silva (orgs.),Origens e Destinos: Desigualdades Sociais ao Longo da Vida. Rio de Janeiro, Topbooks. 2003.

SILVA, N. do V.; HASENBALG, C. Tendências da desigualdade educacional no Brasil. Dados, v. 43, n. 3, p. 423-445, 2000. 
TELLES, Edward E. Race in Another America: The Significance of Skin Color in Brazil. Princeton, Princeton University Press, 2004.

TORCHE, Florencia.; Educational Assortative Mating and Economic Inequality: A Comparative Analysis of Three Latin American Countries. Demography, 47(2): 481-502, 2010

WONG, Linda Y.; Why do only 5:5\% of black men marry white women?, International Economic Review, 44(3):803.826, 2003. 


\section{Anexos}

Tabela A1- Nível educacional dos pais de casamento inter-racial Branco-Pardo dos jovens de 14 a 17 anos

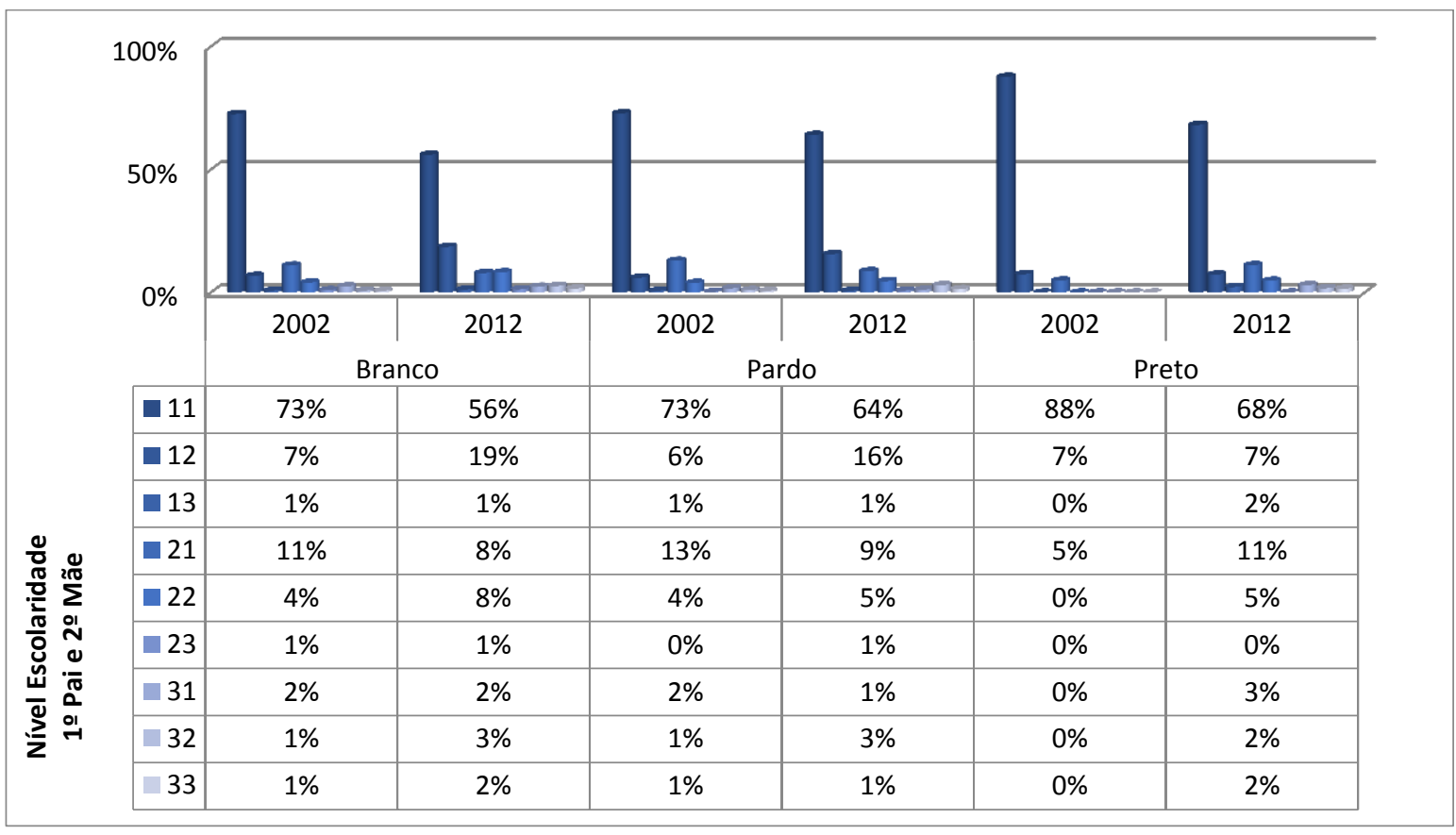

Fonte: Criado pela autora a partir das informações da PNAD.

Legenda - 1 Nível fundamental; 2 - Nível médio; 3 - Nível Superior

Tabela A2 - Nível educacional dos pais de casamento inter-racial Branco-Preto dos jovens de 14 a 17 anos

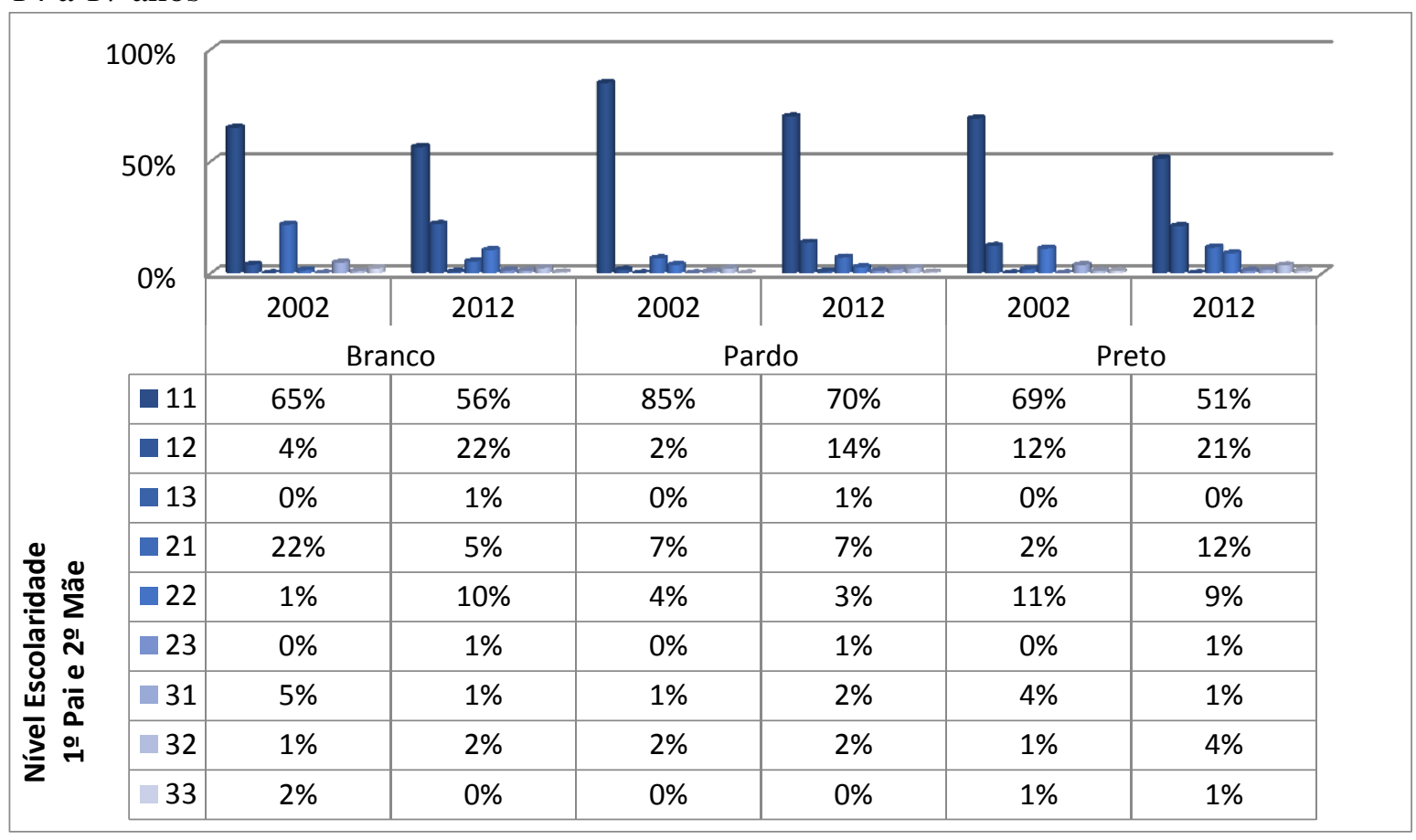

Fonte: Criado pela autora a partir das informações da PNAD.

Legenda - 1 Nível fundamental; 2 - Nível médio; 3 - Nível Superior 
Tabela A3 - Nível educacional dos pais de casamento inter-racial Pardo-Preto dos jovens de 14 a 17 anos

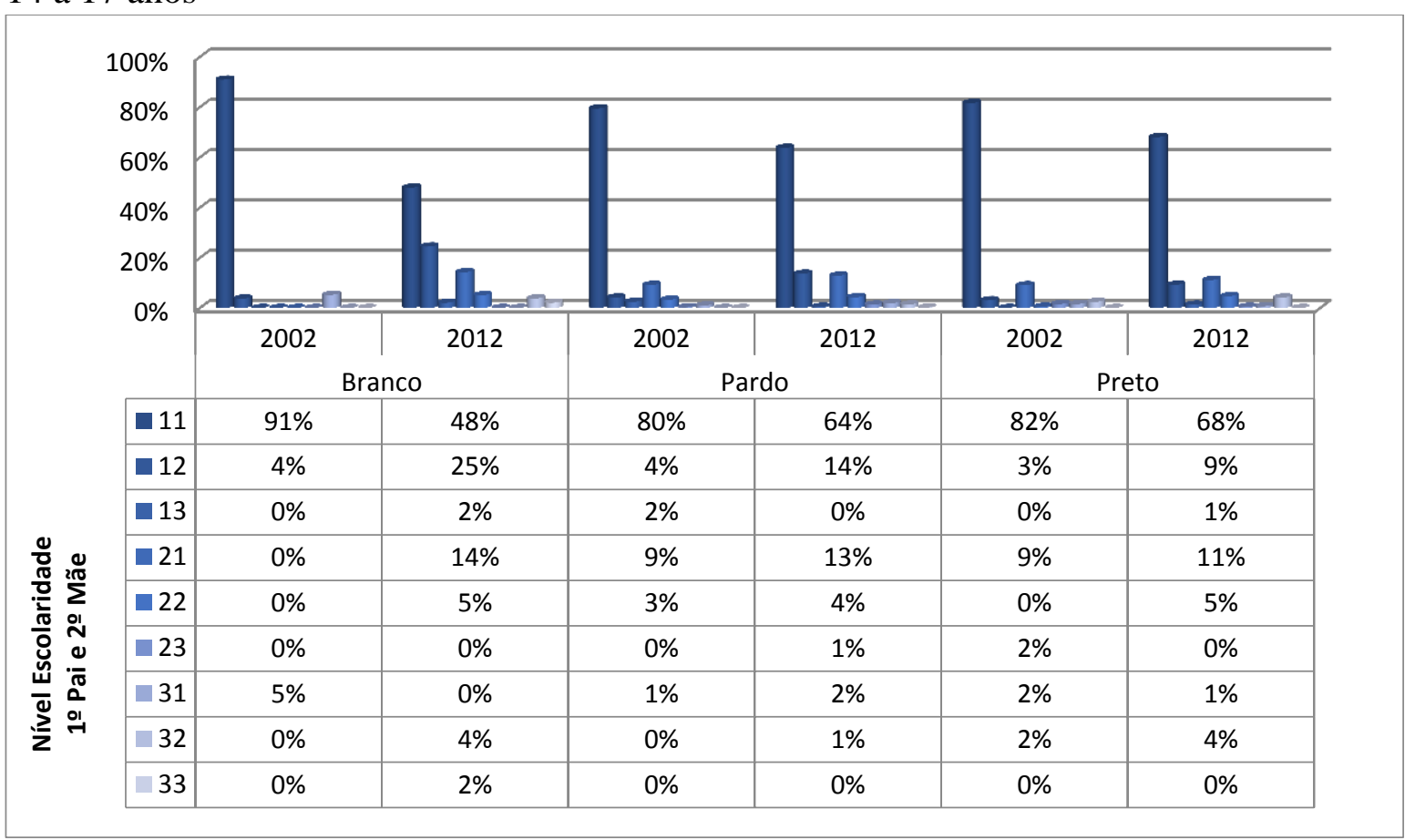

Fonte: Criado pela autora a partir das informações da PNAD.

Legenda - 1 Nível fundamental; 2 - Nível médio; 3 - Nível Superior 
Tabela A4- Classe social por tipo de casamento e classificação racial dos jovens de 14 a 17 anos

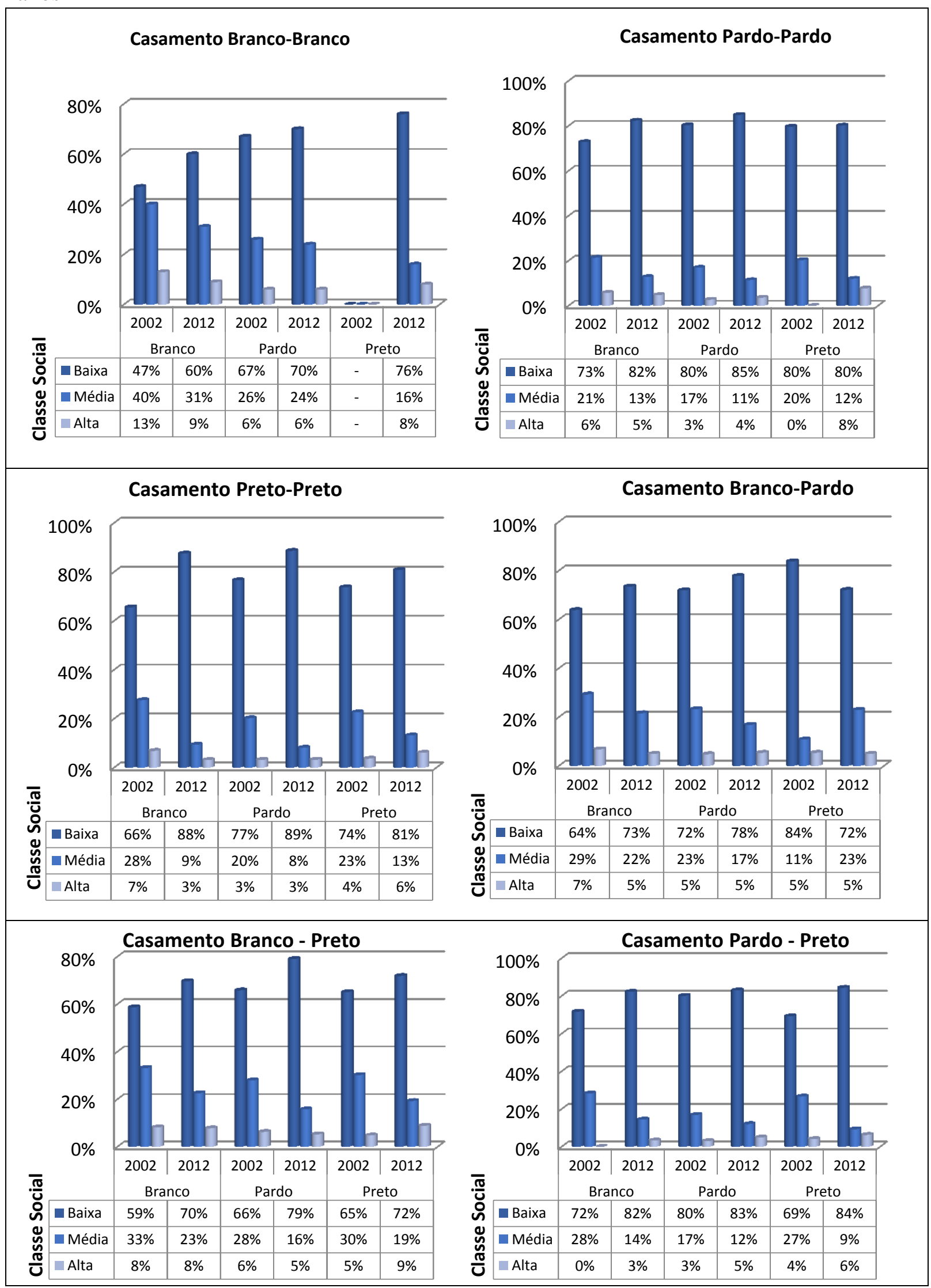

Fonte: Criado pela autora a partir das informações da PNAD. 
Tabela A5 - Tabulação total da variável atraso escolar dos jovens de 14 a 17 anos

Raça do Filho

\begin{tabular}{l|c|c|c|c|c|c}
\hline \multirow{2}{*}{ Tipo de Casamento } & \multicolumn{2}{|c|}{ Branco } & \multicolumn{2}{c|}{ Pardo } & \multicolumn{2}{c}{ Preto } \\
& 2002 & 2012 & 2002 & 2012 & 2002 & 2012 \\
\hline Branco-Branco & 1494 & 1793 & 1128 & 1249 & 136 & 140 \\
Branco-Pardo & 1161 & 1243 & 1215 & 1235 & 175 & 198 \\
Branco-Preto & 1167 & 1165 & 1181 & 1265 & 1147 & 1259 \\
Pardo-Pardo & 1508 & 1603 & 1513 & 1645 & 1106 & 1246 \\
Pardo-Preto & 187 & 185 & 1328 & 1349 & 1171 & 1194 \\
Preto-Preto & 1139 & 1188 & 1122 & 1181 & 1401 & 1651 \\
\hline
\end{tabular}

Fonte: Criado pela autora a partir dos dados da PNAD. 
Tabela A6 - Resultados das regressões dos jovens de 14 a 17 anos - tipo de casamento como referência

\begin{tabular}{|c|c|c|c|c|c|c|}
\hline \multirow{3}{*}{ Variáveis } & \multicolumn{3}{|c|}{2002} & \multicolumn{3}{|c|}{2012} \\
\hline & \multicolumn{3}{|c|}{ Tipos de Casamento } & \multicolumn{3}{|c|}{ Tipos de Casamento } \\
\hline & Branco & $\begin{array}{l}\text { Inter- } \\
\text { racial }\end{array}$ & Preto & Branco & $\begin{array}{l}\text { Inter- } \\
\text { racial }\end{array}$ & Preto \\
\hline \multirow[t]{2}{*}{ Filho Pardo } & 0.457 ** & $0.418^{*}$ & $0.332 *$ & 0.003 & $0.050^{*}$ & $1.258 * *$ \\
\hline & $(0.22)$ & $(0.13)$ & $(0.06)$ & $(0.42)$ & $(0.10)$ & $(0.60)$ \\
\hline \multirow[t]{2}{*}{ Filho Preto } & 0.394 & $0.825^{*}$ & $0.535^{*}$ & 0.399 & $0.320 *$ & $1.386 * *$ \\
\hline & $(0.55)$ & $(0.32)$ & $(0.13)$ & $(0.37)$ & $(0.21)$ & $(0.54)$ \\
\hline \multirow[t]{2}{*}{ Lnrend } & $-0.130 *$ & -0.007 & $-0.011 * * *$ & $-0.030 * * *$ & $-0.148^{*}$ & $-0.180 * *$ \\
\hline & $(0.03)$ & $(0.01)$ & $(0.01)$ & $(0.02)$ & $(0.04)$ & $(0.09)$ \\
\hline \multirow[t]{2}{*}{ Pai_educ_primário } & 0.171 & 0.041 & $0.293^{*}$ & 0.089 & $0.263 * *$ & 0.063 \\
\hline & $(0.12)$ & $(0.11)$ & $(0.09)$ & $(0.28)$ & $(0.12)$ & $(0.34)$ \\
\hline \multirow[t]{2}{*}{ Pai_educ_médio } & $-0.197 * * *$ & $-0.328 *$ & $-0.240^{*}$ & -0.089 & $-0.235 * * *$ & $-1.010 * *$ \\
\hline & $(0.11)$ & $(0.07)$ & $(0.07)$ & $(0.20)$ & $(0.13)$ & $(0.40)$ \\
\hline \multirow[t]{2}{*}{ Pai_educ_superior } & $-0.260 * *$ & $-0.405^{*}$ & $-0.217 * * *$ & -0.242 & $-0.153 * *$ & $0.591 * *$ \\
\hline & $(0.13)$ & $(0.08)$ & $(0.12)$ & $(0.38)$ & $(0.23)$ & $(1.41)$ \\
\hline \multirow[t]{2}{*}{ Mãe_educ_primário } & $0.495^{* *}$ & $0.507 * *$ & $0.540^{*}$ & $0.223^{* *}$ & $0.865^{*}$ & $0.647 *$ \\
\hline & $(0.20)$ & $(0.24)$ & $(0.15)$ & $(0.44)$ & $(0.19)$ & $(0.50)$ \\
\hline \multirow[t]{2}{*}{ Mãe_educ_médio } & $-0.199 * * *$ & $-0.204 *$ & $-0.240^{*}$ & $-0.429 * *$ & $-0.576^{*}$ & 0.991 \\
\hline & $(0.12)$ & $(0.06)$ & $(0.07)$ & $(0.20)$ & $(0.18)$ & $(0.90)$ \\
\hline \multirow[t]{2}{*}{ Mãe_educ_superior } & $-0.462 *$ & $-0.216^{* *}$ & $-0.281 * *$ & $-1.527 *$ & $-1.151^{*}$ & $-0.911 * * *$ \\
\hline & $(0.12)$ & $(0.09)$ & $(0.13)$ & $(0.26)$ & $(0.22)$ & $(0.52)$ \\
\hline \multirow[t]{2}{*}{ RNorte } & $0.445^{*}$ & $0.627^{*}$ & $0.386^{*}$ & 0.206 & $1.192 *$ & $3.010^{*}$ \\
\hline & $(0.16)$ & $(0.21)$ & $(0.09)$ & $(0.36)$ & $(0.16)$ & $(0.57)$ \\
\hline \multirow[t]{2}{*}{ RNordeste } & $0.366 * *$ & $0.309^{*}$ & $0.337^{*}$ & $0.398 * * *$ & $1.082 *$ & $1.590^{*}$ \\
\hline & $(0.14)$ & $(0.11)$ & $(0.08)$ & $(0.21)$ & $(0.13)$ & $(0.34)$ \\
\hline \multirow[t]{2}{*}{ RSul } & $-0.062 *$ & $0.121 * * *$ & $0.231 * *$ & $-0.287^{*}$ & $0.551^{*}$ & $0.483^{*}$ \\
\hline & $(0.09)$ & $(0.07)$ & $(0.10)$ & $(0.27)$ & $(0.19)$ & $(0.33)$ \\
\hline \multirow[t]{2}{*}{ RCentro-Oeste } & 0.090 & -0.003 & -0.061 & $-0.101^{*}$ & $0.628^{*}$ & $1.007 * * *$ \\
\hline & $(0.15)$ & $(0.09)$ & $(0.08)$ & $(0.35)$ & $(0.15)$ & $(0.58)$ \\
\hline \multirow[t]{2}{*}{ H_Trab_Mae } & 0.548 & -0.084 & $0.306^{* *}$ & 0.646 & -0.065 & 0.000 \\
\hline & $(0.36)$ & $(0.23)$ & $(0.14)$ & $(0.46)$ & $(0.32)$ & (.) \\
\hline \multirow[t]{2}{*}{ Urbana $=1$} & $-0.466 * *$ & 0.143 & -0.164 & $-0.837 *$ & $-0.788 * *$ & -0.560 \\
\hline & $(0.22)$ & $(0.13)$ & $(0.12)$ & $(0.31)$ & $(0.35)$ & $(0.83)$ \\
\hline \multirow[t]{2}{*}{ Idade Pai } & -0.010 & 0.009 & -0.015 & -0.011 & -0.006 & -0.028 \\
\hline & $(0.01)$ & $(0.01)$ & $(0.01)$ & $(0.04)$ & $(0.01)$ & $(0.04)$ \\
\hline \multirow[t]{2}{*}{ Idade Mãe } & $-0.017 * * *$ & $-0.014 * * *$ & $-0.005 * *$ & $-0.047 * *$ & $-0.012 * *$ & $0.049 * *$ \\
\hline & $(0.01)$ & $(0.01)$ & $(0.01)$ & $(0.04)$ & $(0.02)$ & $(0.04)$ \\
\hline \multirow[t]{2}{*}{ Constante } & $3.967^{*}$ & $2.888 *$ & $3.605^{*}$ & $5.997 *$ & $4.621 *$ & 1.628 \\
\hline & $(0.58)$ & $(0.36)$ & $(0.31)$ & $(1.15)$ & $(0.82)$ & $(1.61)$ \\
\hline R2 & 0.0909 & 0.0649 & 0.0700 & 0.1467 & 0.1692 & 0.2712 \\
\hline R2 Ajustado & 0.0834 & 0.0587 & 0.0661 & 0.1118 & 0.1615 & 0.2174 \\
\hline $\mathrm{N}^{\circ}$ Observações & 2074 & 2614 & 4076 & 2434 & 1856 & 1234 \\
\hline $\mathrm{F}$ & 14.5923 & 9.5005 & 15.5047 & 7.0102 & 20.4645 & 6.9664 \\
\hline
\end{tabular}

Fonte: Criado pela autora a partir dos dados da PNAD

Nota: Erros padrão entre parênteses e Nível de significância: *** $\mathrm{p}<0.10, * * \mathrm{p}<0.05, * \mathrm{p}<0.01$ 
Tabela A7 - Resultados das regressões dos jovens de 14 a 17 anos - ano 2012 como referência

\begin{tabular}{|c|c|c|}
\hline \multirow{2}{*}{ Variáveis } & \multicolumn{2}{|c|}{ Ano } \\
\hline & 2002 & 2012 \\
\hline \multirow[t]{2}{*}{ Filho Pardo } & $0.375^{*}$ & 0.000 \\
\hline & $(0.05)$ & (.) \\
\hline \multirow[t]{2}{*}{ Filho Preto } & $0.555^{*}$ & 0.000 \\
\hline & $(0.11)$ & (.) \\
\hline \multirow[t]{2}{*}{ Casamento inter-racial } & $-0.073 * *$ & $-0.128 *$ \\
\hline & $(0.06)$ & $(0.04)$ \\
\hline \multirow[t]{2}{*}{ Casamento intra-racial PrPr } & -0.235 & $-0.137 * *$ \\
\hline & $(0.16)$ & $(0.11)$ \\
\hline \multirow[t]{2}{*}{ Lnrend } & $-0.151^{*}$ & $-0.014^{*}$ \\
\hline & $(0.02)$ & $(0.00)$ \\
\hline \multirow[t]{2}{*}{ Pai_educ_primário } & $0.244^{*}$ & $0.417^{*}$ \\
\hline & $(0.08)$ & $(0.07)$ \\
\hline \multirow[t]{2}{*}{ Pai_educ_médio } & $-0.148 * *$ & $0.173^{*}$ \\
\hline & $(0.07)$ & $(0.05)$ \\
\hline \multirow[t]{2}{*}{ Pai_educ_superior } & $-0.259 *$ & -0.006 \\
\hline & $(0.08)$ & $(0.05)$ \\
\hline \multirow[t]{2}{*}{ Mãe_educ_primário } & $1.717^{*}$ & $1.008^{*}$ \\
\hline & $(0.13)$ & $(0.11)$ \\
\hline \multirow[t]{2}{*}{ Mãe_educ_médio } & $0.840^{*}$ & $0.384^{*}$ \\
\hline & $(0.09)$ & $(0.06)$ \\
\hline \multirow[t]{2}{*}{ Mãe_educ_superior } & $0.360 *$ & 0.084 \\
\hline & $(0.10)$ & $(0.06)$ \\
\hline \multirow[t]{2}{*}{ RNorte } & $0.897 *$ & $0.502 *$ \\
\hline & $(0.07)$ & $(0.05)$ \\
\hline \multirow[t]{2}{*}{ RNordeste } & $1.071^{*}$ & $0.426^{*}$ \\
\hline & $(0.07)$ & $(0.04)$ \\
\hline \multirow[t]{2}{*}{ RSul } & 0.103 & $0.125^{*}$ \\
\hline & $(0.07)$ & $(0.05)$ \\
\hline \multirow[t]{2}{*}{ RCentro-Oeste } & $0.290 *$ & 0.048 \\
\hline & $(0.08)$ & $(0.05)$ \\
\hline \multirow[t]{2}{*}{ H_Trab_Mae } & $0.317 * * *$ & -0.064 \\
\hline & $(0.19)$ & $(0.15)$ \\
\hline \multirow[t]{2}{*}{ Urbana $=1$} & $-0.638^{*}$ & $-0.147 * *$ \\
\hline & $(0.14)$ & $(0.07)$ \\
\hline \multirow[t]{2}{*}{ Idade Pai } & -0.003 & 0.001 \\
\hline & $(0.01)$ & $(0.01)$ \\
\hline \multirow{2}{*}{ Idade Mãe } & $-0.021^{*}$ & $-0.022 *$ \\
\hline & $(0.01)$ & $(0.01)$ \\
\hline \multirow[t]{2}{*}{ Constante } & $3.581^{*}$ & $3.425^{*}$ \\
\hline & $(0.38)$ & $(0.24)$ \\
\hline R2 & 0.2053 & 0.1000 \\
\hline R2 Ajustado & 0.2035 & 0.0987 \\
\hline $\mathrm{N}^{\circ}$ Observações & 8254 & 13891 \\
\hline $\mathrm{F}$ & 95.7844 & 71.0586 \\
\hline
\end{tabular}

Fonte: Criado pela autora a partir dos dados da PNAD.

Nota: Erros padrão entre parênteses e Nível de significância: *** $\mathrm{p}<0.10, * * \mathrm{p}<0.05, * \mathrm{p}<0.01$ 
Tabela A8 - Resultados das regressões dos jovens de 14 a 17 anos - ano 2012 como referência e interação raça e educação dos pais

\begin{tabular}{|c|c|c|}
\hline \multirow{2}{*}{ Variáveis } & \multicolumn{2}{|c|}{ Ano } \\
\hline & 2002 & 2012 \\
\hline \multirow[t]{2}{*}{ Filho Pardo } & $-1.698 *$ & $0.545 * *$ \\
\hline & $(0.35)$ & $(0.23)$ \\
\hline \multirow[t]{2}{*}{ Filho Preto } & $-1.102 * * *$ & 0.000 \\
\hline & $(0.65)$ & (.) \\
\hline \multirow[t]{2}{*}{ lnrend } & $-0.141^{*}$ & $-0.012 * *$ \\
\hline & $(0.02)$ & $(0.01)$ \\
\hline \multirow[t]{2}{*}{ Casamento inter-racial } & $-0.141 * * *$ & $-0.103 * *$ \\
\hline & $(0.07)$ & $(0.05)$ \\
\hline \multirow[t]{2}{*}{ Casamento intra-racial PrPr } & -0.083 & -0.111 \\
\hline & $(0.20)$ & $(0.16)$ \\
\hline \multirow[t]{2}{*}{ Pais raça branca \& Educação fundamental } & $-0.360 *$ & -0.180 \\
\hline & $(0.13)$ & $(0.11)$ \\
\hline \multirow[t]{2}{*}{ Pais raça branca \& Educação médio } & $-0.389 * *$ & $-0.307 * *$ \\
\hline & $(0.17)$ & $(0.12)$ \\
\hline \multirow[t]{2}{*}{ Pais raça branca \& Educação superior } & $-0.369 * *$ & $-0.384^{*}$ \\
\hline & $(0.17)$ & $(0.14)$ \\
\hline \multirow[t]{2}{*}{ Pais raça parda \& Educação primário } & $0.404 * * *$ & 0.000 \\
\hline & $(0.23)$ & $()$. \\
\hline \multirow[t]{2}{*}{ Pais raça parda \& Educação fundamental } & 0.064 & $-0.341^{*}$ \\
\hline & $(0.22)$ & $(0.09)$ \\
\hline \multirow{2}{*}{ Pais raça parda \& Educação médio } & -0.067 & $-0.545^{*}$ \\
\hline & $(0.23)$ & $(0.11)$ \\
\hline \multirow[t]{2}{*}{ Pais raça parda \& Educação superior } & 0.000 & $-0.668^{*}$ \\
\hline & $()$. & $(0.17)$ \\
\hline \multirow{2}{*}{ Pais raça preta \& Educação primário } & -0.104 & $0.924 * * *$ \\
\hline & $(0.56)$ & $(0.56)$ \\
\hline \multirow[t]{2}{*}{ Pais raça preta \& Educação fundamental } & 0.349 & 0.622 \\
\hline & $(0.54)$ & $(0.58)$ \\
\hline \multirow[t]{2}{*}{ Pais raça preta \& Educação médio } & -0.355 & 0.317 \\
\hline & (.) & $(0.56)$ \\
\hline \multirow[t]{2}{*}{ Pais raça preta \& Educação superior } & -0.828 & -0.707 \\
\hline & $(0.61)$ & $(0.58)$ \\
\hline \multirow[t]{2}{*}{ RNorte } & $0.864 *$ & $0.385^{*}$ \\
\hline & $(0.10)$ & $(0.08)$ \\
\hline \multirow[t]{2}{*}{ RNordeste } & $0.881^{*}$ & $0.147 * *$ \\
\hline & $(0.09)$ & $(0.06)$ \\
\hline \multirow[t]{2}{*}{ RSul } & 0.116 & 0.088 \\
\hline & $(0.10)$ & $(0.07)$ \\
\hline \multirow[t]{2}{*}{ RCentro-Oeste } & $0.187 * * *$ & -0.032 \\
\hline & $(0.10)$ & $(0.06)$ \\
\hline \multirow[t]{2}{*}{ H_Trab_Mae } & 0.242 & -0.097 \\
\hline & $(0.33)$ & $(0.16)$ \\
\hline \multirow[t]{2}{*}{ Urbana=1 } & $-0.342 * * *$ & -0.069 \\
\hline & $(0.19)$ & $(0.09)$ \\
\hline Idade Pai & -0.011 & -0.005 \\
\hline & $(0.01)$ & $(0.01)$ \\
\hline
\end{tabular}


Continuação Tabela A8

\begin{tabular}{|c|c|c|}
\hline \multirow[t]{2}{*}{ Idade Mãe } & -0.008 & -0.005 \\
\hline & $(0.01)$ & $(0.01)$ \\
\hline \multirow[t]{2}{*}{ Constante } & $4.662 *$ & $3.900 *$ \\
\hline & $(0.55)$ & $(0.32)$ \\
\hline $\mathrm{R} 2$ & 0.1940 & 0.0749 \\
\hline R2 Ajustado & 0.1870 & 0.0702 \\
\hline $\mathrm{N}^{\mathrm{o}}$ Observações & 3606 & 6233 \\
\hline $\mathrm{F}$ & 29.3336 & 15.0773 \\
\hline
\end{tabular}


Tabela A9 - Decomposição das desigualdades educacionais com interação raça \& educação para jovens de 14 a 17 anos

\begin{tabular}{|c|c|}
\hline Grupo & $2002 \times 2012$ \\
\hline $\begin{array}{c}\text { 1. Características Individuais } \\
\qquad X_{i t} \bar{\beta}_{S}+\bar{F}_{S}^{-1}\left(\theta_{i t} \mid X_{i t}\right)\end{array}$ & -0.10 \\
\hline 1.1. Raça Filho Pardo & $0.03 \nabla$ \\
\hline 1.2. Renda & $-0.02 \Delta$ \\
\hline 1.3. Idade Pai & $-0.011 \wedge$ \\
\hline 1.4. Idade Mãe & $-0.0018 \wedge$ \\
\hline 1.5. Casamento inter-racial & $-0.008 \Delta$ \\
\hline 1.6. Casamento intra-racial preto-preto & $-0.0002 \wedge$ \\
\hline 1.7. Pais raça branca \& Educação fundamental & $0.0034 \nabla$ \\
\hline 1.8. Pais raça branca \& Educação médio & $0.0007 \nabla$ \\
\hline 1.9. Pais raça branca \& Educação superior & $0.0005 \nabla$ \\
\hline 1.8. Pais raça parda \& Educação fundamental & -0.020 \\
\hline 1.10. Pais raça parda \& Educação médio & $-0.015 \Delta$ \\
\hline 1.11. Pais raça parda \& Educação superior & $0.006 \nabla$ \\
\hline 1.12. Pais raça preta \& Educação primária & -0.003 \\
\hline 1.13. Pais raça preta \& Educação fundamental & $-0.004 \Delta$ \\
\hline 1.14. Pais raça preta \& Educação médio & $-0.001 \wedge$ \\
\hline 1.15. Pais raça preta \& Educação superior & $0.00007 \nabla$ \\
\hline 1.16. Horas Trabalhadas - Mãe & $-0.00002 \Delta$ \\
\hline 1.17. Região Norte & $-0.004 \Delta$ \\
\hline 1.18. Região Nordeste & $-0.002 \Delta$ \\
\hline 1.19. Região Sul & $0.001 \nabla$ \\
\hline 1.20. Região Centro Oeste & $0.00008 \nabla$ \\
\hline 1.21. Situação Censitária & $0.003 \nabla$ \\
\hline $\begin{array}{l}\text { 2. Diferença nas respostas (parâmetros) } \\
\qquad X_{i t} \beta_{t}+\bar{F}_{S}^{-1}\left(\theta_{i t} \mid X_{i t}\right)\end{array}$ & $\mathbf{0 . 5 3}$ \\
\hline $\begin{array}{l}\text { 3. Diferença em não observados (resíduos) } \\
\qquad X_{i t} \beta_{t}+F_{t}^{-1}\left(\theta_{i t} \mid X_{i t}\right)\end{array}$ & 0.001 \\
\hline 4. Diferença Total $(1+2+3)$ & 0.43 \\
\hline
\end{tabular}

Fonte: Criado pela autora, a partir dos dados da PNAD 2002 e 2012.

$\Delta$ - As setas vermelhas indicam que as variáveis contribuem para aumentar o diferencial entre os grupos.

$\boldsymbol{\nabla}$ - As setas azuis indicam que as variáveis contribuem para reduzir o diferencial entre os grupos. 
Tabela A10 - Tabulação total da variável atraso escolar dos jovens de 18 a 25 anos

\begin{tabular}{l|c|c|c|c|c|c}
\hline \multicolumn{1}{|c|}{ Raça do Filho } \\
\hline \multirow{2}{*}{ Tipo de Casamento } & \multicolumn{2}{|c|}{ Branco } & \multicolumn{2}{c}{ Pardo } & \multicolumn{2}{c}{ Preto } \\
& 2002 & 2012 & 2002 & 2012 & 2002 & 2012 \\
\hline Branco-Branco & 1231 & 1424 & 1182 & 1156 & 123 & 126 \\
Branco-Pardo & 1131 & 1283 & 1114 & 1126 & 169 & 175 \\
Branco-Preto & 193 & 1124 & 1145 & 1211 & 163 & 172 \\
Pardo-Pardo & 1277 & 1302 & 1223 & 1294 & 1103 & 1109 \\
Pardo-Preto & 191 & 1107 & 1247 & 1318 & 182 & 1145 \\
Preto-Preto & 151 & 169 & 151 & 155 & 1201 & 1254 \\
\hline
\end{tabular}

Fonte: Criado pela autora a partir dos dados da PNAD.

Tabela A11 - Nível educacional de pais de casamento inter-racial Branco-Pardo dos jovens de 18 a 25 anos

\begin{tabular}{|c|c|c|c|c|c|c|c|}
\hline \multirow{2}{*}{\multicolumn{2}{|c|}{$\begin{array}{l}80 \% \\
60 \%\end{array}$}} & & & & & & \\
\hline & & & & & & & \\
\hline & $40 \%$ & & & & & & \\
\hline & $20 \%$ & & & & & & \\
\hline \multirow{11}{*}{ 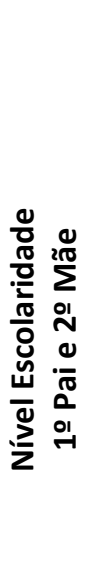 } & \multirow{2}{*}{$0 \%$} & \multirow[t]{2}{*}{2002} & \multirow[t]{2}{*}{2012} & 2002 & \multirow[t]{2}{*}{2012} & 2002 & \multirow[t]{2}{*}{2012} \\
\hline & & & & Pardo & & Preto & \\
\hline & $\square 11$ & $59 \%$ & $48 \%$ & $71 \%$ & $55 \%$ & $72 \%$ & $70 \%$ \\
\hline & - 12 & $7 \%$ & $25 \%$ & $4 \%$ & $16 \%$ & $8 \%$ & $6 \%$ \\
\hline & 13 & $0 \%$ & $0 \%$ & $0 \%$ & $2 \%$ & $0 \%$ & $2 \%$ \\
\hline & $\square 21$ & $25 \%$ & $8 \%$ & $16 \%$ & $12 \%$ & $5 \%$ & $14 \%$ \\
\hline & 22 & $3 \%$ & $12 \%$ & $6 \%$ & $8 \%$ & $3 \%$ & $3 \%$ \\
\hline & 23 & $0 \%$ & $4 \%$ & $0 \%$ & $1 \%$ & $0 \%$ & $1 \%$ \\
\hline & -31 & $2 \%$ & $1 \%$ & $0 \%$ & $3 \%$ & $9 \%$ & $1 \%$ \\
\hline & 32 & $1 \%$ & $2 \%$ & $2 \%$ & $2 \%$ & $2 \%$ & $3 \%$ \\
\hline & 33 & $3 \%$ & $0 \%$ & $1 \%$ & $1 \%$ & $0 \%$ & $0 \%$ \\
\hline
\end{tabular}

Fonte: Criado pela autora a partir das informações da PNAD.

Legenda - 1 Nível fundamental; 2 - Nível médio; 3 - Nível Superior 
Tabela A12 - Nível educacional de pais de casamento inter-racial Branco-Preto dos jovens de 18 a 25 anos

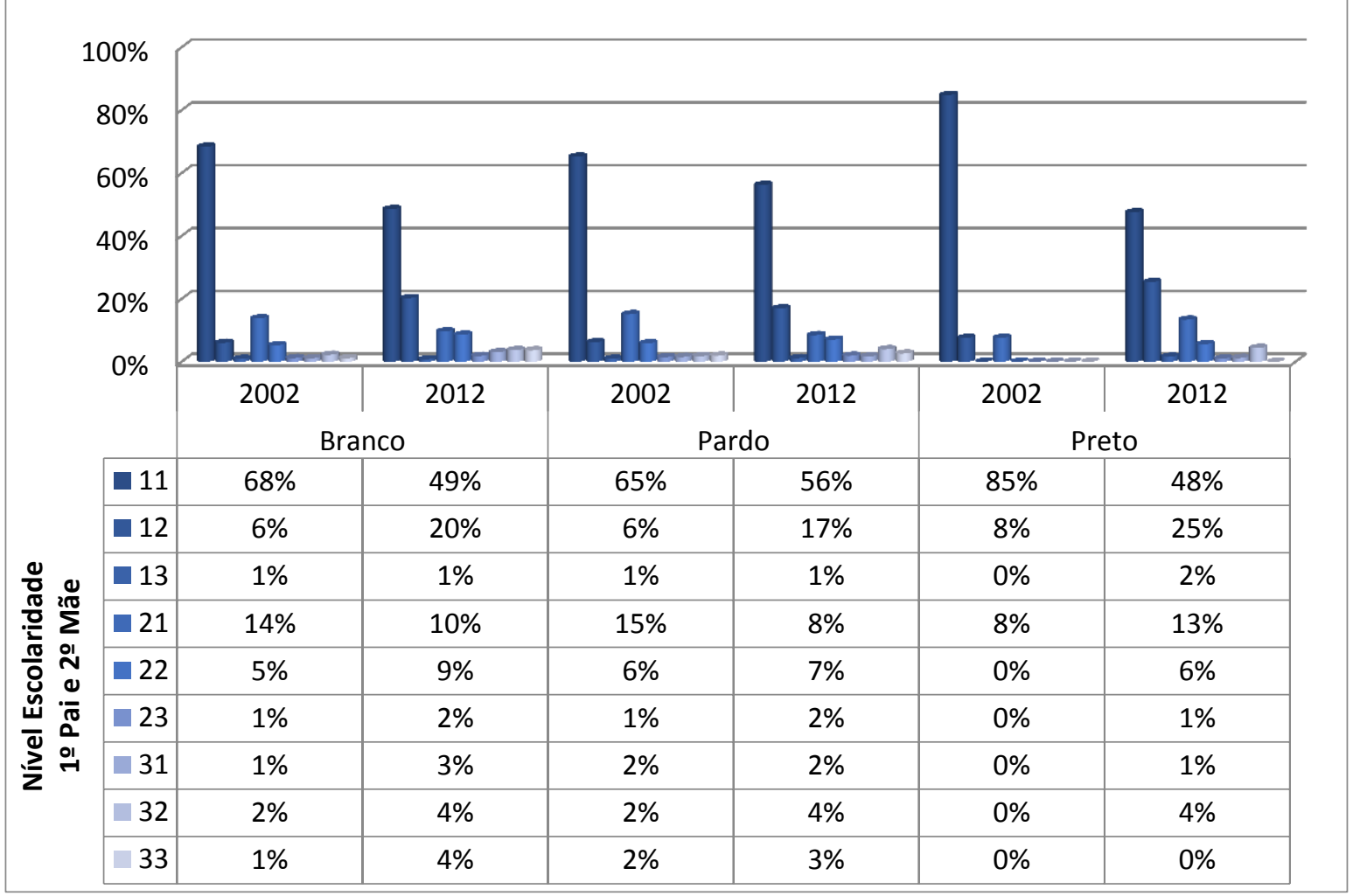

Fonte: Criado pela autora a partir das informações da PNAD.

Legenda - 1 Nível fundamental; 2 - Nível médio; 3 - Nível Superior

Tabela A13 - Nível educacional de pais de casamento inter-racial Preto-Pardo dos jovens de 18 a 25 anos

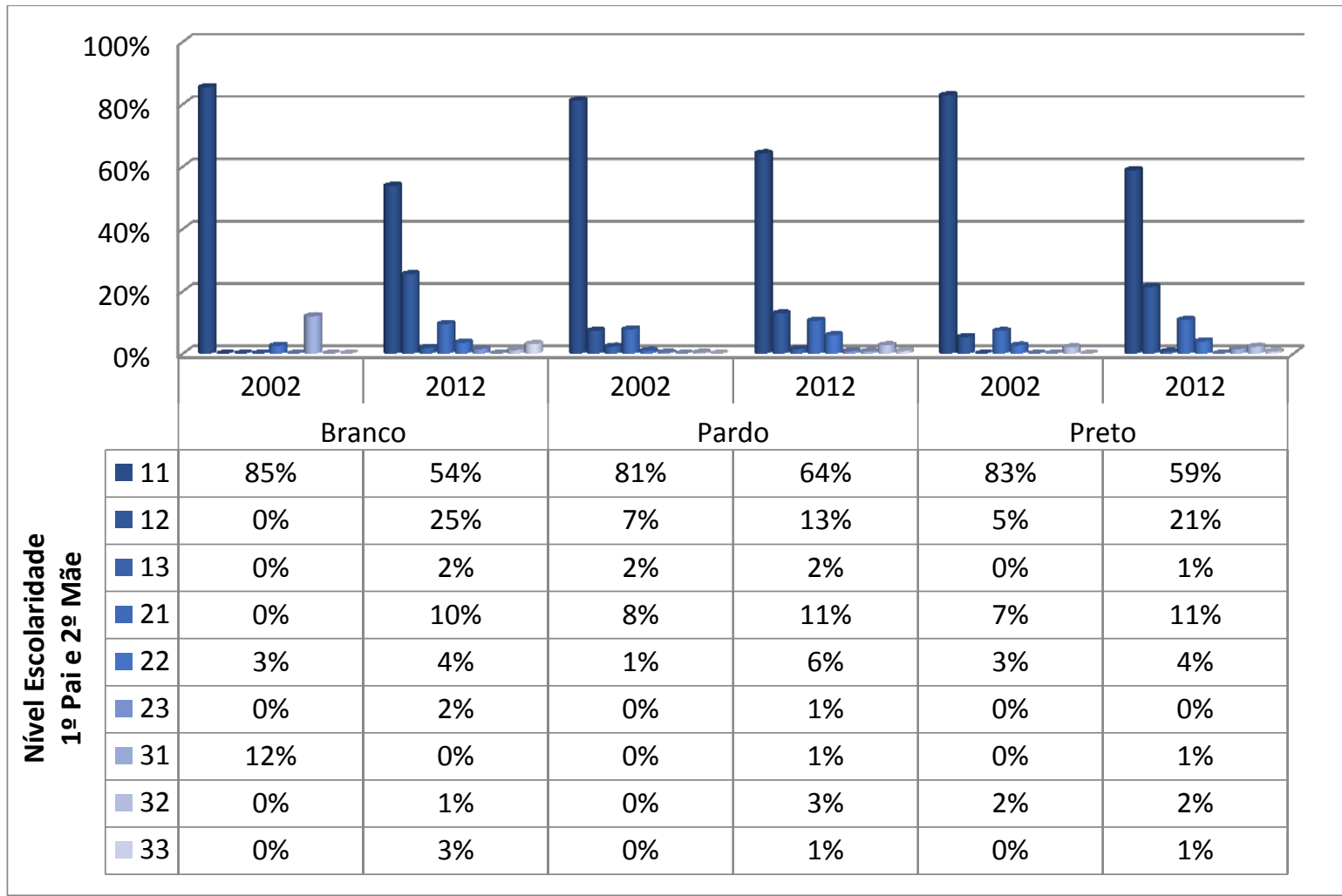

Fonte: Criado pela autora a partir das informações da PNAD.

Legenda - 1 Nível fundamental; 2 - Nível médio; 3 - Nível Superior 
Tabela A14 - Anos de estudos dos filhos de casamento intra-racial Branco-Branco dos jovens de 18 a 25

\begin{tabular}{|c|c|c|c|c|c|c|}
\hline \multicolumn{3}{|c|}{} & \multicolumn{3}{c|}{} \\
\hline
\end{tabular}

Fonte: Criado pela autora, a partir dos dados da PNAD 2002 e 2012. 
Tabela A15 - Anos de estudos dos filhos de casamento intra-racial Pardo-Pardo dos jovens de 18 a 25

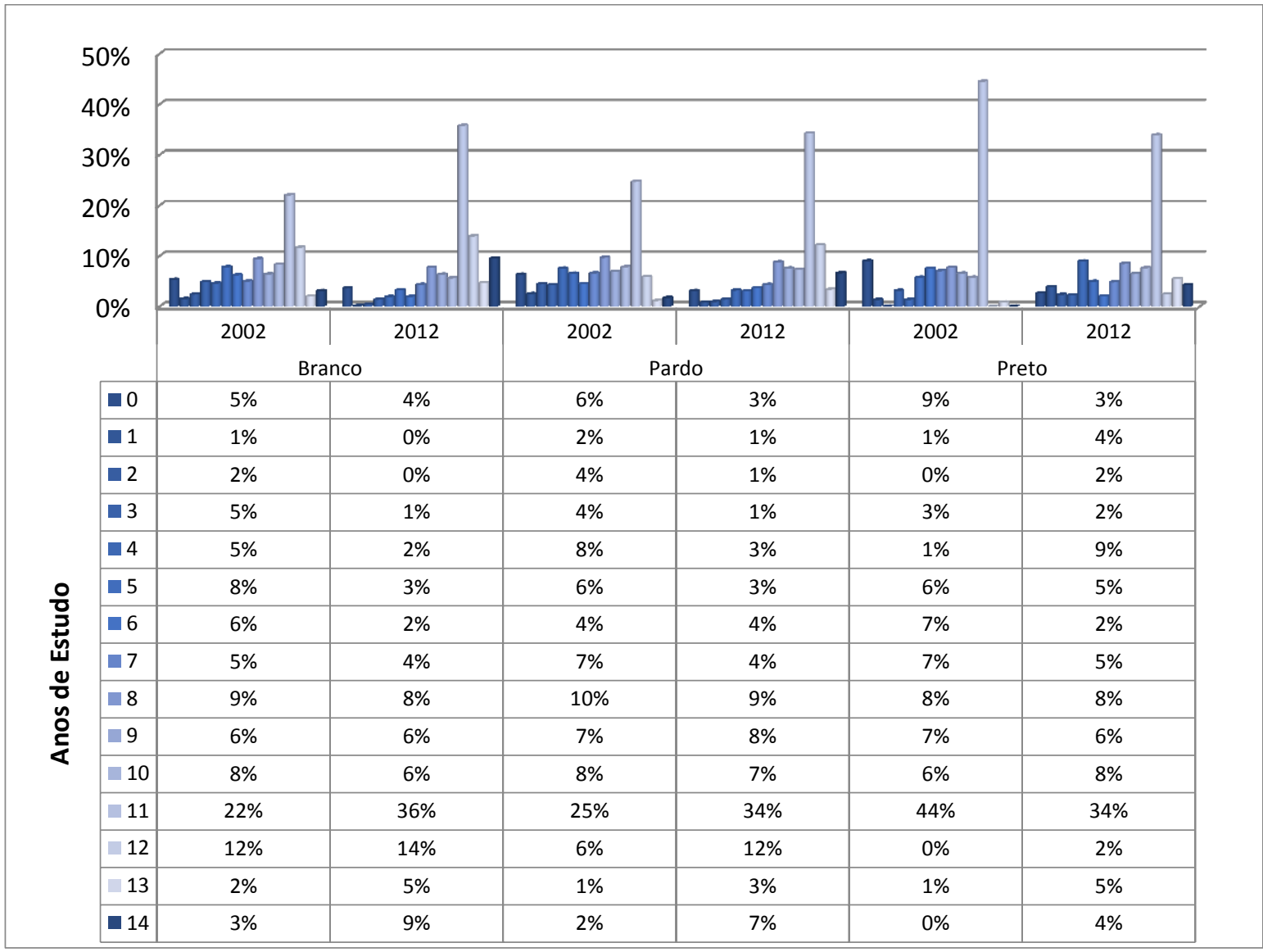

Fonte: Criado pela autora, a partir dos dados da PNAD 2002 e 2012. 
Tabela A16 - Anos de estudos dos filhos de casamento intra-racial Preto-Preto dos jovens de 18 a 25

\begin{tabular}{|c|c|c|c|c|c|c|c|}
\hline & \multicolumn{3}{|c|}{} \\
\hline
\end{tabular}

Fonte: Criado pela autora, a partir dos dados da PNAD 2002 e 2012. 
Tabela A17 - Anos de estudos dos filhos de casamento inter-racial Branco-Pardo dos jovens de 18 a 25

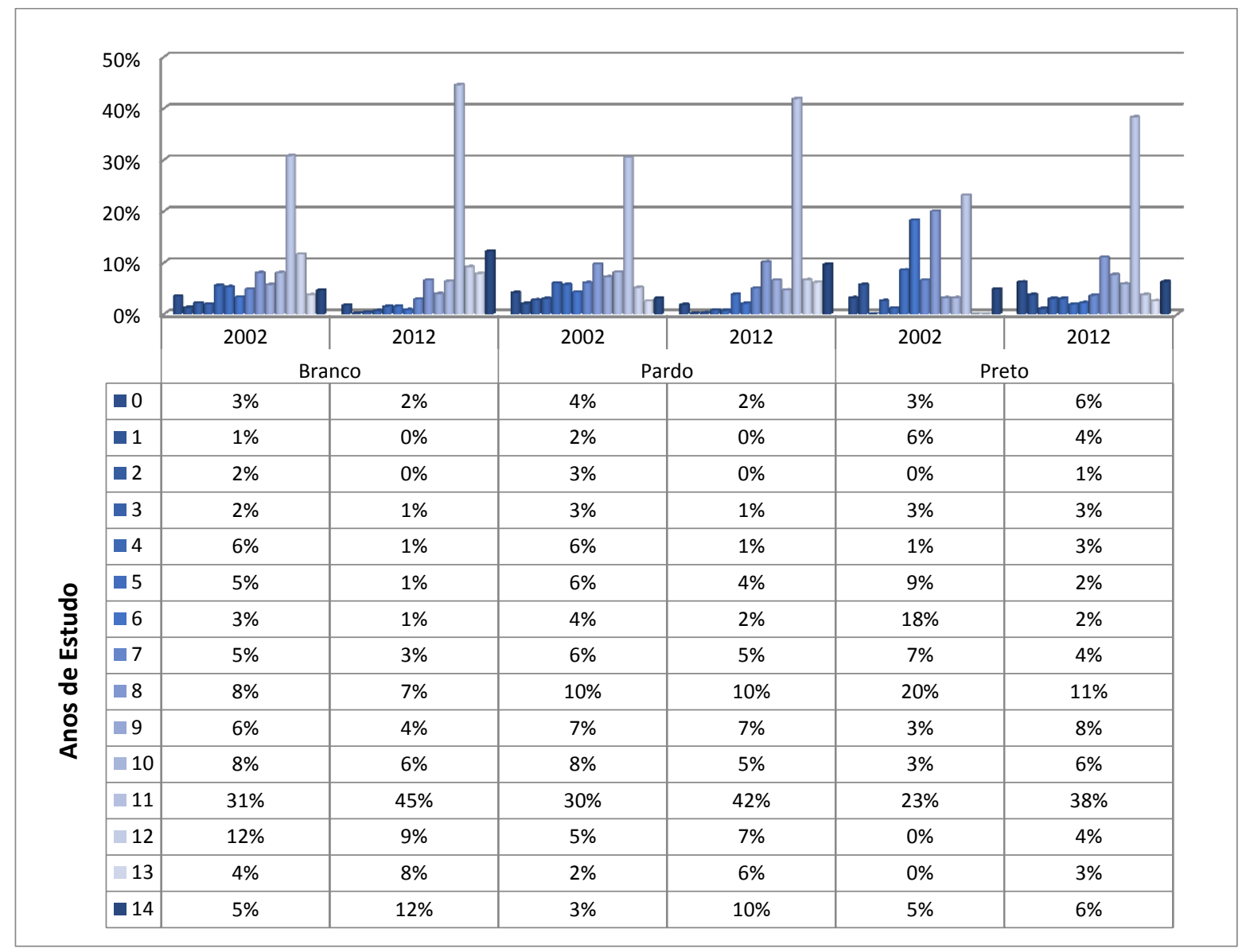

Fonte: Criado pela autora, a partir dos dados da PNAD 2002 e 2012. 
Tabela A18 - Anos de estudos dos filhos de casamento inter-racial Branco-Preto dos jovens de 18 a 25

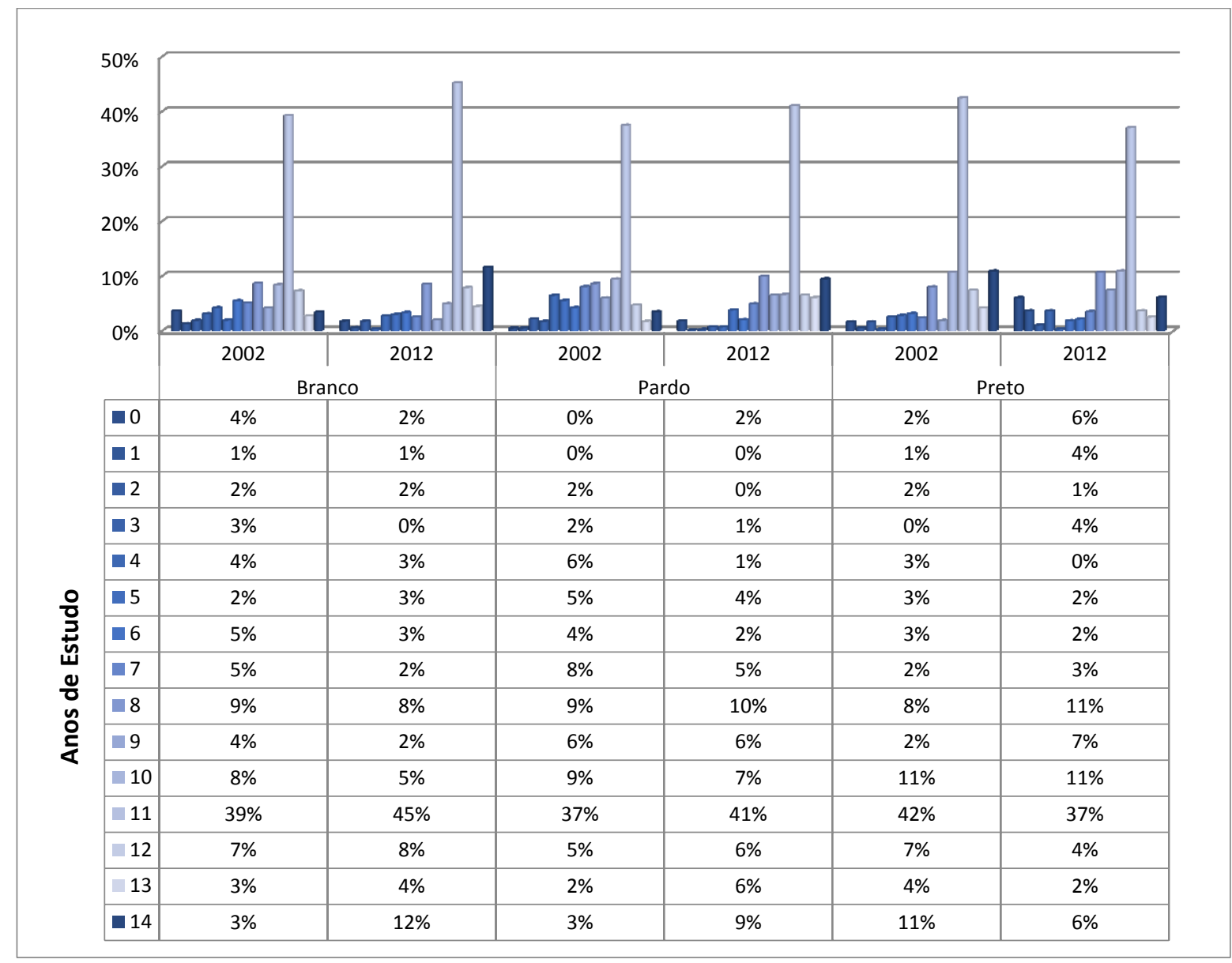

Fonte: Criado pela autora, a partir dos dados da PNAD 2002 e 2012. 
Tabela A19 - Anos de estudos dos filhos de casamento inter-racial Pardo-Preto dos jovens de 18 a 25

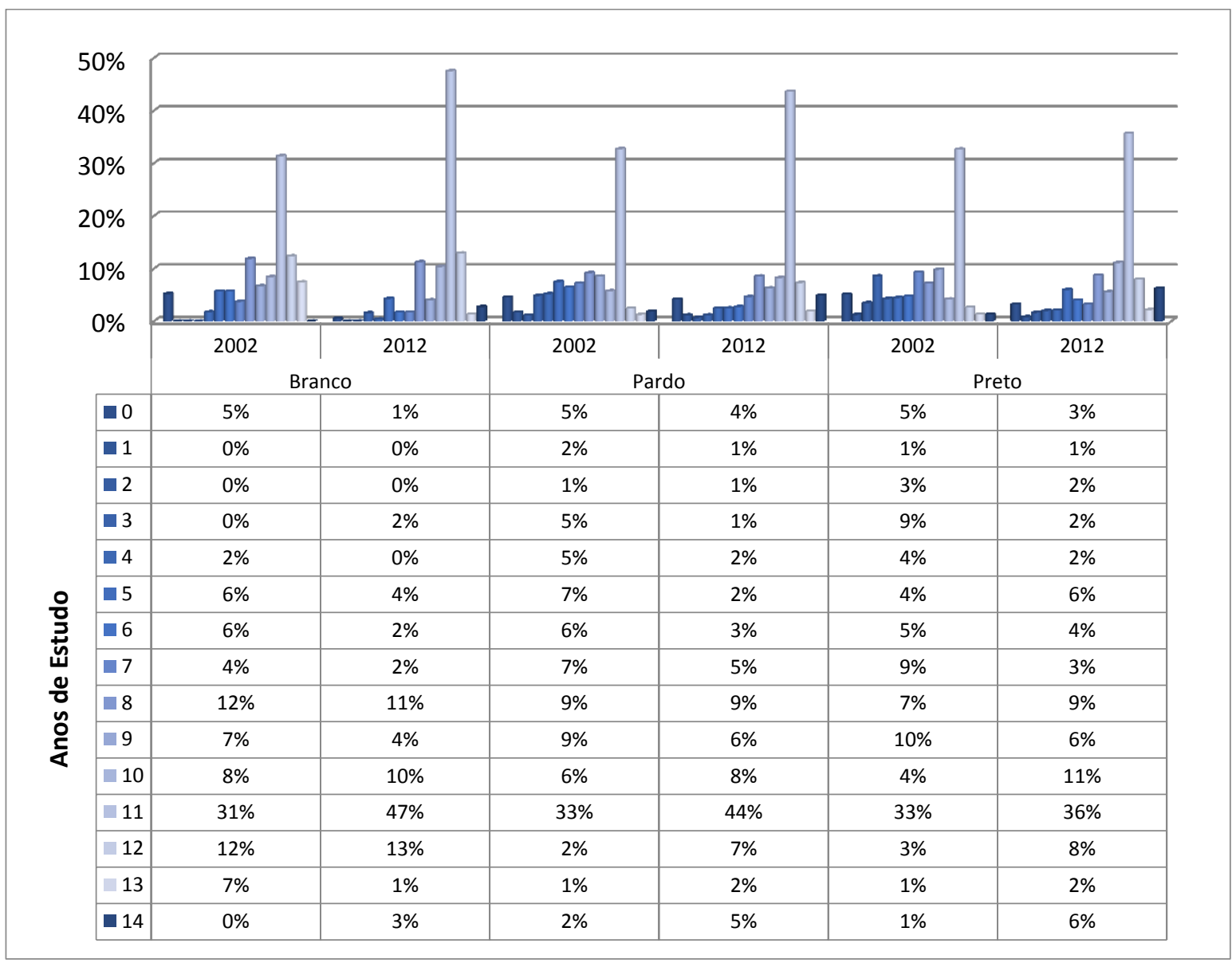


Tabela A20 - Classe social por tipo de casamento e classificação racial dos jovens de 18 a 25 anos

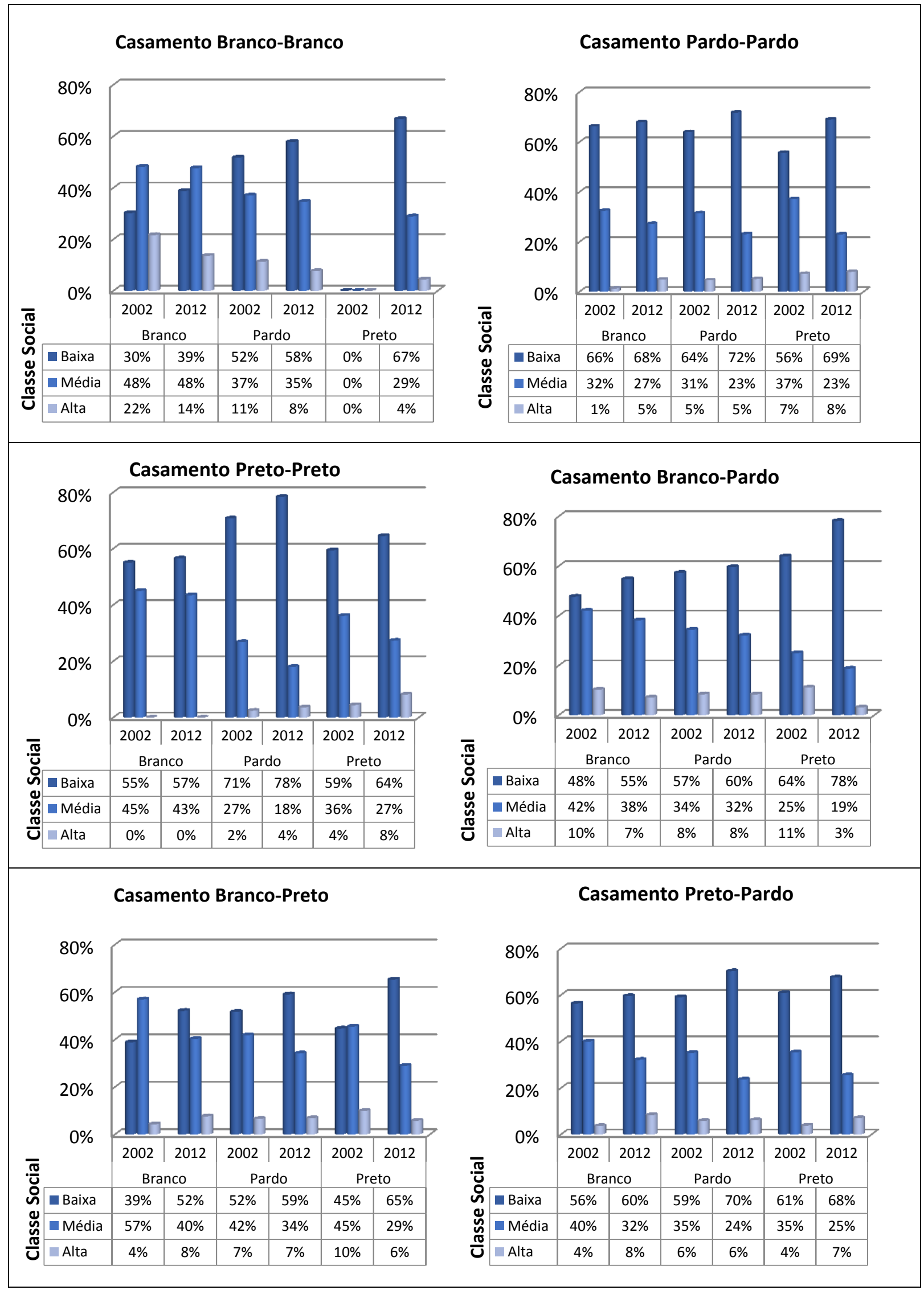

Fonte: Criado pela autora a partir das informações da PNAD. 
Tabela A21 - Resultados das regressões dos jovens de 18 a 25 anos

\begin{tabular}{|c|c|c|c|c|c|c|}
\hline \multirow{3}{*}{ Variáveis } & \multirow{2}{*}{\multicolumn{3}{|c|}{$\begin{array}{c}2002 \\
\text { Tinos de Casamento }\end{array}$}} & \multirow{2}{*}{\multicolumn{3}{|c|}{$\begin{array}{c}2012 \\
\text { Tipos de Casamento }\end{array}$}} \\
\hline & & & & & & \\
\hline & Branco & $\begin{array}{l}\text { Inter- } \\
\text { racial }\end{array}$ & Preto & Branco & $\begin{array}{l}\text { Inter- } \\
\text { racial }\end{array}$ & Preto \\
\hline \multirow[t]{2}{*}{ Filho Pardo } & $0.912 * *$ & 0.124 & $2.896^{* *}$ & 0.411 & $0.412 * *$ & 1.336 \\
\hline & $(0.37)$ & $(0.17)$ & $(1.14)$ & $(0.34)$ & $(0.19)$ & $(1.02)$ \\
\hline \multirow[t]{2}{*}{ Filho Preto } & $1.946^{* *}$ & 0.158 & $1.690^{* *}$ & 1.873 & $1.169 *$ & -0.239 \\
\hline & $(0.78)$ & $(0.31)$ & $(0.85)$ & $(1.37)$ & $(0.38)$ & $(0.62)$ \\
\hline \multirow[t]{2}{*}{ Pchefejovem } & $9.554 * * *$ & $-7.915 * * *$ & $24.074 * * *$ & -13.758 & $-21.639 * * *$ & $18.572 * * *$ \\
\hline & $(11.60)$ & $(14.30)$ & $(53.37)$ & $(10.07)$ & (12.03) & $(47.96)$ \\
\hline \multirow{2}{*}{ Lnrend } & $-0.116^{*}$ & $-0.167 *$ & -0.209 & 0.001 & $-0.030 * *$ & 0.025 \\
\hline & $(0.03)$ & $(0.05)$ & $(0.18)$ & $(0.03)$ & $(0.01)$ & $(0.04)$ \\
\hline \multirow[t]{2}{*}{ Pai_educ_primário } & 0.186 & $0.755^{*}$ & -0.052 & -0.233 & 0.278 & -0.535 \\
\hline & $(0.18)$ & $(0.21)$ & $(0.69)$ & $(0.31)$ & $(0.31)$ & $(0.74)$ \\
\hline \multirow[t]{2}{*}{ Pai_educ_médio } & $-0.337 * *$ & -0.359 & -0.213 & $-0.393 * *$ & -0.171 & -0.263 \\
\hline & $(0.16)$ & $(0.22)$ & $(0.64)$ & $(0.20)$ & $(0.22)$ & $(0.49)$ \\
\hline \multirow{2}{*}{ Pai_educ_superior } & -0.195 & -0.438 & 0.470 & $-0.670^{*}$ & 0.057 & 0.000 \\
\hline & $(0.19)$ & $(0.30)$ & $(1.86)$ & $(0.25)$ & $(0.38)$ & (.) \\
\hline \multirow[t]{2}{*}{ Mãe_educ_primário } & $0.855^{*}$ & $1.642 *$ & $3.513^{*}$ & 0.114 & $1.246^{* *}$ & -0.530 \\
\hline & $(0.32)$ & $(0.30)$ & $(0.70)$ & $(0.48)$ & $(0.50)$ & $(1.34)$ \\
\hline \multirow[t]{2}{*}{ Mãe_educ_médio } & $-0.912 *$ & $-0.854^{*}$ & -0.900 & $-0.480 * *$ & $-0.847^{*}$ & $-0.826 * * *$ \\
\hline & $(0.15)$ & $(0.25)$ & $(1.10)$ & $(0.21)$ & $(0.18)$ & $(0.48)$ \\
\hline \multirow[t]{2}{*}{ Mãe_educ_superior } & $-1.387^{*}$ & $-1.184^{*}$ & $-0.913 * *$ & $-0.687^{*}$ & $-0.094 * *$ & $-0.730 * *$ \\
\hline & $(0.18)$ & $(0.39)$ & $(1.75)$ & $(0.22)$ & $(0.63)$ & $(1.25)$ \\
\hline \multirow[t]{2}{*}{ RNorte } & 0.106 & $0.734^{*}$ & 1.149 & $0.623 * * *$ & -0.018 & -1.562 \\
\hline & $(0.27)$ & $(0.23)$ & $(1.23)$ & $(0.34)$ & $(0.24)$ & $(1.11)$ \\
\hline \multirow[t]{2}{*}{ RNordeste } & 0.325 & $0.756^{*}$ & -0.290 & $0.653 * *$ & $0.499 * *$ & -0.208 \\
\hline & $(0.20)$ & $(0.20)$ & $(0.56)$ & $(0.31)$ & $(0.25)$ & $(0.66)$ \\
\hline \multirow{2}{*}{ RSul } & $0.345 * *$ & $1.010 *$ & 0.501 & -0.085 & 0.185 & 0.059 \\
\hline & $(0.15)$ & $(0.32)$ & $(0.79)$ & $(0.19)$ & $(0.37)$ & $(1.10)$ \\
\hline \multirow[t]{2}{*}{ RCentro-Oeste } & -0.059 & $0.445 * * *$ & 0.214 & 0.103 & 0.208 & $-2.122 * *$ \\
\hline & $(0.20)$ & $(0.27)$ & (1.07) & $(0.36)$ & $(0.35)$ & $(0.85)$ \\
\hline \multirow[t]{2}{*}{ H_Trab_Mae } & $1.220^{*}$ & $1.274 * *$ & 0.000 & 0.240 & 0.228 & $2.026 * * *$ \\
\hline & $(0.31)$ & $(0.50)$ & (.) & $(0.72)$ & $(0.43)$ & $(1.06)$ \\
\hline \multirow[t]{2}{*}{ Urbana $=1$} & $-1.301 *$ & -0.055 & -0.789 & -0.545 & $-0.973 * *$ & -0.678 \\
\hline & $(0.38)$ & $(0.47)$ & $(1.22)$ & $(0.38)$ & $(0.41)$ & $(1.22)$ \\
\hline \multirow[t]{2}{*}{ Idade Pai } & -0.014 & -0.027 & 0.020 & -0.056 & $-0.063 * * *$ & -0.108 \\
\hline & $(0.02)$ & $(0.03)$ & $(0.07)$ & $(0.04)$ & $(0.03)$ & $(0.09)$ \\
\hline \multirow[t]{2}{*}{ Idade Mãe } & -0.030 & -0.034 & 0.004 & 0.031 & 0.001 & 0.022 \\
\hline & $(0.02)$ & $(0.03)$ & $(0.08)$ & $(0.04)$ & $(0.03)$ & $(0.10)$ \\
\hline \multirow[t]{2}{*}{ Constante } & $6.170^{*}$ & $6.477^{*}$ & 3.873 & $5.568^{*}$ & $8.179 *$ & $7.645 * *$ \\
\hline & $(0.82)$ & $(1.18)$ & $(3.27)$ & $(1.10)$ & $(1.14)$ & $(3.32)$ \\
\hline $\mathrm{R} 2$ & 0.1673 & 0.1650 & 0.1968 & 0.1157 & 0.1050 & 0.1371 \\
\hline R2 Ajustado & 0.1585 & 0.1540 & 0.1218 & 0.0889 & 0.0907 & 0.0234 \\
\hline $\mathrm{N}^{\circ}$ Observações & 1717 & 1390 & 900 & 1613 & 1337 & 1147 \\
\hline $\mathrm{F}$ & 18.0478 & 12.5094 & 3.1783 & 4.5842 & 6.1223 & 4.3096 \\
\hline
\end{tabular}

Fonte: Criado pela autora a partir dos dados da PNAD.

Nota: Erros padrão entre parênteses e Nível de significância: *** $\mathrm{p}<0.10, * * \mathrm{p}<0.05, * \mathrm{p}<0.01$ 
Tabela A22 - Resultados das regressões dos jovens de 18 a 25 anos - ano 2012 como referência

\begin{tabular}{|c|c|c|}
\hline \multirow{2}{*}{ Variáveis } & \multicolumn{2}{|c|}{ Ano } \\
\hline & 2002 & 2012 \\
\hline \multirow[t]{2}{*}{ Filho Pardo } & $0.723 *$ & $0.571 *$ \\
\hline & $(0.09)$ & $(0.10)$ \\
\hline \multirow[t]{2}{*}{ Filho Preto } & $0.690^{*}$ & $1.001 *$ \\
\hline & $(0.18)$ & $(0.21)$ \\
\hline \multirow[t]{2}{*}{ Casamento inter-racial } & $-0.226 * *$ & -0.104 \\
\hline & $(0.10)$ & $(0.11)$ \\
\hline \multirow[t]{2}{*}{ Casamento intra-racial $\mathrm{PrPr}$} & 0.253 & -0.242 \\
\hline & $(0.29)$ & $(0.30)$ \\
\hline \multirow[t]{2}{*}{ Pchefejovem } & -6.848 & -5.017 \\
\hline & $(7.29)$ & $(6.24)$ \\
\hline \multirow[t]{2}{*}{ Lnrend } & $-0.205^{*}$ & $-0.017 * * *$ \\
\hline & $(0.02)$ & $(0.01)$ \\
\hline \multirow[t]{2}{*}{ Pai_educ_primário } & $0.593 *$ & 0.236 \\
\hline & $(0.13)$ & $(0.21)$ \\
\hline \multirow[t]{2}{*}{ Pai_educ_médio } & -0.150 & -0.174 \\
\hline & $(0.12)$ & $(0.20)$ \\
\hline \multirow[t]{2}{*}{ Pai_educ_superior } & 0.000 & $-0.492 * *$ \\
\hline & (.) & $(0.24)$ \\
\hline \multirow[t]{2}{*}{ Mãe_educ_primário } & $3.136 *$ & $1.351 *$ \\
\hline & $(0.21)$ & $(0.31)$ \\
\hline \multirow[t]{2}{*}{ Mãe_educ_médio } & $1.615 *$ & $0.483 * *$ \\
\hline & $(0.14)$ & $(0.21)$ \\
\hline \multirow[t]{2}{*}{ Mãe_educ_superior } & $0.599 *$ & -0.085 \\
\hline & $(0.15)$ & $(0.21)$ \\
\hline \multirow[t]{2}{*}{ RNorte } & $0.625^{*}$ & 0.202 \\
\hline & $(0.12)$ & $(0.13)$ \\
\hline \multirow[t]{2}{*}{ RNordeste } & $0.944 *$ & $0.396^{*}$ \\
\hline & $(0.11)$ & $(0.13)$ \\
\hline \multirow[t]{2}{*}{ RSul } & $0.445^{*}$ & -0.030 \\
\hline & $(0.12)$ & $(0.16)$ \\
\hline \multirow[t]{2}{*}{ RCentro-Oeste } & $0.309 * *$ & -0.211 \\
\hline & $(0.13)$ & $(0.18)$ \\
\hline \multirow[t]{2}{*}{ H_Trab_Mae } & $0.592 * *$ & $0.652 * *$ \\
\hline & $(0.25)$ & $(0.30)$ \\
\hline \multirow[t]{2}{*}{ Urbana $=1$} & $-0.769 *$ & $-0.703 *$ \\
\hline & $(0.23)$ & $(0.18)$ \\
\hline \multirow[t]{2}{*}{ Idade Pai } & 0.002 & -0.026 \\
\hline & $(0.01)$ & $(0.02)$ \\
\hline \multirow[t]{2}{*}{ Idade Mãe } & $-0.053^{*}$ & -0.017 \\
\hline & $(0.01)$ & $(0.02)$ \\
\hline \multirow[t]{2}{*}{ Constante } & $5.891 *$ & $5.663 *$ \\
\hline & $(0.58)$ & $(0.62)$ \\
\hline R2 & 0.2058 & 0.0984 \\
\hline R2 Ajustado & 0.2034 & 0.0938 \\
\hline $\mathrm{N}^{\circ}$ Observações & 6419 & 4085 \\
\hline $\mathrm{F}$ & 70.7151 & 18.5483 \\
\hline
\end{tabular}

Fonte: Criado pela autora a partir dos dados da PNAD.

Nota: Erros padrão entre parênteses e Nível de significância: *** $\mathrm{p}<0.10$, ** $\mathrm{p}<0.05, * \mathrm{p}<0.01$ 
Tabela A23 - Resultados das regressões dos jovens de 18 a 25 anos - ano 2012 como referência e interação raça e educação dos pais

\begin{tabular}{|c|c|c|}
\hline \multirow{2}{*}{ Variáveis } & \multicolumn{2}{|c|}{ Ano } \\
\hline & 2002 & 2012 \\
\hline \multirow[t]{2}{*}{ Filho Pardo } & $-2.998 *$ & 0.497 \\
\hline & $(0.53)$ & $(0.84)$ \\
\hline \multirow[t]{2}{*}{ Filho Preto } & -0.201 & $-2.244 * *$ \\
\hline & $(1.36)$ & $(0.91)$ \\
\hline \multirow[t]{2}{*}{ Pchefejovem } & $-19.921 * *$ & $-18.417 * * *$ \\
\hline & $(9.90)$ & (10.04) \\
\hline \multirow[t]{2}{*}{ Lnrend } & $-0.212 *$ & $-0.029 * *$ \\
\hline & $(0.03)$ & $(0.01)$ \\
\hline \multirow[t]{2}{*}{ Casamento inter-racial } & $-0.377 *$ & -0.011 \\
\hline & $(0.14)$ & $(0.15)$ \\
\hline \multirow[t]{2}{*}{ Casamento intra-racial PrPr } & -0.023 & 0.439 \\
\hline & $(0.35)$ & $(0.43)$ \\
\hline \multirow{2}{*}{ Pais raça branca \& Educação fundamental } & -0.219 & 0.080 \\
\hline & $(0.24)$ & $(0.34)$ \\
\hline \multirow[t]{2}{*}{ Pais raça branca \& Educação médio } & $-0.725^{*}$ & -0.068 \\
\hline & $(0.24)$ & $(0.36)$ \\
\hline \multirow{2}{*}{ Pais raça branca \& Educação superior } & $-0.530 * * *$ & 0.015 \\
\hline & $(0.28)$ & $(0.42)$ \\
\hline \multirow[t]{2}{*}{ Pais raça parda \& Educação primário } & $1.230^{*}$ & 0.508 \\
\hline & $(0.35)$ & $(0.43)$ \\
\hline \multirow{2}{*}{ Pais raça parda \& Educação fundamental } & 0.494 & 0.291 \\
\hline & $(0.34)$ & $(0.35)$ \\
\hline \multirow[t]{2}{*}{ Pais raça parda \& Educação médio } & $0.920 *$ & 0.336 \\
\hline & $(0.32)$ & $(0.36)$ \\
\hline \multirow[t]{2}{*}{ Pais raça parda \& Educação superior } & 0.000 & 0.000 \\
\hline & (.) & $()$. \\
\hline \multirow[t]{2}{*}{ Pais raça preta \& Educação primário } & -0.487 & $1.660 * *$ \\
\hline & $(0.93)$ & $(0.71)$ \\
\hline \multirow[t]{2}{*}{ Pais raça preta \& Educação fundamental } & -0.556 & $2.009^{*}$ \\
\hline & $(0.88)$ & $(0.51)$ \\
\hline \multirow[t]{2}{*}{ Pais raça preta \& Educação médio } & -1.190 & $1.467 * *$ \\
\hline & $(0.89)$ & $(0.71)$ \\
\hline \multirow[t]{2}{*}{ Pais raça preta \& Educação superior } & 0.000 & 0.000 \\
\hline & $()$. & $()$. \\
\hline \multirow[t]{2}{*}{ RNorte } & $0.612 *$ & $0.374 * *$ \\
\hline & $(0.18)$ & $(0.19)$ \\
\hline \multirow[t]{2}{*}{ RNordeste } & $0.732 *$ & $0.349 * * *$ \\
\hline & $(0.16)$ & $(0.19)$ \\
\hline \multirow[t]{2}{*}{ RSul } & $0.292 * * *$ & -0.018 \\
\hline & $(0.16)$ & $(0.22)$ \\
\hline \multirow[t]{2}{*}{ RCentro-Oeste } & 0.258 & 0.010 \\
\hline & $(0.18)$ & $(0.25)$ \\
\hline \multirow[t]{2}{*}{ H_Trab_Mae } & $0.731 * * *$ & 0.448 \\
\hline & $(0.38)$ & $(0.46)$ \\
\hline Urbana=1 & -0.286 & $-0.696 * *$ \\
\hline & $(0.37)$ & $(0.31)$ \\
\hline
\end{tabular}


Continuação Tabela A23

\begin{tabular}{l|c|c}
\hline Idade Pai & $0.025^{* * *}$ & -0.034 \\
Idade Mãe & $(0.01)$ & $(0.02)$ \\
& $-0.054^{*}$ & -0.010 \\
Constante & $(0.02)$ & $(0.02)$ \\
& $7.077^{*}$ & $6.871^{*}$ \\
\hline $\mathrm{R} 2$ & $(0.93)$ & $(0.99)$ \\
$\mathrm{R} 2$ Ajustado & 0.1993 & 0.1035 \\
$\mathrm{~N}^{\circ}$ Observações & 0.1891 & 0.0863 \\
$\mathrm{~F} \quad 2542$ & 1700 \\
\hline \multicolumn{2}{c|}{ Fonte: Criado pela autora a partir dos dados da PNAD. } \\
\multicolumn{2}{c}{ Nota: Erros padrão entre parênteses e Nível de significância: *** $\mathrm{p}<0.10, * * \mathrm{p}<0.05, * \mathrm{p}<0.01$}
\end{tabular}


Tabela A24 - Decomposição das desigualdades educacionais com interação raça \& educação para jovens de 18 a 25 anos

\begin{tabular}{|c|c|}
\hline Grupo & $2002 \times 2012$ \\
\hline $\begin{array}{l}\text { 1. Características Individuais } \\
\qquad X_{i t} \bar{\beta}_{S}+\overline{\boldsymbol{F}}_{S}^{-1}\left(\theta_{i t} \mid X_{i t}\right)\end{array}$ & -0.16 \\
\hline 1.1. Raça Filho Pardo & $0.04 \nabla$ \\
\hline 1.2. Renda & $-0.03 \Delta$ \\
\hline 1.3. Pchefejovem & $-0.06 \Delta$ \\
\hline 1.4. Idade Pai & $-0.017 \Delta$ \\
\hline 1.5. Idade Mãe & $-0.0019 \Delta$ \\
\hline 1.6. Casamento inter-racial & $-0.008 \Delta$ \\
\hline 1.7. Casamento intra-racial preto-preto & $-0.003 \Delta$ \\
\hline 1.8. Pais raça branca \& Educação fundamental & $-0.006 \Delta$ \\
\hline 1.9. Pais raça branca \& Educação médio & -0.007 \\
\hline 1.10. Pais raça branca \& Educação superior & $0.0005 \nabla$ \\
\hline 1.11. Pais raça parda \& Educação fundamental & $-0.04 \Delta$ \\
\hline 1.12. Pais raça parda \& Educação médio & -0.006 \\
\hline 1.13. Pais raça parda \& Educação superior & $0.004 \nabla$ \\
\hline 1.14. Pais raça preta \& Educação primária & $-0.005 \Delta$ \\
\hline 1.15. Pais raça preta \& Educação fundamental & $-0.005 \Delta$ \\
\hline 1.16. Pais raça preta \& Educação médio & $-0.002 \Delta$ \\
\hline 1.17. Pais raça preta \& Educação superior & $0.00006 \nabla$ \\
\hline 1.18. Horas Trabalhadas - Mãe & $-0.00002 \wedge$ \\
\hline 1.19. Região Norte & $-0.005 \Delta$ \\
\hline 1.20. Região Nordeste & $-0.003 \Delta$ \\
\hline 1.21. Região Sul & $-0.003 \wedge$ \\
\hline 1.22. Região Centro Oeste & $-0.00008 \wedge$ \\
\hline 1.23. Situação Censitária & $-0.003 \wedge$ \\
\hline $\begin{array}{l}\text { 2. Diferença nas respostas (parâmetros) } \\
\qquad X_{i t} \beta_{t}+\bar{F}_{S}^{-1}\left(\theta_{i t} \mid X_{i t}\right)\end{array}$ & 0.57 \\
\hline $\begin{array}{l}\text { 3. Diferença em não observados (resíduos) } \\
\qquad X_{i t} \beta_{t}+F_{t}^{-1}\left(\theta_{i t} \mid X_{i t}\right)\end{array}$ & 0.0001 \\
\hline 4. Diferença Total $(1+2+3)$ & 0.41 \\
\hline
\end{tabular}

Fonte: Criado pela autora, a partir dos dados da PNAD 2002 e 2012.

$\Delta$ - As setas vermelhas indicam que as variáveis contribuem para aumentar o diferencial entre os grupos.

$\nabla$ - As setas azuis indicam que as variáveis contribuem para reduzir o diferencial entre os grupos. 